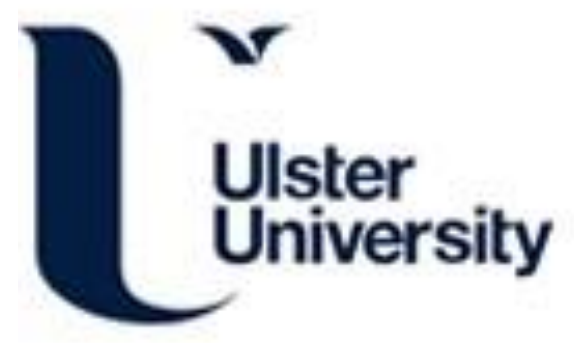

\title{
Accidental release of Liquefied Natural Gas in a processing facility: Effect of equipment congestion level on dispersion behaviour of the flammable vapour
}

Baalisampang, T., Abbassi, R., Khan, F., Garaniya, V., \& Dadashzadeh, M. (2019). Accidental release of
Liquefied Natural Gas in a processing facility: Effect of equipment congestion level on dispersion behaviour of
the flammable vapour. Journal of Loss Prevention in the Process Industries, 61, 237-248. https://doi.org/10.1016/j.jlp.2019.07.001

Link to publication record in Ulster University Research Portal

Published in:

Journal of Loss Prevention in the Process Industries

Publication Status:

Published (in print/issue): 01/09/2019

DOI:

10.1016/j.jlp.2019.07.001

Document Version

Author Accepted version

\section{General rights}

Copyright for the publications made accessible via Ulster University's Research Portal is retained by the author(s) and / or other copyright owners and it is a condition of accessing these publications that users recognise and abide by the legal requirements associated with these rights.

\section{Take down policy}

The Research Portal is Ulster University's institutional repository that provides access to Ulster's research outputs. Every effort has been made to ensure that content in the Research Portal does not infringe any person's rights, or applicable UK laws. If you discover content in the Research Portal that you believe breaches copyright or violates any law, please contact pure-support@ulster.ac.uk. 


\title{
Manuscript Details
}

\section{Manuscript number}

Title

Article type
JLP_2019_16_R2

Accidental release of Liquefied Natural Gas in an offshore processing facility: effect of equipment congestion level on dispersion behaviour of the flammable vapour

Full Length Article

\begin{abstract}
An accidental leakage of Liquefied Natural Gas (LNG) can occur during processes of production, storage and transportation. LNG has a complex dispersion characteristic after release into the atmosphere. This complex behaviour demands a detailed description of the scientific phenomena involved in the dispersion of the released LNG. Moreover, a fugitive LNG leakage may remain undetected in complex geometry usually in semi-confined or confined areas and is prone to fire and explosion events. To identify location of potential fire and/or explosion events, resulting from accidental leakage and dispersion of LNG, a dispersion modelling of leakage is essential. This study proposes a methodology comprising of release scenarios, credible leak size, simulation, comparison of congestion level and mass of flammable vapour for modelling the dispersion of a small leakage of LNG and its vapour in a typical layout using Computational Fluid Dynamics (CFD) approach. The methodology is applied to a case study considering a small leakage of LNG in three levels of equipment congestion. The potential fire and/or explosion hazard of small leaks is assessed considering both time dependent concentration analysis and area-based model. Mass of flammable vapour is estimated in each case and effect of equipment congestion on source terms and dispersion characteristics are analysed. The result demonstrates that the small leak of LNG can create hazardous scenarios for a fire and/or explosion event. It is also revealed that higher degree of equipment congestion increases the retention time of vapour and intensifies the formation of pockets of isolated vapour cloud. This study would help in designing appropriate leak and dispersion detection systems, effective monitoring procedures and risk assessment.
\end{abstract}

Keywords

Taxonomy

Corresponding Author

Corresponding Author's Institution

Order of Authors
Offshore Complex layout; LNG; fugitive leakage; dispersion modelling; CFD; FLACS;

Chemical Engineering, Engineering

Rouzbeh Abbassi

Macquarie University

Til Baalisampang, Rouzbeh Abbassi, Vikram Garaniya, Faisal Khan, Mohammad Dadashzadeh

\section{Submission Files Included in this PDF}

File Name [File Type]

Cover Letter.docx [Cover Letter]

Dispersion paper_Comments and responses-26 May.docx [Response to Reviewers]

Main Paper_without track changes.docx [Revised Manuscript with Changes Marked]

Highlights.docx [Highlights]

Main Paper_without track changes_27 June 2019.docx [Manuscript File]

To view all the submission files, including those not included in the PDF, click on the manuscript title on your EVISE Homepage, then click 'Download zip file'.

\section{Research Data Related to this Submission}

There are no linked research data sets for this submission. The following reason is given:

The required data are available within the manuscript. 


\section{Dear Editor,}

Kindly find attached the revised manuscript entitled "Accidental release of Liquefied Natural Gas in an offshore processing facility: effect of equipment congestion level on dispersion behaviour of the flammable vapour" for possible publication in the Journal of Loss Prevention in the Process Industries. This is original work of authors and unpublished. All references have been checked to follow the guideline provided by the Journal. I am corresponding author and all authors are agreed to submit this MS to this journal. There is no conflict of interest.

Best regards,

Rouzbeh Abbassi, PhD., P. Eng.

Senior Lecturer, School of Engineering, Faculty of Science and Engineering, Macquarie University 


\section{Editorial Comment}

Comment 1. The manuscript is now accepted on technical grounds.

Before final acceptance, the references must be cited and listed in the format required by JLPPI (author/date).

Response 1: Thank you very much for your time and consideration. The reference style of the paper has been changed to author/date as suggested by the editor. 
Accidental release of Liquefied Natural Gas in a processing facility: effect of equipment congestion level on dispersion behaviour of the flammable vapour

Til Baalisampang ${ }^{\mathrm{a}}$, Rouzbeh Abbassi ${ }^{\mathrm{b}, *}$, Vikram Garaniya ${ }^{\mathrm{a}}$, Faisal Khan ${ }^{\mathrm{a}, \mathrm{c}}$, Mohammad Dadashzadeh $^{\mathrm{d}}$

a National Centre for Maritime Engineering and Hydrodynamics, Australian Maritime College, University of Tasmania, Launceston, Tasmania, Australia

${ }^{b}$ School of Engineering, Faculty of Science and Engineering, Macquarie University, Sydney, NSW, Australia

${ }^{c}$ Centre for Risk, Integrity and Safety Engineering, Faculty of Engineering \& Applied Science, Memorial University of Newfoundland, St. John's, NL, Canada

dHydrogen Safety Engineering and Research Centre (HySAFER), Ulster University, Newtownabbey, Northern Ireland, UK.

* Corresponding Author: rouzbeh.abbassi@mq.edu.au

\section{Abstract}

An accidental leakage of Liquefied Natural Gas (LNG) can occur during processes of production, storage and transportation. LNG has a complex dispersion characteristic after release into the atmosphere. This complex behaviour demands a detailed description of the scientific phenomena involved in the dispersion of the released LNG. Moreover, a fugitive LNG leakage may remain undetected in complex geometry usually in semi-confined or confined areas and is prone to fire and explosion events. To identify location of potential fire and/or explosion events, resulting from accidental leakage and dispersion of LNG, a dispersion modelling of leakage is essential. This study proposes a methodology comprising of release scenarios, credible leak size, simulation, comparison of congestion level and mass of flammable vapour for modelling the dispersion of a small leakage of LNG and its vapour in a typical layout using Computational Fluid Dynamics (CFD) approach. The methodology is applied to a case study considering a small leakage of LNG in three levels of equipment congestion. The potential fire and/or explosion hazard of small leaks is assessed considering both time dependent concentration analysis and area-based model. Mass of flammable vapour is estimated in each case and effect of equipment congestion on source terms and dispersion characteristics are analysed. The result demonstrates that the small leak of LNG can create hazardous scenarios for a fire and/or explosion event. It is also revealed that higher degree of equipment congestion increases the retention time of vapour and intensifies the formation of pockets of isolated vapour cloud. This study would help in designing appropriate leak and dispersion detection systems, effective monitoring procedures and risk assessment.

Keywords: Complex layout, LNG, fugitive leakage, dispersion modelling, CFD, FLACS 


\section{Introduction}

High demand for the consumption of natural gas, (LNG), means an outstanding increase in production, storage and transportation of natural gas [1]. Hence, the potential hazards of LNG spills and the associated impacts on the exposed population and environment is of major concern [2]. To assess potential risk of LNG spills and the consequences, it is vital to study LNG vapour dispersion behaviour. After the leakage, LNG hazards can be evaluated in three stages: source term (pool development and its evaporation); dispersion; and effects (due to fire thermal radiation and/or explosion overpressure) [3]. To identify and assess the risks of LNG release, hazards of each phase need to be considered. Being 1.5 times heavier than air, after release into the atmosphere, the dispersion of LNG occurs in three phases: negative buoyancy dominated; stably stratified; and passive dispersion [4]. The dispersion of LNG mainly depends on the evaporation rate of LNG pool and atmospheric effect. The LNG vapour initially released from spill is denser than the air and forms a vapour cloud around the release location close to the ground. The buoyancy is not dominant at this stage and the vapour disperses into the surrounds due to the wind. The atmospheric condition also matters at this phase by warming the vapour due to conduction when it is diluted in the surrounding environment [5]. This causes instantaneous vaporisation of LNG due to its cryogenic nature which leads to the formation of a flammable vapour cloud [6]. Considering its complex dispersion behaviour, a detailed understanding of spilled LNG behaviour is required for the accurate prediction of potential consequences.

An accidental LNG release and its dispersion may cause severe consequences such as structural failure due to brittle fracture, asphyxiation, and fire and explosion. Dispersion of combustion products released after LNG vapour fire and explosion also presents a serious hazard to humans and the surrounding structures [7]. These events may lead to fatalities and financial losses. Past LNG accidents are reported in Woodward and Pitblado [5]. For example, fire and explosion occurred in a LNG facility in Skikda, Algeria on 19 January 2004 which resulted in 27 casualties, 56 injuries and $\$ 900$ million loss [8]. Either LNG or refrigerant leakage from a defective pipe used to transport LNG and hydrocarbon products in liquid state was identified as a primary cause of the fire and explosion event [8]. The release rate was about $10 \mathrm{~kg} / \mathrm{s}$ [9]. More recently, on 3 March 2014, the Plymouth-Liquefied Natural Gas Peak Shaving Plant experienced a catastrophic failure which resulted in an explosion in a portion of the facility's LNG-1 purification and regeneration system [10]. The investigation report [10] found that the 
primary cause of this accident was operator error which led to vessel and piping failure from detonation caused by internal auto-ignition due to a purge that failed to remove a gas air mixture from the system. The incident injured 5 employees and cost $\$ 45,749,300$. This shows that formation of a flammable vapour cloud after the release of LNG is a major issue. The wide flammability range of natural gas makes its dispersion behaviour a critical priority to be fully understood. If an ignition source is present and the vapour air mixture is in its flammable range, the vapour cloud will ignite and catastrophic consequences are likely [11]. The US Federal Regulation 49 CFR Part 193.2059 [12] and standard NFPA 59A [13] require the use of validated consequence models to predict potential hazardous areas adjacent to LNG facilities in the event of an accidental LNG spill [14]. For quantitative risk assessment of an accidental LNG spill, no sufficient data are available to calculate LNG leak frequency in LNG production and receiving facilities. To avoid this limitation, Kim, Koh, Kim and Theofanous [15] provided the top events of major LNG releases from membrane type LNG storage tanks and associated pipes considering release scenarios of overfilling, over-pressurisation, under-pressurisation, failure of inlet lines and outlet lines and loss of mechanical integrity of the tank using Fault Tree analysis. Based on these failure mechanisms, total leak frequency was found to be 5.2 $\times 10^{-5}$ per year. However, this may not be adequate for risk assessment and management of a large and complex facility with liquefaction and offloading processes.

Some large scale experiments and tests were carried out to gain an understanding of spill and dispersion characteristics of LNG such as the Burro series [16], Coyote series [17], Falcon series [18], Maplin Sands tests [19], Esso tests [20], Shell jettison tests [21], Avocet [22], and Brayton Fire Training Field (BFTF) [23]. Due to the difficulties, costs, and risks involved in conducting such experiments, computational modelling of LNG spill and dispersion is strongly favoured [24]. To model LNG vapour dispersion, there are various approaches with different levels of complexity are available, i.e. simple empirical models, integral, shallow-layer models and fully three-dimensional CFD models [25]. The use of CFD codes for LNG vapour cloud dispersion simulation is strongly recommended by the Sandia National Laboratories 2004 report [26]. CFD modelling allows for the representation of complex geometry and its effects on flow and dispersion [23, 27]. According to Cormier, Qi, Yun, Zhang and Mannan [23] four publicly available CFD codes are widely used for LNG dispersion modelling namely FEM3 [28], Flame Acceleration Simulator (FLACS) [29], ANSYS Fluent [27] and ANSYS CFX [14, 30]. Moreover, Open Field Operation and Manipulation (OpenFoam) [31] and Fire Dynamics Simulator (FDS) have also been used for LNG dispersion modelling [32]. 
Past LNG dispersion modellings were studied based on spill into impoundment [27, 33], over water [26, 34, 35], trenches [32, 36] and terrain [37]. These studies were performed incorporating large leaks of gas or LNG vapour. The large-scale field tests for LNG dispersion are summarised in Table 1.

Table 1. Large scale LNG dispersion tests

\begin{tabular}{|l|l|l|l|l|l|l|}
\hline Name & $\begin{array}{l}\text { Trial } \\
\text { number }\end{array}$ & $\begin{array}{l}\text { Atmospheric } \\
\text { condition based on } \\
\text { Pasquill Stability } \\
\text { Classes }\end{array}$ & $\begin{array}{l}\text { Wind } \\
\text { speed } \\
(\mathrm{m} / \mathrm{s})\end{array}$ & $\begin{array}{l}\text { Dispersion } \\
\text { over land (L) } \\
\text { or water (W) }\end{array}$ & $\begin{array}{l}\text { Mass } \\
\text { flow rate } \\
(\mathrm{kg} / \mathrm{s})\end{array}$ & $\begin{array}{l}\text { Release } \\
\text { duration } \\
(\mathrm{s})\end{array}$ \\
\hline Maplin & 27 & C-D & 5.5 & $\mathrm{~W}$ & 23.2 & 160 \\
Sands & 34 & D & 8.6 & W & 21.5 & 95 \\
1980 [38] & 35 & D & 9.8 & W & 27.1 & 135 \\
\hline Burro Test & 3 & B & 5.6 & L & 88 & 167 \\
1980 [39] & 7 & D & 8.8 & L & 99 & 174 \\
& 8 & E & 1.8 & L & 117 & 107 \\
& 9 & D & 5.9 & L & 136 & 79 \\
\hline Coyote & 3 & B-C & 6.8 & L & 101 & 65 \\
1981 [17] & 5 & C-D & 10.5 & L & 129 & 98 \\
& 6 & D & 5.0 & L & 123 & 82 \\
\hline Falcon & 1 & G & 1.2 & L & 202 & 131 \\
1987 [18] & 3 & D & 3.7 & L & 133 & 154 \\
& 4 & D-E & 4.3 & L & 61 & 301 \\
\hline
\end{tabular}

The US Department of Energy Report 2012 [40] considered $0.005 \mathrm{~m}^{2}$ (80 mm diameter) as a very small breach size in studying the impact of LNG spill. According to Fitzgerald [41] the oil and gas industry has generally adopted the 2 inch $(50.8 \mathrm{~mm})$ maximum leak size for Facility Siting Studies (FSSs) and guidance relevant to leak size also tends to agree in either limiting leaks to a maximum diameter of 2 inches or uses a portion of the pipe cross-section as their assumed leak size. This has been considered as the accepted level of conservatism in most facilities. This shows that these leaks sizes, or smaller, are often not considered in risk analysis and their prevention or control strategies are not emphasised. However, typically smaller leaks (10-25 mm) are highly likely to occur in the LNG facility's lifetime [5]. A fugitive leakage often represents only a small source of leaks and seems to be inconsequential. However, if the leaked fuel is exposed to an ignition source within its flammable range, it will cause various transitional events in congested layout leading to catastrophic consequences. According to an HSE report [42], more than $50 \%$ of the total hydrocarbons (HCs) release incidents are minor ones (Table 2). On the other hand, an accumulation of several fugitive leakages from any source, or group of sources, creates a major release into the air which is equivalent to a large release. 
Given the high frequency of small leaks and the high potential to trigger major accidents, smaller leak and its dispersion may be too simplistic to ignore. Despite the high frequency of small leaks and potential for major accidents, dispersion of gas or LNG leaked from small leak sizes (smaller than or equal to 2-inch) has not been emphasised considering the effect of congestion levels on source terms and LNG vapour dispersion. According to Paris [45] the strength of a gas explosion depends on various variables such as congestion, fuel types, flammable cloud size, shape and ignition location and strength. Equipment congestion plays a critical role in the gas dispersion and explosion [46, 47]. Because equipment congestion changes Lower Flammability Limit (LFL) distance and concentration level [23]. According to the Yellow Book [48] the percentage of the vapour cloud varies, depending on different factors, including the type and amount of the material released, pressure at release, size of release opening, degree of confinement of the cloud, and wind, humidity and other environmental effects. The equipment congestion, obstacle and roughness of the surface affect source term parameters and dispersion behaviour. Cormier, Qi, Yun, Zhang and Mannan [23] claimed that wind velocity, obstacles, sensible heat flux, and the released mass affect LFL distance and vapour concentration level. Thus, this study considers the effects of equipment congestion on source terms, namely pool evaporation rate, pool area and evaporation rate per area for spreading pool on a steel plate.

Table 2. HCs release incidents and percentage of minor release incidents on the UK Continental Shelf.

\begin{tabular}{|l|l|l|l|}
\hline Year & $\begin{array}{l}\text { Total HC } \\
\text { release } \\
\text { incidents }\end{array}$ & $\begin{array}{l}\text { Number of } \\
\text { minor } \\
\text { releases }\end{array}$ & $\begin{array}{l}\text { Percentage of } \\
\text { minor release } \\
\text { incidents (\%) }\end{array}$ \\
\hline 2007 & 185 & 110 & 59.46 \\
\hline 2008 & 147 & 93 & 63.27 \\
\hline 2009 & 179 & 95 & 53.07 \\
\hline 2010 & 186 & 109 & 58.60 \\
\hline 2011 & 142 & 82 & 57.75 \\
\hline 2012 & 105 & 58 & 55.24 \\
\hline 2013 & 118 & 70 & 59.32 \\
\hline 2014 & 94 & 47 & 50 \\
\hline 2015 & 93 & 50 & 53.76 \\
\hline 2016 & 104 & 55 & 52.88 \\
\hline
\end{tabular}


Modelling of gas dispersion in an offshore facility is generally difficult due to complex geometries and layouts. Contrary to conventional offshore facilities, a floating LNG (FLNG) processing facility is expected to have higher risks of vapour cloud dispersion, fire and explosion due to processing, storage and offloading of LNG and other flammable products in harsh environmental conditions [49]. It is stated by Cataylo and Tanigawa [50] that leaks occur across LNG facilities. Li, Ma, Abdel-jawad and Huang [51] investigated the effect of safety gap on dispersion of gas releases in FLNG platform and claimed that the safety gap reduces the gas cloud size between adjacent modules. But these studies [51,52] investigated the LNG dispersion phenomena considering large leak size which is a rare event. Small leaks occur frequently, which can be too simple to ignore in a complex layout due to resulting volume of LNG under ambient conditions and potential to cause serious events. Because of these, there is a need for modelling small leak and dispersion characteristics of LNG in FLNG processing facility for risk assessment and management. The current study aims at investigating small leak and dispersion behaviour of LNG in a typical FLNG processing facility by considering effect of equipment congestion. The result demonstrates that small leak of LNG can create hazardous scenarios for fire and explosion events and reveals that higher degree of equipment congestion increases the retention time of vapour and intensifies the formation of pockets of isolated vapour cloud.

\section{Release and dispersion modelling}

Figure 1 illustrates the developed procedure for the dispersion modelling of small LNG leak in a complex geometry. This consists of release scenario development, credibility estimation of release scenario, consideration of various degrees of congestion, CFD simulation and comparison of flammable vapour profile.

In step 1, possible release scenarios based on potential release cases of LNG are identified. This helps to select representative release scenarios which cause the release of hazardous material. Due to the large number of release scenarios, it is usual to consider only a few release cases to represent the entire range of scenarios. The release scenarios can be developed using analytical processes such as hazard identification (HAZID), and Hazard and Operability Study (HAZOP). The parameters related to release scenario have been considered in several studies (examples [53-57]). Pool shape and spreading depend on surface types, pouring conditions, and obstacles [56]. Once the LNG pool is formed, the rate at which vapour is produced is related mainly to the LNG spilled area and the rate of heat transfer to the liquid. The pool area 
is highly dependent on the local terrain over which the spill takes place [56]. The presence of obstructions such as dyke or bund walls, the roughness of the ground can have a significant effect on pool area and shape [56, 57]. The vaporisation rate depends on the thermal conductivity of the ground, heat transferred from the air, and take-up rates by the air flow over the pool [57]. As LNG vapour dispersion behaviour depends on source terms, all parameters associated with an LNG release scenario need to be carefully considered in the dispersion modelling [57].

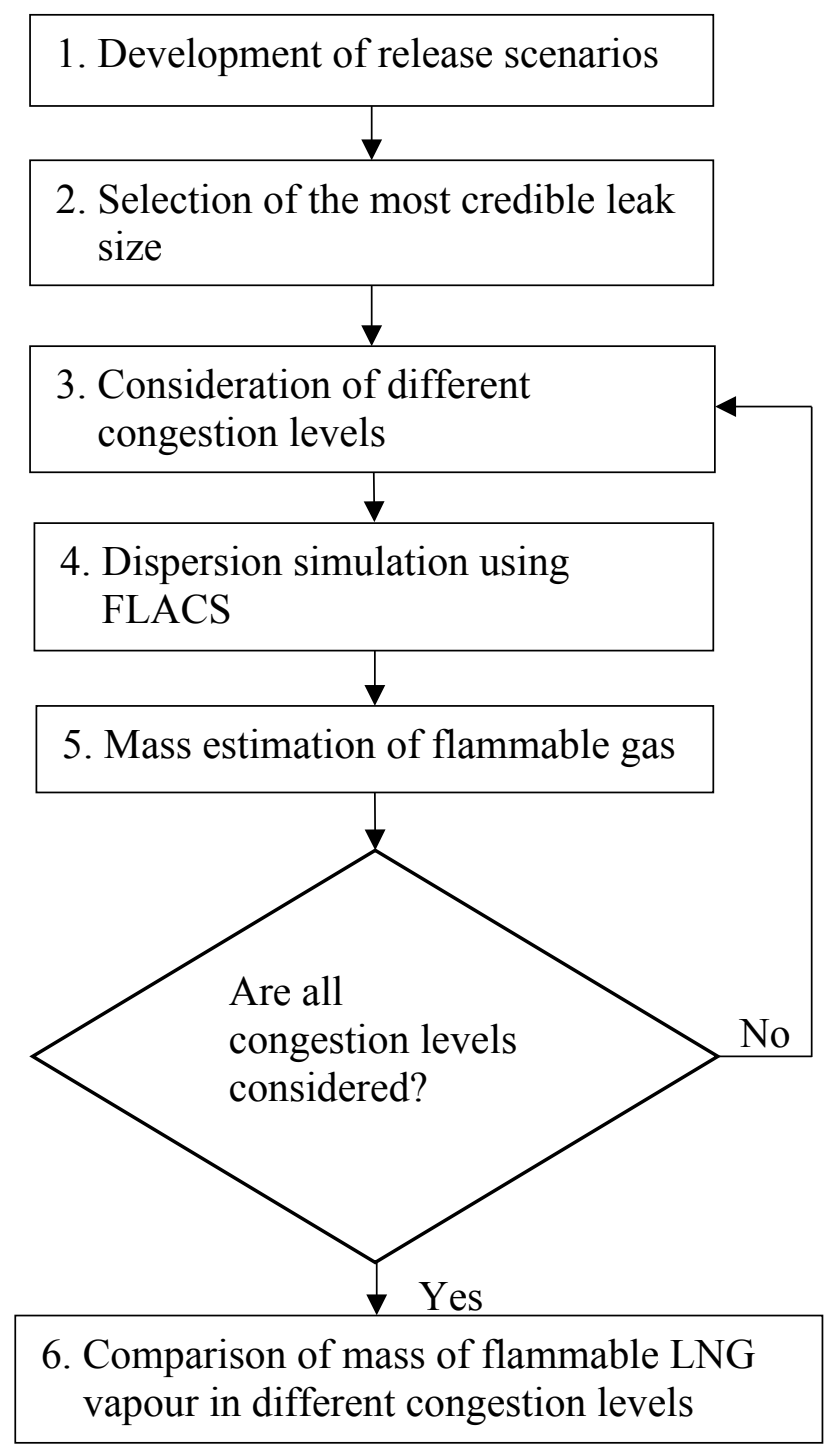

Figure 1. Procedure for modelling LNG dispersion using CFD code

In step 2, probable LNG release scenarios are identified according to hazard identification and estimation. The past accident analyses [59-61] reveal that most of the catastrophic accidents occurred due to ignorance (the accident was unforeseen) and inadequate control arrangements. Thus, it is essential to adequately assess any potential threats/hazards in all areas of a facility 
foreseeing accident scenario to ensure effectiveness of control measures or emergency plans. The credibility of occurrence facilitates the identification of worse case scenarios and application of effective countermeasures. In a complex processing facility, there can be hundreds of potential release or leak scenarios, hence randomly selecting a few scenarios for modelling is neither appropriate nor reasonable. This makes the credibility estimation an efficient method to identify the most credible scenarios. A credible scenario is one with high probability of occurrence and high damage potential. The damage potential of each scenario is calculated based on hazard identification and assessment. For hazard identification and assessment during release of LNG, several approaches are used, i.e. worst case approaches, maximum credible event approaches and risk assessment approaches [62]. Pitblado, Baik, Hughes, Ferro and Shaw [63] have identified several maximum credible events including;

a. Maximum credible puncture hole $=0.25 \mathrm{~m}$,

b. Maximum credible hole from accidental operation events $=0.75 \mathrm{~m}$,

c. Maximum credible hole from terrorist events $=1.5 \mathrm{~m}\left(1.7 \mathrm{~m}^{2}\right)$,

d. Maximum credible operational spillage events $(10$ minutes $)=7,000 \mathrm{~m}^{3} / \mathrm{hr}$, and

e. Maximum credible sabotage event $(60$ minutes $)=10,000 \mathrm{~m}^{3} / \mathrm{hr}$.

In step 3, various parameters that directly affect dispersion simulation are identified and defined. In semi-confined areas, gas dispersion depends on several factors such as wind speed and its direction, equipment congestion, mass flow rate and atmospheric conditions. In several literatures $[23,64,65]$, the impact of wind speed and its direction, mass flow rate and atmospheric conditions are commonly included. However, the impact of congestion level on dispersion of fugitive gases has not received much attention. Equipment arrangement or congestion is important in any processing facility that handles flammable or combustible materials. Tightly packed equipment increases equipment confinement and congestion and affects operations, maintenance, and emergency responses [66]. In such congested areas, an ignition source would be likely, as opposed to remote areas [26]. The consequences associated with the incidental loss of containment are expected to be less severe in less congested layouts than those with higher level of congestion. For instance, larger spaces between equipment reduce the fire impact on surroundings by decreasing exposure level and the thermal radiation intensity. For explosions, larger gaps between equipment reduce the congestion density which enhances the blast decay. These larger gaps decrease the magnitude of the blast waves and the potential effects on equipment, buildings and their occupants. In the case of toxic release, greater distances help reduce the impact on personnel by increasing diffusion and dilution of the toxic gas or vapour [67]. Degree of equipment congestion is often defined based on Area 
Blockage Ratio (ABR) and Volume Blockage Ratio (VBR) [68]. ABR is defined as the area blocked by obstacles in relation to the total cross-sectional area, and the pitch, which is the distance between successive obstacles or obstacle rows. VBR is defined as the ratio of the volume occupied by congestion elements such as pipes, beams and plates to the volume of the portion of the plant under consideration. Kinsella [69] defined congestion as the fractional area in the path of the flame front occupied by equipment, piping, fittings and other structures such as buildings and supporting columns. If congestion is more than the threshold of $30 \%$, it is considered 'high' for an offshore oil and gas facility [70]. Baker, Tang, Scheier and Silva [71] have suggested the following definitions of degree of congestion:

- Low congestion: ABR $<10 \%$, obstacles widely spaced, $<3$ layers of obstacles

- High congestion: ABR $>40 \%$, obstacles fairly closely spaced, $\geq 3$ layers of obstacles

- Medium congestion: Between low and high

In step 4, CFD simulation of the most credible leakage and dispersion scenario is performed considering plausible environmental conditions. The CFD model helps to determine the dispersion of the LNG vapour cloud in response to wind-vapour interaction, including heat transfer from the air and ground to the vapour cloud. This can inherently account for the effects of complex geometries, layouts and equipment, and also can assess the effect of vapour barriers on cloud dispersion [36]. For CFD simulation in the current study, FLACS software is used. FLACS has been the leading tool for explosion consequence prediction in petrochemical installations for more than a decade and it is approved for LNG Vapour Dispersion Modelling under US Federal Regulations (49 CFR 193.2059) [72]. Using a finite volume method, FLACS solves the conservations of mass, momentum, enthalpy, and mass fraction of species, closed by the ideal gas law represented by the general Equation 1 [73].

$\frac{\partial}{\partial t}(\rho \emptyset)+\frac{\partial}{\partial x_{j}}\left(\rho u_{i} \emptyset\right)-\frac{\partial}{\partial x_{j}}\left(\rho \Gamma_{\varnothing} \frac{\partial}{\partial x_{j}}(\emptyset)\right)=S_{\varnothing}$

Where $t, \rho, u$ and $\emptyset$ represent time, density, velocity and general variable.

FLACS has been extensively validated against different dispersion experiments including Coyote series (3, 5 and 6), Burro tests (3, 7, 8 and 9), Falcon Tests (1, 3 and 4), Maplin Sand Test series (27 and 34) and Thorney Island Tests (45 and 47) [74].

In step 5, flammable vapour footprint is estimated using a concentration range of $2.5-15 \%$. Estimation of flammable mass of dispersed vapour is needed to estimate fire and explosion hazards. In order to cause fire and or explosion, the concentration of LNG vapour should be within the flammability range (5 - 15\%) [75]. However, for computing safety distance, the U.S. 
Federal Government regulation 49-CFR-193 (Flammable vapour-gas dispersion protection) recommended using $50 \%$ of LFL. This recommendation has been done to account for two potential effects during vapour dispersion [76]. Firstly, wind may break away pockets of flammable vapour from the continuous cloud and they may be carried beyond the continuous cloud. Secondly, there is the potential expansion of the area of combustion attributed to expanding gases and the high energy release overdriving the flammability limit. Thus, a conservative estimate of the downwind flammable distance is considered by assuming that the vapour pocket will dissipate when the cloud concentration is below half the LFL. Due to these assumptions the resulting cloud coverage length should be considered worst-case possibility [76].

In the final step, flammable mass or volume of LNG vapour is estimated against different congestion levels and dispersion characteristics of fugitive LNG being assessed. Identification of a hazardous region in a facility would help to better understand the requirement of leak detection design and monitoring and control measures. It also would help to identify potentially safer areas during fugitive leaks at given atmospheric conditions.

\section{Application of the modelling procedure (A case study)}

The case study and analysis presented in this paper represents a generic solution method for simulation of vapour dispersion from an LNG spill in a facility with various degrees of equipment congestion. The proposed methodology is applied to a generic layout of a processing facility as shown in Figure 2. The model is $160 \mathrm{~m}$ long, $60 \mathrm{~m}$ wide and $40 \mathrm{~m}$ high. Responses to leak, vaporisation and dispersion depend on several operating parameters. For illustration purposes, only a specific case was presented considering prevalent conditions.

\subsection{Development of release scenarios}

In an FLNG processing facility, LNG is present in liquefaction module, storage tanks, offloading system and their connecting pipes. As the main objective of this study is to assess the dispersion phenomenon of fugitive leakage of LNG, a typical small leakage under operational conditions is considered. In chemical processes, fugitive emissions result from equipment leaks, solvent transfers, filter changes, and spills [44]. 


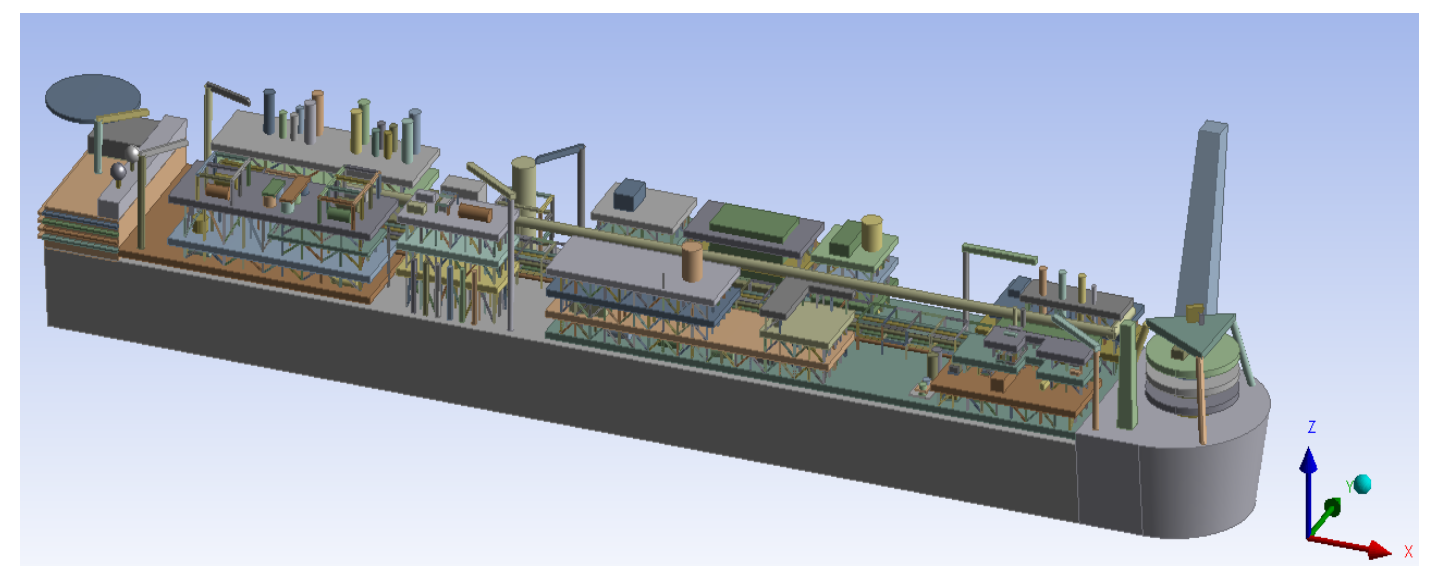

Figure 2. A typical FLNG processing facility

For dispersion modelling, the most congested module is considered as shown in Figure 3 with the dimensions of $60 \mathrm{~m} \times 45 \mathrm{~m} \times 5 \mathrm{~m}$. This layout is the lowest deck of a module which includes a greater amount of processing equipment than other modules. To assess impact of equipment congestion during LNG dispersion, three different layouts of equipment are considered as illustrated in Figure 3. In this study, the equipment layout of the three congestions are derived considering a strategy to reduce vapour turbulence. LNG vapour dispersion depends on source terms (examples: leak rate, pool area and evaporation rate) [57]. The detailed study of source terms is beyond the purpose of the study. However, in this study source terms are incorporated with a careful consideration of the recommendations given in FLACS user's manual [73]. 


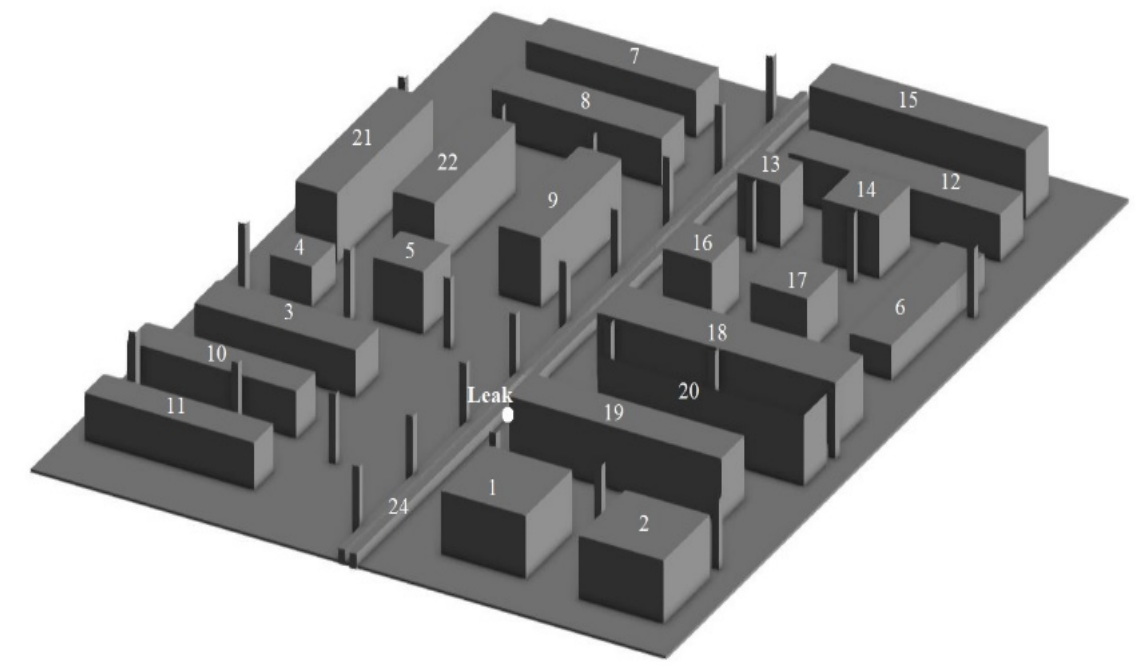

(a)

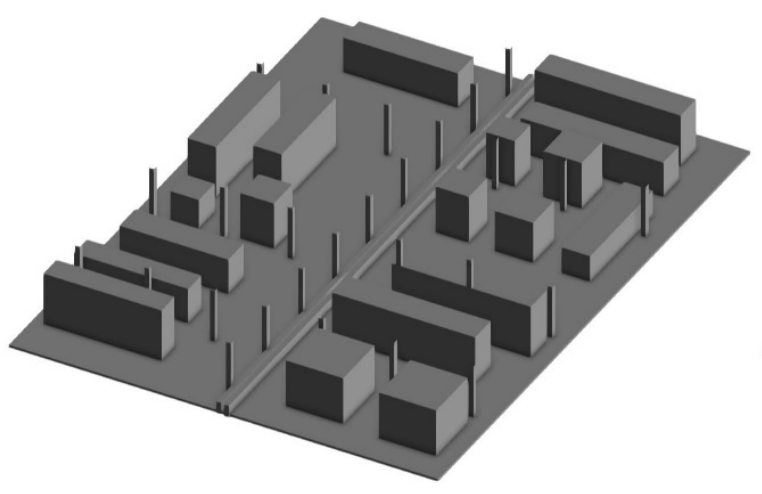

(b)

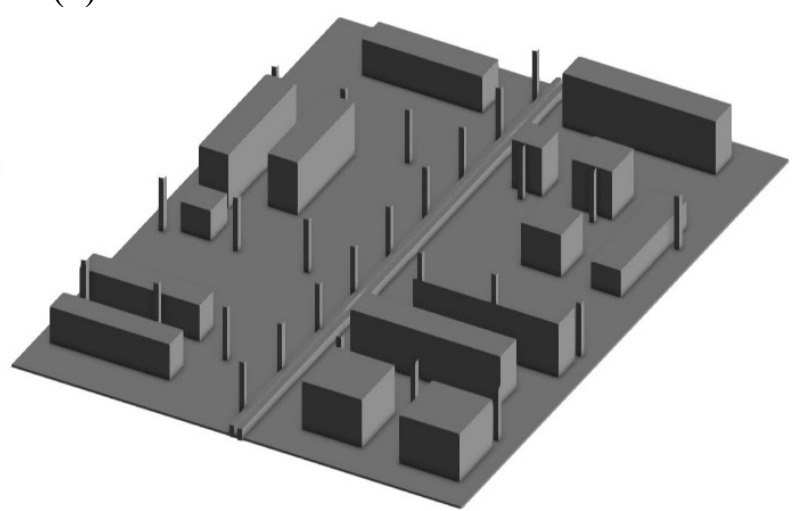

(c)

Figure 3. Equipment layout in the three congestions based on VBR; (a) $22 \%$, (b) $18 \%$ and (c) $14 \%$.

\subsection{Selection of credible leak size}

In a complex processing facility, there can be several potential LNG release scenarios [77]. Generally, in such large facilities, non-hazardous areas are ignored or not given due attention for risk assessment and mitigation because few or no accidents have been reported in such areas. In such situations, even a small leak may lead to a catastrophic accident. There is no universal consensus regarding the credible fugitive leak size. The maximum credible event (leak size/hole) proposed/identified by Pitblado, Baik, Hughes, Ferro and Shaw [63] contradicts Woodward and Pitblado [5] which stated that smaller leak size of 10-25 mm are highly likely to occur in an LNG plant lifetime. However, it has been found that 2 inch $(50.8 \mathrm{~mm})$ leak size is adopted as the maximum permissible leak in oil and gas industry in determining maximum credible events for Facility Siting Studies [41]. This study aims to assess dispersion behaviour of LNG using permissible leak size to investigate potential hazards for fire and explosion. In 
this study, LNG leak from a puncture hole of $25 \mathrm{~mm}$ is considered as the maximum credible size which is $50 \%$ less than the maximum permissible leak. Additionally, after release, LNG shows different phenomena of vaporisation and dispersion than that of natural gas due to rapid phase change and volume. This signifies the need to study small leakage of LNG.

\subsection{Degree of congestion level}

Degree of equipment congestion is a pivotal part of safety management [66]. The volumetric congestions calculated in the three layouts are presented in Table 3. The first column shows the equipment number according to Figure 3 (a). Equipment congestion along the flow front of the vapour is used to determine its effect on dispersion. Columns 2, 3 and 4 represent VBR in cases 1, 2 and 3 respectively. To compare the potential impact of small emission of LNG in different levels of equipment congestion and confinement, three levels of equipment congestion are considered: $22 \%, 18 \%$ and $14 \%$. Dispersion characteristic of small leakage of LNG is assessed based on the mass or volume of combustible vapour in each layout.

Table 3. Calculation of equipment congestion in the three layouts.

\begin{tabular}{|c|c|c|c|}
\hline Equipment & Case $1\left(\mathrm{~m}^{3}\right)$ & Case $2\left(\mathrm{~m}^{3}\right)$ & Case $3\left(\mathrm{~m}^{3}\right)$ \\
\hline 1 & 90 & 90 & 90 \\
\hline 2 & 90 & 90 & 90 \\
\hline 3 & 108 & 108 & - \\
\hline 4 & 21.20 & 21.20 & 21.20 \\
\hline 5 & 38.47 & 38.47 & - \\
\hline 6 & 108 & 108 & 108 \\
\hline 7 & 90 & 90 & 90 \\
\hline 8 & 90 & - & - \\
\hline 9 & 108 & - & - \\
\hline 10 & 108 & 108 & 108 \\
\hline 11 & 135 & 135 & 135 \\
\hline 12 & 135 & 135 & - \\
\hline 13 & 28.26 & 28.26 & 28.26 \\
\hline 14 & 50.24 & 50.24 & 50.24 \\
\hline 15 & 126 & 126 & 126 \\
\hline 16 & 28.26 & 28.26 & - \\
\hline 17 & 43.96 & 43.96 & 43.96 \\
\hline 18 & 240 & - & - \\
\hline 19 & 180 & 180 & 180 \\
\hline 20 & 192 & 192 & 192 \\
\hline 21 & 144 & 144 & 144 \\
\hline 22 & 144 & 144 & 144 \\
\hline
\end{tabular}




\begin{tabular}{|c|c|c|c|}
23 & 23.84 & 23.84 & 23.84 \\
\hline 24 & 30 & 30 & 30 \\
\hline Total volume & 2352.22 & 1914.22 & 1514.50 \\
\hline $\begin{array}{c}\text { Congestion levels } \\
\text { based on VBR }\end{array}$ & $22 \%$ & $18 \%$ & $14 \%$ \\
\hline
\end{tabular}

\subsection{Dispersion simulation using FLACS}

Dispersion of LNG vapour is greatly influenced by local atmospheric conditions, wind speed, atmospheric stability, and ground roughness. For an accurate dispersion simulation using CFD code, a precise representation of boundary conditions, initial conditions and atmospheric parameters are important. It is assumed that the gas cloud releases instantaneously and disperses under ambient atmospheric conditions considering the presence of the obstacles. Defining boundary conditions is a key player in an accurate CFD simulation [78]. According to Luketa-Hanlin, Koopman and Ermak [79], seven boundary conditions are required for an LNG simulation: inlet, outlet, top, two sides, bottom, and LNG pool. In all three layouts, the same boundary and initial conditions are used. The lower boundary in x-axis, the upper boundary in y-axis and upper boundary in z-axis are assigned as wind (inflow or parallel boundaries). The appropriate wind speed for flammable cloud dispersion is usually close to 2 to $4 \mathrm{~m} / \mathrm{s}$ [68]. Thus, wind speed is considered as $3 \mathrm{~m} / \mathrm{s}$ diagonally in the direction of $225^{\circ}$ to allow for maximum interaction of the dispersed gas with equipment. The reference height of the wind is considered as $2 \mathrm{~m}$. In these boundaries, relative turbulence intensity and turbulence length scale are assigned as 0.1 and $0.014 \mathrm{~m}$ respectively, based on recommendation given in FLACS user manual [73]. The remaining boundaries, except the bottom boundary, are considered as nozzle at the outflow). The outlet boundaries are kept sufficiently far from the potential natural gas cloud build up location to avoid their effects on dispersion phenomena. Initial conditions assigned for the simulation are provided in Table 4. To reduce uncertainty in this study, value of sensitive parameters such as wind speed, atmospheric stability and release rate have been chosen according to past studies [23, 80-82].

Table 4. Initial conditions used for the current study

\begin{tabular}{|l|l|}
\hline Parameters & Values \\
\hline Characteristic velocity & $3 \mathrm{~m} / \mathrm{s}$ \\
\hline Relative turbulence intensity & 0.1 \\
\hline Turbulence length scale & $0.014 \mathrm{~m}$ \\
\hline
\end{tabular}




\begin{tabular}{|l|l|}
\hline Temperature & $20^{\circ} \mathrm{C}$ \\
\hline Ambient pressure & $100 \mathrm{kPa}$ \\
\hline Ground roughness & $0.01 \mathrm{~m}$ \\
\hline Reference height & $2 \mathrm{~m}$ \\
\hline Pascal class & $\mathrm{F}$ \\
\hline
\end{tabular}

It is assumed that the LNG vapour consists of $92 \%$ methane, $7 \%$ ethane and $1 \%$ propane [73]. Release scenario depends on various parameters, i.e. leakage velocity, leaked size and type of surface. The leakage parameters are given in Table 5 . It is assumed that a leak commences after $10 \mathrm{~s}$ so that the wind field can reach steady state before the occurrence of the leakage. A constant mass flow rate of $3 \mathrm{~kg} / \mathrm{s}$ is considered with an effective leak diameter of $0.025 \mathrm{~m}$ based on small leak characteristic [5,83]. In each simulation, the maximum simulation time is considered as $120 \mathrm{~s}$ and the leak stops at $80 \mathrm{~s}$. The release duration and the simulation time has been selected considering Emergency Shutdown (ESD) response time and response time of gas detectors. This duration is confirmed by offshore personnel. These values are also similar to those reported in the literature [84, 85]. According to Napier and Roopchand [86], release duration from dock manifold area (nozzle/line discharge rate) failure is 1.5 minutes. Based on this, the release duration has been chosen. The focus of the case study was to primarily demonstrate the various steps of the release and dispersion modelling approach. However, this duration can be changed to any field scenario.

Table 5. Leak parameters

\begin{tabular}{|l|l|}
\hline Leak type & Jet \\
\hline Leak position & $(25.57,16,1)$ \\
\hline Leak direction & $-\mathrm{X}$ \\
\hline Start time & $0 \mathrm{~s}$ \\
\hline Duration & $80 \mathrm{~s}$ \\
\hline Outlet & \\
a. Area & $0.005 \mathrm{~m}^{2}$ \\
b. Mass flow rate & $3 \mathrm{~kg} / \mathrm{s}$ \\
c. Relative turbulence intensity & $0.02($ Low $)$ \\
d. Turbulence length scale & $0.025 \mathrm{~m}$ \\
e. Temperature & $-162^{\circ} \mathrm{C}$ \\
f. Surface & Steel plate with thickness of $0.01905 \mathrm{~m}$ \\
\hline
\end{tabular}


The simulation volume is considered as $47 \mathrm{~m} \times 62 \mathrm{~m} \times 5 \mathrm{~m}$ with maximum grid size of $1 \mathrm{~m}$ in all directions. Around the leak location, the grid resolution is adjusted to $0.01 \mathrm{~m}$ in $\mathrm{x}, \mathrm{y}$ and $\mathrm{z}$ directions while at the locations far from this area, grids were stretched. The total number of control volumes during the dispersion simulation is 319,200 . Setting up the required parameters, the FLACS solver (dispersion and ventilation module) was used to run the simulation. To make the simulation results grid independent, sensitivity analysis was conducted by comparing gas concentrations at a monitoring point using the technique advised by GexCon AS [73].

\subsection{Estimating mass of flammable LNG vapour}

The total mass of the released LNG is $240 \mathrm{~kg}$ which is the same in all simulations. However, this value does not represent the actual mass of flammable vapour as an entire mass of released LNG is not within the flammable range. All released mass of LNG does not remain in flammable concentration. The fraction of the released mass within the flammable range is estimated using a utility program of FLACS post processing result. The maximum vapours with $2.5-15 \%$ concentration obtained in the three simulations at $2.3 \mathrm{~m}$ above the ground are illustrated in Figures 4-6. Under the given conditions, volume and mass of flammable vapour dispersed (available) in the three layouts are estimated using post processing results of simulation as shown in Table 6. The flammable mass is the mass of the fuel when the ratio ((fuel mass)/(fuel and air mass)) is within the flammable range (2.5-15\%). Thus, the flammable volume consists of the mixture of fuel and air. The likelihood of vapour ignition outside the given range at the given time is considered negligible.

Table 6. Mass and volume of flammable vapour in the three layouts

\begin{tabular}{|l|l|l|l|}
\hline Congestion levels & $\begin{array}{l}\text { Case 1 } \\
(22 \%)\end{array}$ & $\begin{array}{l}\text { Case 2 } \\
(18 \%)\end{array}$ & $\begin{array}{l}\text { Case 3 } \\
(14 \%)\end{array}$ \\
\hline Maximum flammable mass of vapour $(\mathrm{kg})$ & 9.53 & 3.52 & 2.05 \\
\hline Maximum flammable volume of vapour $\left(\mathrm{m}^{3}\right)$ & 218 & 84 & 45 \\
\hline
\end{tabular}




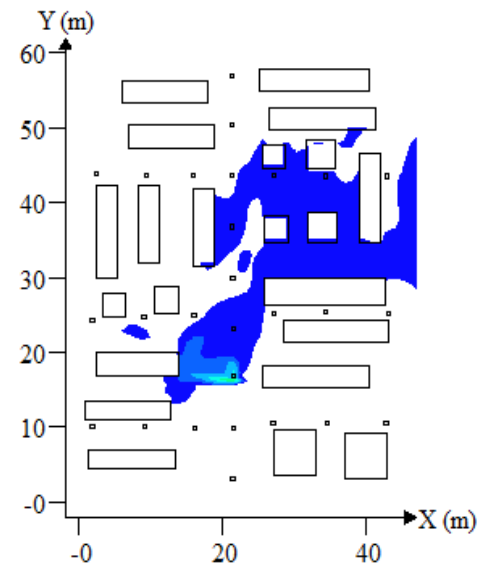

(a)

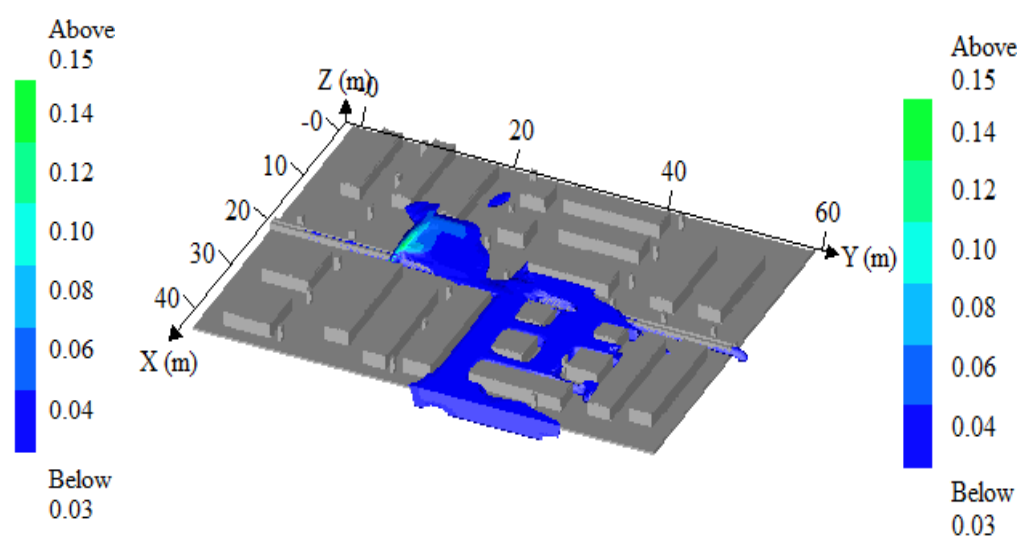

(b)

Figure 4. Footprints of flammable vapour $\left(\mathrm{m}^{3} / \mathrm{m}^{3}\right)$ at $2.3 \mathrm{~m}$ above the ground in Case 1 (a) 2D and (b) $3 \mathrm{D}$ at $90 \mathrm{~s}$. The concentration range is selected to assess the presence of the flammable vapour in the layout.

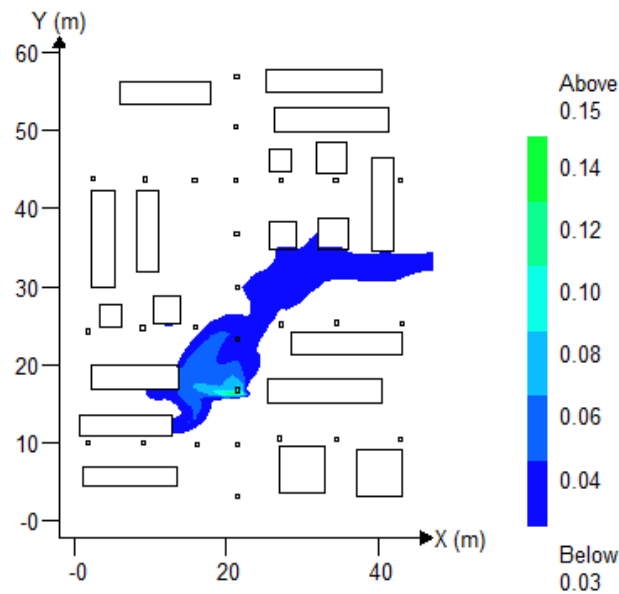

(b)

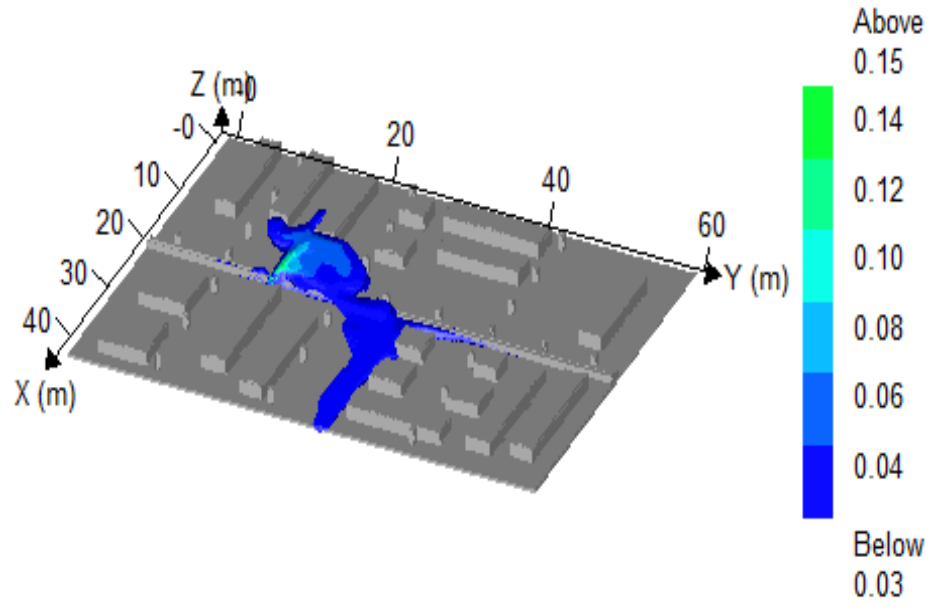

(b)

Figure 5. Footprints of flammable vapour $\left(\mathrm{m}^{3} / \mathrm{m}^{3}\right)$ at $2.3 \mathrm{~m}$ above the ground in Case 2 (a) 2D and (b) $3 \mathrm{D}$ at $90 \mathrm{~s}$. The concentration range is selected to assess the presence of the flammable vapour in the layout. 


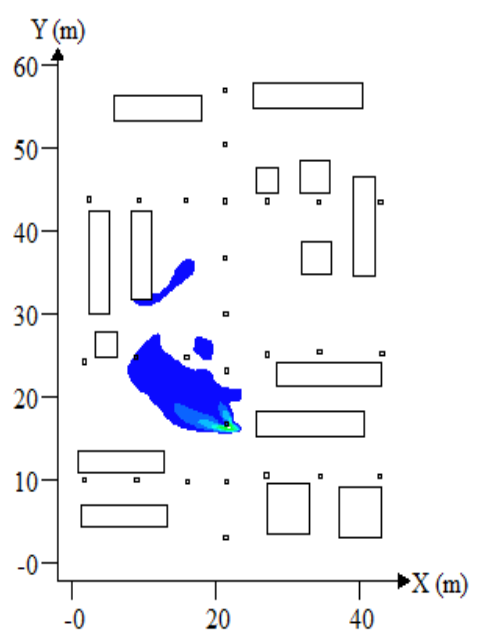

(a)

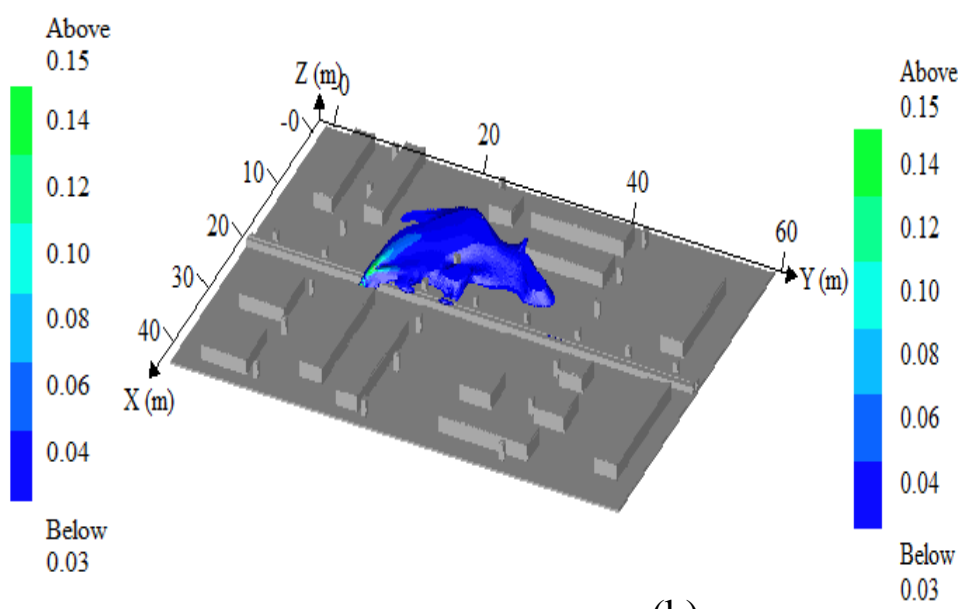

(b)

Figure 6. Footprints of flammable vapour $\left(\mathrm{m}^{3} / \mathrm{m}^{3}\right)$ at $2.3 \mathrm{~m}$ above the ground in Case 3 (a) 2D and (b) 3D at $90 \mathrm{~s}$. The concentration range is selected to assess the presence of the flammable vapour in the layout.

\section{Results and discussion}

The most important parameter for dispersion is the footprint of flammable vapour in the air within the layout. To be ignited, the fuel vapour formed through the dispersion should be in the flammable range. The vapour mixture has a LFL of 0.05 and an Upper Flammability Limit (UFL) of 0.15 . Considering the safety margin, advised by the US Federal Regulation 49 CFR Part 193.2059 [12], the LFL is defined as 0.025. The effect of congestion level on the formation of flammable vapour was analysed by monitoring the dispersion characteristics. In each case, the areas outside the boundary of the vapour are non-hazardous at that time because in those areas LNG vapour is not in the flammable range. In this study, the potential fire and/or explosion hazard of small LNG leak is assessed considering both time dependent concentration analysis and area-based model which focused on the maximum damage area because a flammable cloud takes some time to develop before reaching its maximum value and the ignition can occur anytime and anywhere after the release. Hence, a given leak can lead to several explosion or fire scenarios depending on the cloud size at the time of the delayed ignition. Thus, this study considered interactions between congested regions and drifting clouds or gas cloud built-up from pool evaporation. A concentration plot at any given location as a function of time is helpful to determine the need of safety measures such as forced ventilation or vapour barrier and to analyse subsequent fire and/or explosion hazards. 


\subsection{Case 1}

The first level of congestion considered in the current study is $22 \%$. The LNG vapour tends to slump in the congested layout due to low air movement, after vaporisation of LNG as demonstrated in Figure 7. The exact location of the leak is marked with red circle in Figure 7 (ii), which is same in Figures 8 and 9. The maximum flammable mass and volume are $9.53 \mathrm{~kg}$ and $218 \mathrm{~m}^{3}$, respectively at $40 \mathrm{~s}$. The presence of an obstacle in the centre of the flow path diverted the flow front and pockets of vapour accumulated around equipment. In addition to this, the presence of obstacles in the flow path diverted the flow and vapour was distributed in the spaces between obstacles. This allowed the vapour to remain in the layout for a longer time which increased the cloud size. The LNG vapour dispersed according to wind direction and entrained around obstacles leading to formation of pockets of vapour concentration in isolated locations. The leak stopped at $80 \mathrm{~s}$ and the hazardous vapour remained in the layout until 120 $\mathrm{s}$ as shown in Figure 7. This increased the retention time and the likelihood of ignition of flammable hazard. This also points out how important it is to consider the appropriate flammable range in a safety design of such processing plants. One may only consider the regular value of $5 \%$ which shows a safer layout according to the dispersion results. However, in considering the LFL value recommended by the US Federal Regulation [12], it reveals that the layout is not safe after the release of LNG. If an ignition occurs within $110 \mathrm{~s}$, the vapour could be ignited with catastrophic consequences, i.e. flash fire in the case of immediate ignition or Vapour Cloud Explosion (VCE) in the case of delayed ignition. This implies that the 22\% level of equipment congestion cannot be considered as a safe level. 


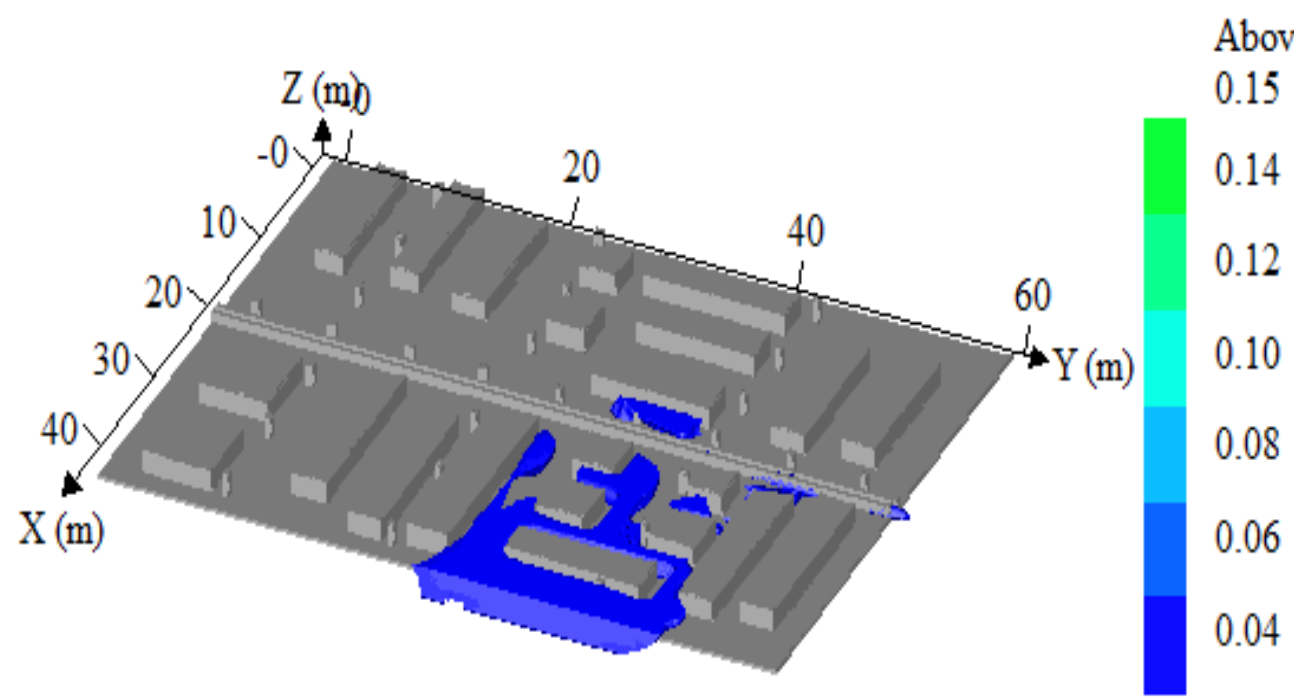

(i)

Below

0.03

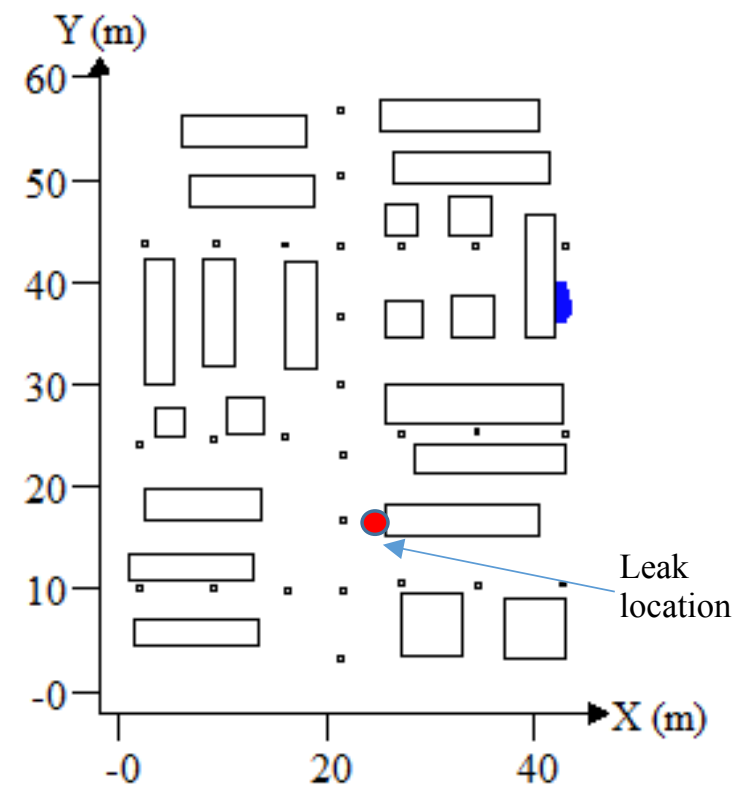

(ii)

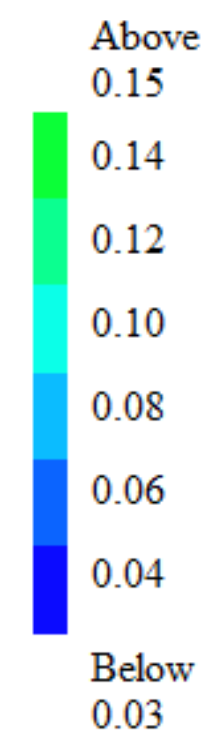

Figure 7. Dispersion of LNG vapour in flammable volume concentration $\left(\mathrm{m}^{3} / \mathrm{m}^{3}\right)$ at $2.3 \mathrm{~m}$ above the ground in Case 1 at (i) $110 \mathrm{~s}$ and (ii) $120 \mathrm{~s}$. The concentration range is selected to assess the presence of the flammable vapour in the layout.

\subsection{Case 2}

In Case 2, the volumetric congestion is $18 \%$. The flow paths and vapour size at $100 \mathrm{~s}$ is shown in Figure 8. The number of obstacles with larger influence in flow diversion in the middle of the flow was reduced. This reduced obstruction in the flow path of the cloud. As a result, the pockets of vapour were not formed, and the vapour path was simply diverted in two directions. The flammable vapour disappeared at $110 \mathrm{~s}$. Although the dispersion analysis shows an 
improvement in the safety level of the layout with $18 \%$ congestion, in this case the ignition of the vapour and flash fire is still a likely scenario.

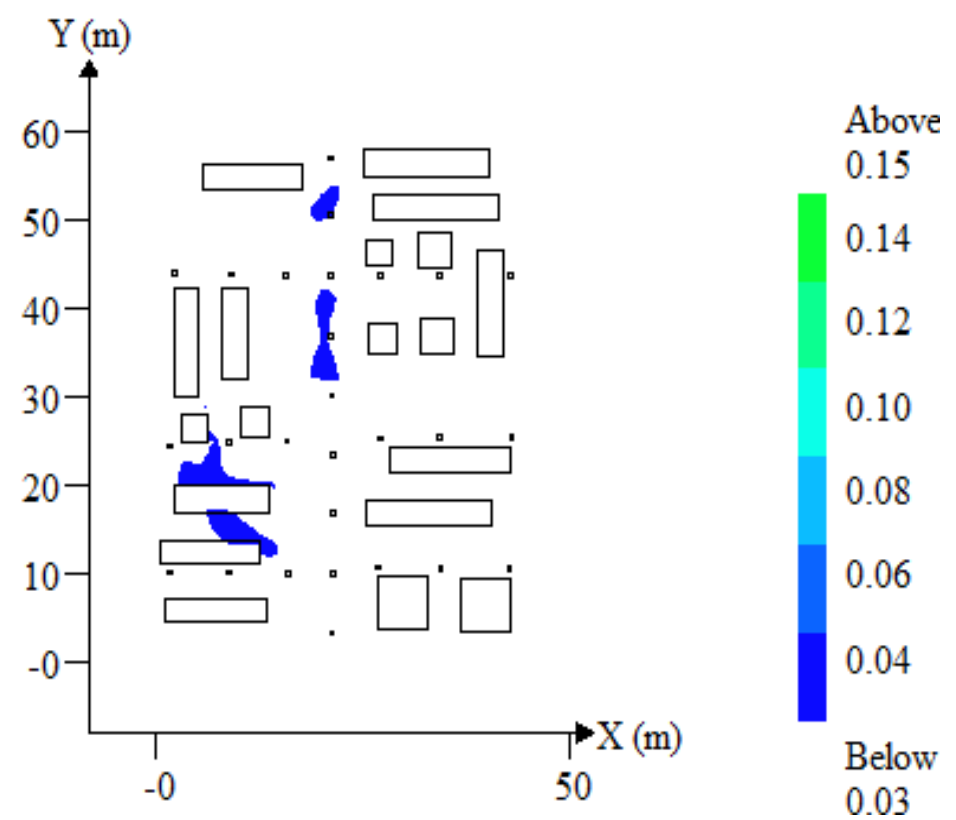

Figure 8. Dispersion of LNG vapour in flammable volume concentration $\left(\mathrm{m}^{3} / \mathrm{m}^{3}\right)$ at $2.3 \mathrm{~m}$ above the ground in Case 2 at $100 \mathrm{~s}$. The concentration range is selected to assess the presence of the flammable vapour in the layout.

\subsection{Case 3}

In this layout, three more pieces of equipment were eliminated from the nearby flow front and $14 \%$ volumetric equipment congestion is obtained. The maximum vapour cloud footprint is observed at $78 \mathrm{~s}$. The absence of an obstacle immediate to the leakage area in the flow path resulted in undiverted flow of the vapour as demonstrated in Figure 9. The decrease of congestion level facilitated the quick dispersion of vapour leading to the rapid dilution of flammable vapour with it disappearing at $100 \mathrm{~s}$. 


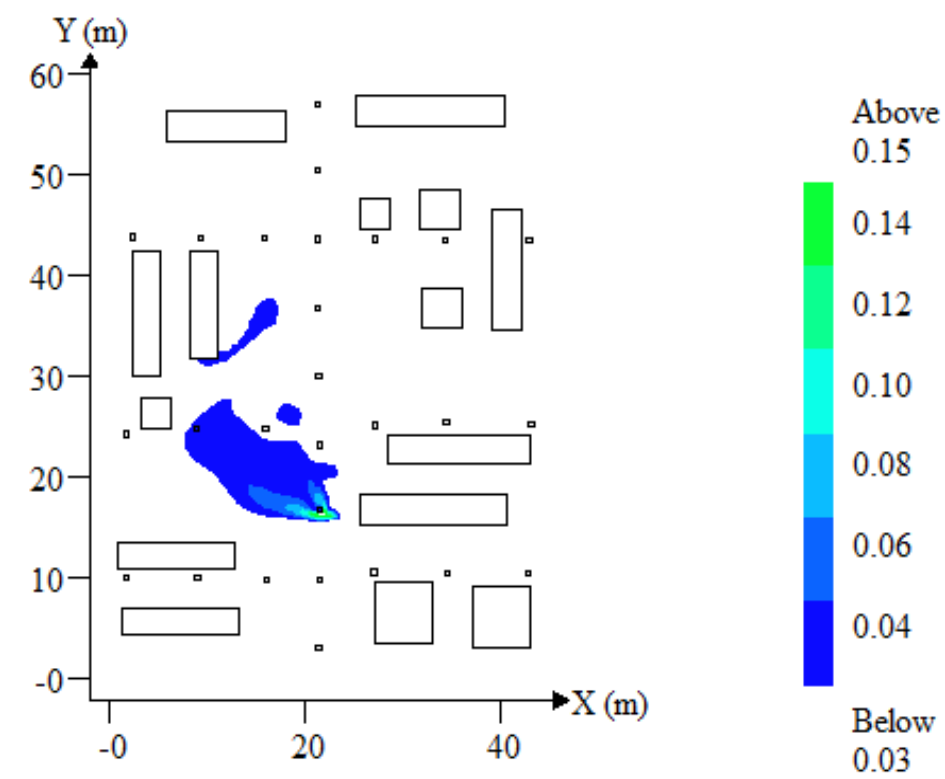

Figure 9. Dispersion of LNG vapour in flammable volume concentration $\left(\mathrm{m}^{3} / \mathrm{m}^{3}\right)$ at $2.3 \mathrm{~m}$ above the ground in Case 3 at $90 \mathrm{~s}$. The concentration is selected to assess the presence of the flammable vapour in the layout.

The flammable mass of LNG vapour in three cases at different times is presented in Figure 10. The flammable mass of LNG vapour is estimated using an inbuilt utility program of FLACS post processing result. The total mass of flammable material released as a function of time was calculated and determined the flammable mass in a vapor cloud by integrating across the concentration profiles between two concentration limits, the LFL and the UFL. It is found that under the same conditions, the dispersion characteristics influenced by obstacles have significant impact on the existence of flammable mass and volume in the given layout. There is no significant reduction in the mass and volume of flammable vapour after $10 \mathrm{~s}$ of the termination of the leak. In Case 1, flammable vapour remains in the layout until $40 \mathrm{~s}$ after the leak ceases and in Case 2, it remains $25 \mathrm{~s}$ after the termination of the leak. Similarly, in Case 3 , the flammable vapour disappeared after $18 \mathrm{~s}$ of the leak stopping. It is confirmed that the retention time of vapour drops with the decrease in congestion level and the formation of vapour pockets depends on obstacles in the flow path. The flammable concentration does not disappear promptly after stoppage of the leak; however, it gradually decreases within different time ranges which depend on the equipment congestion level. The isolated pockets of LNG vapour formation can remain undetected for certain time intervals. This suggests that in any typical congested or semi-confined areas, such accumulation may exist for a significant time even if the leak ceases. 


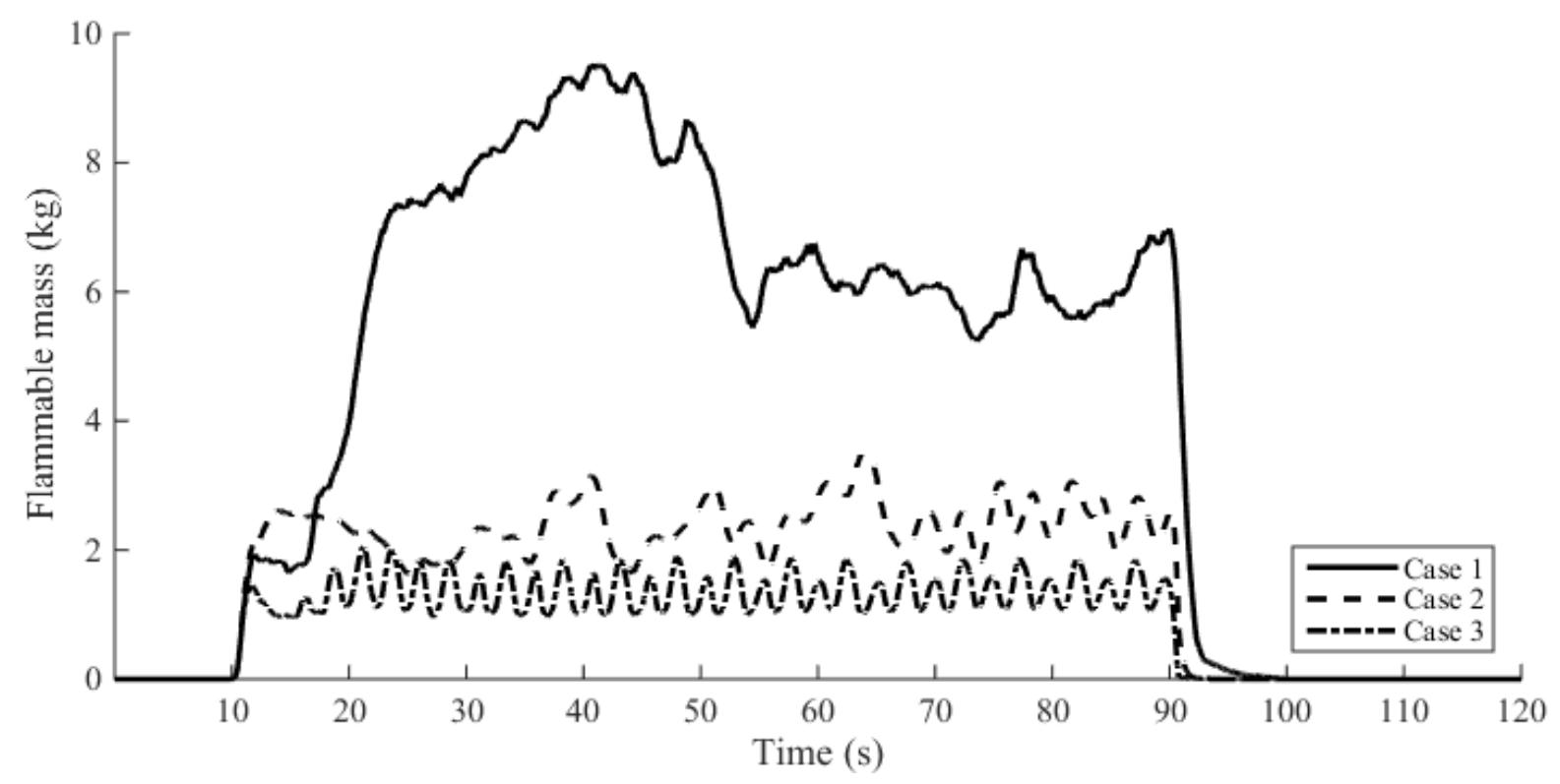

Figure 10. The flammable mass of LNG vapour in three cases at different times

Changing the congestion level, even by a small percentage and change of layout, can produce different vapour flow front and vapour cloud shape under the same environmental conditions. Furthermore, it is observed that mass and volume of flammable vapour in a layout depend on equipment congestion during the fugitive leakage of LNG. The presence of vapour at any instant of time decreases with reduction of congestion level as illustrated in Figure 10. This is due to the combined effects of the increased effective contact area and heat transfer rate, and higher vapour dissipation rate than that of high congestion level [57]. For illustration purposes, source terms such as a pool evaporation rate per area, pool area and pool mass for spreading pool on a steel plate are plotted and compared as given in Figures 11-13. These illustrations show that equipment congestion can affect these parameters and subsequently the dispersion behaviour. However, under these considered scenarios, a clear correlation was not obtained due to the lack of uniform variations. As illustrated in Figures 11-13, the time dependent plots in different congestion levels were not same under the same input parameters. Because of this, the effect of equipment congestion and layout on dispersion of LNG seems to be a key factor in assessing and modelling potential vapour dispersion hazards. This also signifies a need for vapour dispersion control strategies such as vapour barriers that can be employed to mitigate potential vapour dispersion hazards in the event of an LNG spill around the safety critical areas. 


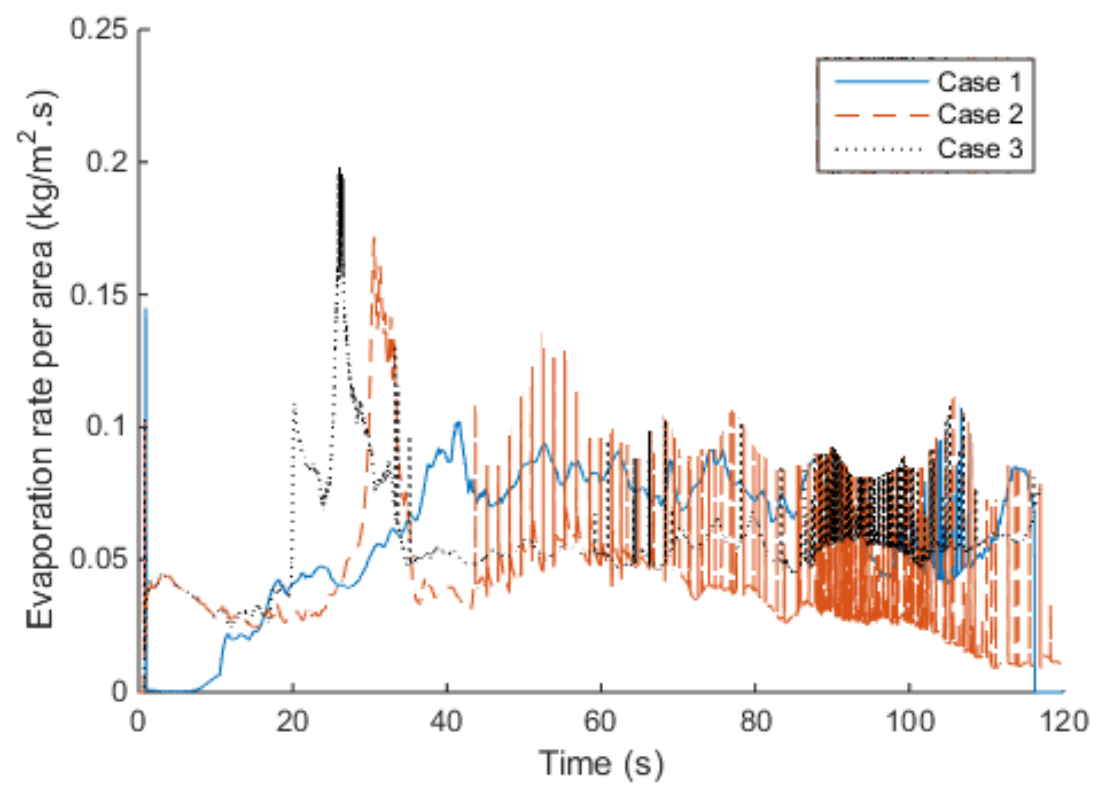

Figure 11. A comparison of evaporation rate per area of the LNG pool in three cases.

Often fugitive gas dispersion is neglected assuming that a fugitive gas leak has no potential to cause major accidents and it is difficult to assess its direct impact [87]. It may have no impact, or its impact can be insignificant if the released gas does not ignite or ignites without propagating and transitioning to other events such as explosion event. However, there are many instances where fugitive leaks, dispersions and ignitions have caused catastrophic fire and explosion [88]. It is agreed that heat radiation from the ignition of such a small quantity of gas may not cause direct asset damage, but, has the potential to trigger secondary or tertiary events thereby causing domino effects (chain of accidents). One example of small leak and major accident is the Skikda LNG accident which was initially caused by small leak which ignited and resulted in the first small explosion [8]. This explosion breached the boiler and provided an ignition source to the external accumulation of combustible gas leading to the larger explosion. 


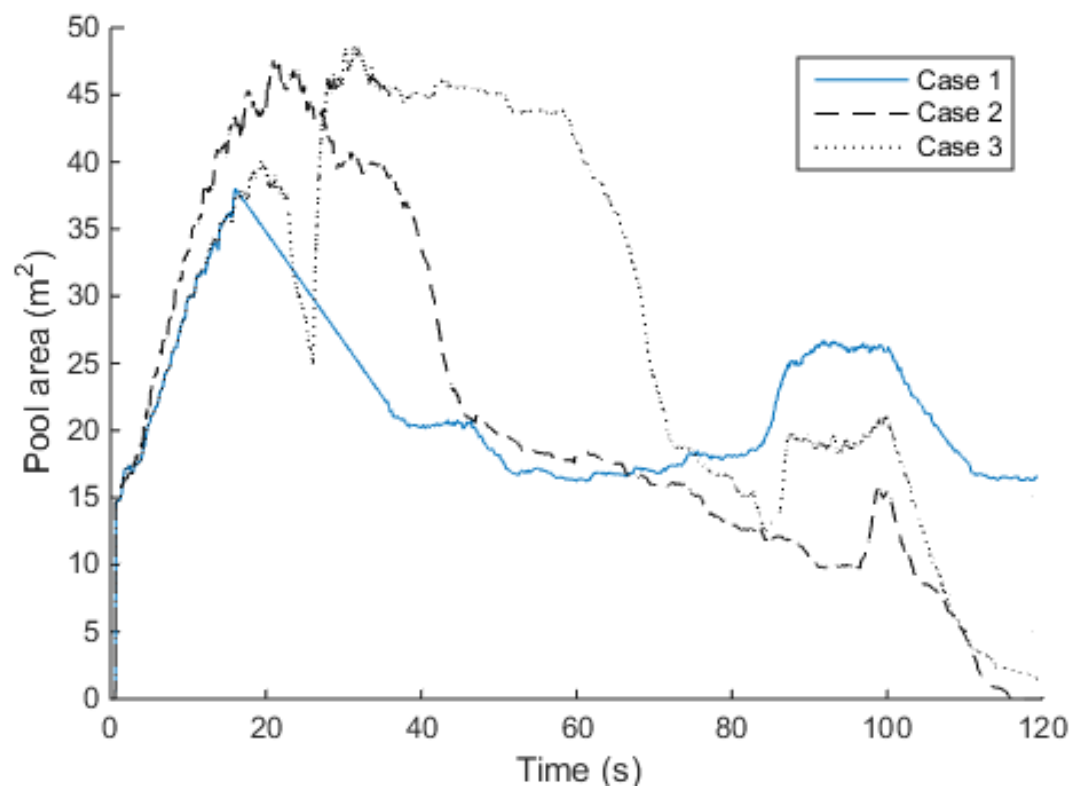

Figure 12. A comparison of pool area in three cases.

Besides, fire and explosion hazard, LNG vapour has potential for asphyxiation hazard during an accidental release of LNG. Integration of an asphyxiation hazard analysis with dispersion modelling would help to identify potential impact to personnel in the facility. According to Lipton and Lynch [89], workers frequently exposed to gases from fugitive emissions in processing plants. Even though, the quantity of fugitive emissions is very small, prolonged exposure may be threatening to health especially if carcinogens are involved. Consideration of fugitive emissions from an occupational health viewpoint is essential because each year more people die from work-related diseases than are killed in industrial accidents [87]. Therefore, it is important to reduce fugitive emissions as low as reasonably practicable to create a healthier, safer, more productive workplace as well as improving operating efficiency. 


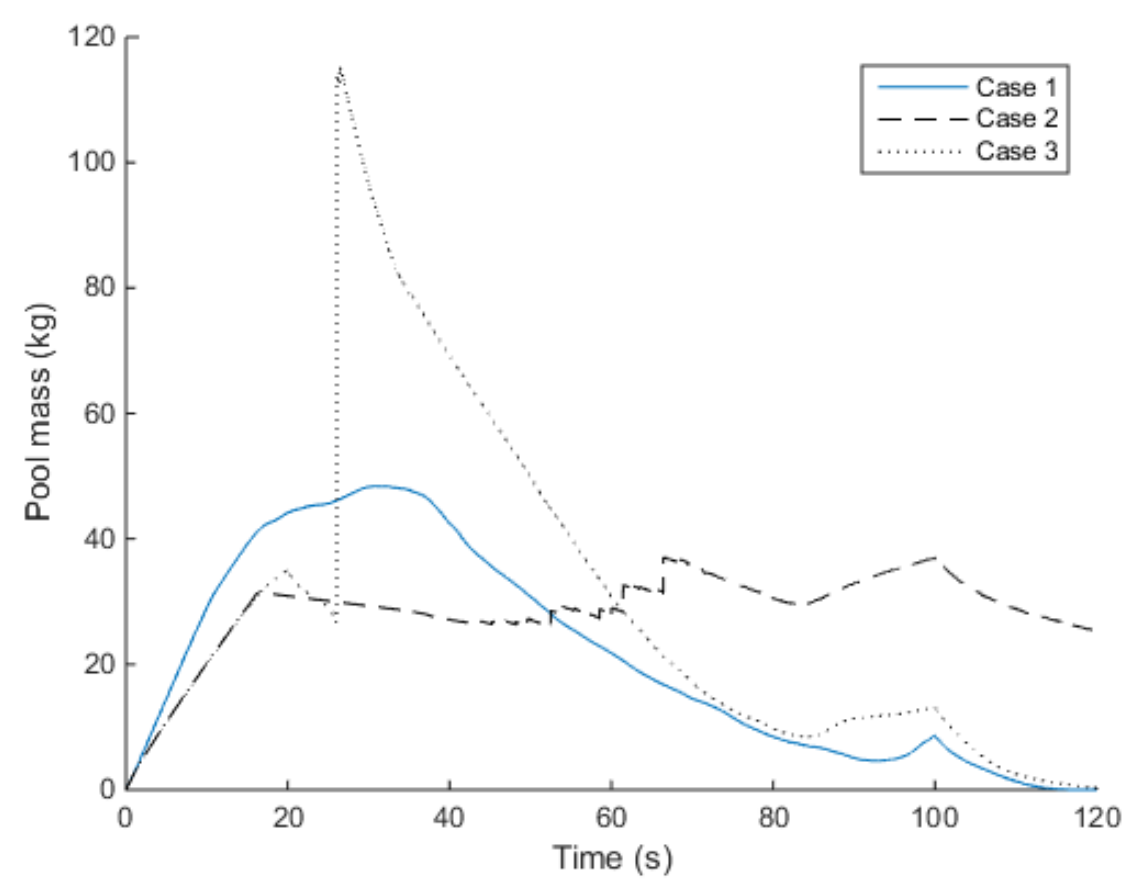

Figure 13. A comparison of pool mass in three cases

For handling uncertainty of various parameters in dispersion modelling, different techniques are available such as Monte Carlo simulation and fuzzy sets theory. In the proposed methodology, uncertainties can be handled by using mean value of sensitive parameters obtained from past studies [23, 80-82]. Uncertainty analysis in dispersion of gas is well discussed in past studies [80-82]. For instance, Siuta, Markowski and Mannan [80] used fuzzy sets theory and Monte Carlo simulation for uncertainty analysis to model LNG source terms and dispersion models. To reduce uncertainty in dispersion modelling, value of sensitive parameters such as wind speed, atmospheric stability and release rate have been chosen according to these past studies. Moreover, a grid sensitivity analysis was performed using volumetric concentration to obtain grid independence solution. A comprehensive uncertainty analysis was beyond the scope of this study as the main purpose of the case study was to show the application of the proposed methodology. However, a detailed uncertainty analysis can be considered in future work.

\section{Conclusions}

In any congested and complex layout of processing facilities, a fugitive release of LNG would be a major safety concern. A methodology is proposed for modelling a small LNG leak and its dispersion. The methodology comprises of release scenarios, credible leak size, simulation, comparison of congestion level and mass of flammable vapour. The methodology is applied to 
a typical layout considering three levels of equipment congestion. The potential fire and/or explosion hazard of small LNG leak is assessed considering both time dependent concentration analysis and area-based model. The case study demonstrated that even after the termination of the leak, the LNG vapour continued to disperse, and the volumetric concentration was still within the flammable range. This led to accumulation of pockets of LNG vapours in the spaces between equipment. In the higher degree of congestion layout, higher amount of flammable mass and volume of LNG vapour was observed. The retention time of the flammable vapour in the higher congestion level layout was also more than that in the lower congestion level layout under the same operating conditions. Subsequently, this intensifies the formation of pockets of isolated vapour cloud. In a congested layout, the accumulation of flammable vapour of LNG would remain undetected and could pose fire and explosion hazards. It is therefore too conservative to neglect small leak scenario in a complex layout because of the effect of equipment congestion on source terms and dispersion behaviour. The case study results demonstrated that equipment congestion has effects on both source terms and dispersion of LNG vapour. This signifies a need for robust measures for detection and monitoring of such releases, including effective prevention and control measures such as ventilation, vapour barriers and emergency shutdown systems in a congested LNG processing facility. The study also confirmed that in considering $2.5 \%$ as lower flammability limit for assessment of hazard distance, as recommended by the US 49-CFR-193.2059 regulation, design safety could be improved. Furthermore, an asphyxiation hazard, likely to be posed by LNG vapour, would be an important aspect of LNG vapour dispersion modelling in future works.

\section{Acknowledgement}

The first author, Til Baalisampang would like to acknowledge the financial support received from the Australian Maritime College (AMC) of the University of Tasmania. The author thankfully acknowledges the technical support received from the Centre for Risk, Integrity and Safety Engineering (c-RISE), Faculty of Engineering \& Applied Science, Memorial University of Newfoundland, St. John's, NL, Canada.

\section{References}

[1] S. Kumar, H.-T. Kwon, K.-H. Choi, J.H. Cho, W. Lim, I. Moon, Current status and future projections of LNG demand and supplies: A global prospective, Energy Policy, 39 (2011) 4097-4104. 
[2] M.M. Foss, F. Delano, G. Gulen, R. Makaryan, LNG safety and security, Center for Energy Economics (CEE), (2003).

[3] M. Lvings, S. Jagger, C. Lee, Evaluating vapor dispersion models for safety analysis of LNG facilities research project, The Fire Protection Research Foundation, Massachusetts, (2007).

[4] B. Sun, R.P. Utikar, V.K. Pareek, K. Guo, Computational fluid dynamics analysis of liquefied natural gas dispersion for risk assessment strategies, Journal of Loss Prevention in the Process Industries, 26 (2013) 117-128.

[5] J.L. Woodward, R. Pitblado, LNG Risk Based Safety: modeling and consequence analysis, John Wiley \& Sons, 2010.

[6] A. Bui, T. Liu, M. Reed, E. Potorson, CFD Modeling of LNG Spreading and Atmospheric Dispersion, in: 11th Global Congress on Process Safety, Austin, 2015.

[7] M. Dadashzadeh, F. Khan, R. Abbassi, K. Hawboldt, Combustion products toxicity risk assessment in an offshore installation, Process Safety and Environmental Protection, 92 (2014) 616-624.

[8] R. Ouddai, H. Chabane, A. Boughaba, M. Frah, The Skikda LNG accident: losses, lessons learned and safety climate assessment, International Journal of Global Energy Issues, 35 (2012) 518-533.

[9] G. Atkinson, E. Cowpe, J. Halliday, D. Painter, A review of very large vapour cloud explosions: Cloud formation and explosion severity, Journal of Loss Prevention in the Process Industries, 48 (2017) 367-375.

[10] S. Rukke, P. Katchmar, C. Hoidal, Failure Investigation Report - Liquefied Natural Gas (LNG) Peak Shaving Plant, Plymouth, Washington, in, 2016.

[11] J.A. Alderman, Introduction to LNG safety, Process safety progress, 24 (2005) 144-151.

[12] US Goverment Publishing Office (GPO), Title 49 Code of Federal Regulations Part 193

(49-CFR-193), Liquefied natural gas facilities: Federal safety standards, U.S. Government Printing Office, Washington, DC, 1980.

[13] National Fire Protection Association (NFPA), NFPA 13: Standard for the Installation of Sprinkler Systems (2002), National Fire Protection Association, 2006.

[14] R. Qi, D. Ng, B.R. Cormier, M.S. Mannan, Numerical simulations of LNG vapor dispersion in Brayton Fire Training Field tests with ANSYS CFX, Journal of Hazardous Materials, 183 (2010) 51-61.

[15] H. Kim, J.-S. Koh, Y. Kim, T.G. Theofanous, Risk assessment of membrane type LNG storage tanks in Korea-based on fault tree analysis, Korean Journal of Chemical Engineering, $22(2005) 1-8$.

[16] R. Koopman, J. Baker, R. Cederwall, H. Goldwire Jr, W. Hogan, L. Kamppinen, R. Keifer, J. McClure, T. McRae, D. Morgan, Burro Series Data Report-LLNL/NWC 1980 LNG Spill Tests, UCID-19075, Lawrence Livermore National Laboratory, Livermore, CA, (1982).

[17] H. Goldwire Jr, H. Rodean, R. Cederwall, E. Kansa, R. Koopman, J. McClure, T. McRae, L. Morris, L. Kamppinen, R. Kiefer, Coyote series data report LLNL/NWC 1981 LNG spill tests dispersion, vapor burn, and rapid-phase-transition. Volume 1.[7 experiments with liquefied natural gas, 2 with liquid methane, and one with liquid nitrogen], in, Lawrence Livermore National Lab., CA (USA), 1983.

[18] T. Brown, R. Cederwall, S. Chan, D. Ermak, R. Koopman, K. Lamson, J. McClure, L. Morris, Falcon series data report: 1987 LNG vapor barrier verification field trials, in, Lawrence Livermore National Lab., CA (USA), 1990.

[19] G. Colenbrander, A. Evans, J. Puttock, Spill Tests of LNG and Refrigerated Liquid Propane on the Sea, Maplin Sands, 1980: Dispersion Data Digest; Trial 27, Shell Research Limited, TNER, 84 (1984). 
[20] G. Feldbauer, J. Heigl, W. McQueen, R. Whipp, W. May, Spills of LNG on watervaporization and downwind drift of combustible mixtures, API Report EE61E-72, (1972).

[21] A. Kneebone, L. Prew, Shipboard jettison test of LNG onto the sea, in: Proc. 4th Int. Conf. on LNG, Algiers, 1974, pp. 1-25.

[22] R. Koopman, B. Bowman, D.L. Ermak, Data and calculations of dispersion on $5 \mathrm{~m} 3$ LNG spill tests, Lawrence Livermore Laboratory, 1979.

[23] B.R. Cormier, R. Qi, G. Yun, Y. Zhang, M.S. Mannan, Application of computational fluid dynamics for LNG vapor dispersion modeling: a study of key parameters, Journal of Loss Prevention in the Process Industries, 22 (2009) 332-352.

[24] W.C. Ikealumba, H. Wu, Modeling of Liquefied Natural Gas Release and Dispersion: Incorporating a Direct Computational Fluid Dynamics Simulation Method for LNG Spill and Pool Formation, Industrial \& Engineering Chemistry Research, 55 (2016) 1778-1787.

[25] T. Baalisampang, R. Abbassi, V. Garaniya, F. Khan, M. Dadashzadeh, Modelling the impacts of fire in a typical FLNG processing facility, in: Paper Presented at the International Conference on Safety and Fire Engineering-SAFE'17, 2017.

[26] M. Hightower, L. Gritzo, A. Luketa-Hanlin, J. Covan, S. Tieszen, G. Wellman, M. Irwin, M. Kaneshige, B. Melof, C. Morrow, Guidance on risk analysis and safety implications of a large liquefied natural gas (LNG) spill over water, in, DTIC Document, 2004.

[27] F. Gavelli, E. Bullister, H. Kytomaa, Application of CFD (Fluent) to LNG spills into geometrically complex environments, Journal of Hazardous Materials, 159 (2008) 158-168.

[28] S.T. Chan, Heavy Gas Dispersion Incompressible Flow, in, Lawrence Livermore National Laboratory, 1992.

[29] S. Dharmavaram, S. Hanna, O. Hansen, Consequence Analysis-Using a CFD model for industrial Sites, Process Safety Progress, 24 (2005) 316-272.

[30] S. Sklavounos, F. Rigas, Validation of turbulence models in heavy gas dispersion over obstacles, Journal of Hazardous Materials, 108 (2004) 9-20.

[31] J. Fiates, R.R.C. Santos, F.F. Neto, A.Z. Francesconi, V. Simoes, S.S.V. Vianna, An alternative CFD tool for gas dispersion modelling of heavy gas, Journal of Loss Prevention in the Process Industries, 44 (2016) 583-593.

[32] T.A. Melton, J.B. Cornwell, LNG trench dispersion modeling using computational fluid dynamics, Journal of Loss Prevention in the Process Industries, 23 (2010) 762-767.

[33] J. Havens, T. Spicer, LNG vapor cloud exclusion zones for spills into impoundments, Process Safety Progress, 24 (2005) 181-186.

[34] J. Brandeis, D.L. Ermak, Numerical simulation of liquefied fuel spills: II. Instantaneous and continuous LNG spills on an unconfined water surface, International Journal for Numerical Methods in Fluids, 3 (1983) 347-361.

[35] D.W. Hissong, Keys to modeling LNG spills on water, Journal of Hazardous Materials, 140 (2007) 465-477.

[36] F. Gavelli, M.K. Chernovsky, E. Bullister, H.K. Kytomaa, Modeling of LNG spills into trenches, Journal of Hazardous Materials, 180 (2010) 332-339.

[37] S.T. Chan, D.L. Ermak, Recent Results in Simulating LNG Vapor Dispersion over Variable Terrain, in: G. Ooms, H. Tennekes (Eds.) Atmospheric Dispersion of Heavy Gases and Small Particles: Symposium, Delft, The Netherlands August 29 - September 2, 1983, Springer Berlin Heidelberg, Berlin, Heidelberg, 1984, pp. 105-114.

[38] S. Hanna, D. Strimaitis, J. Chang, Hazard Response Modeling Uncertainty (A Quantitative Method). Volume 2. Evaluation of Commonly Used Hazardous Gas Dispersion Models, in, SIGMA RESEARCH CORP WESTFORD MA, 1993.

[39] R. Koopman, J. Baker, R. Cederwall, H. Goldwire Jr, W. Hogan, L. Kamppinen, R. Keifer, J. McClure, T. McRae, D. Morgan, Burro series data report LLNL/NWC 1980 LNG spill tests, UCID-19075, Lawrence Livermore National Laboratory, Livermore, CA, (1982). 
[40] United States Department of Energy, Liquefied Natural Gas Safety Research, Report to Congress May 2012, in, Washington, DC 20585, 2012.

[41] G.A. Fitzgerald, Calculating facility siting study leak sizes-one size does not fit all, Process Safety Progress, 35 (2016) 176-178.

[42] Health and Safety Executive (HSE), Offshore Statistics and Regulatory Activity Report 2016, in, 2017.

[43] C. Bello, J. Siegell, Why valves leak: A search for the cause of fugitive emissions, Environmental Progress \& Sustainable Energy, 16 (1997) 13-15.

[44] G.A. Keoleian, C.E. Blackler, R. Denbow, R. Polk, Comparative assessment of wet and dry garment cleaning Part 1. Environmental and human health assessment, Journal of Cleaner Production, 5 (1997) 279-289.

[45] L. Paris, An engineer-based methodology to perform Explosion Risk Analyses, Journal of Loss Prevention in the Process Industries, 57 (2019) 254-272.

[46] G. Ma, J. Li, M. Abdel-jawad, Accuracy improvement in evaluation of gas explosion overpressures in congestions with safety gaps, Journal of Loss Prevention in the Process Industries, 32 (2014) 358-366.

[47] J. Li, M. Abdel-jawad, G. Ma, New correlation for vapor cloud explosion overpressure calculation at congested configurations, Journal of Loss Prevention in the Process Industries, 31 (2014) 16-25.

[48] C. Van Den Bosh, R. Weterings, Methods for the calculation of physical effects (Yellow Book), Committee for the Prevention of Disasters, The Hague (NL), (1997).

[49] T. Baalisampang, R. Abbassi, F. Khan, Overview of Marine and Offshore Safety, Methods in Chemical Process Safety, (2018).

[50] A. Cataylo, K. Tanigawa, Floating LNG Challenges on Cryogenic Spill Control, in: SPE International Conference on Health, Safety, and Environment, Society of Petroleum Engineers, 2014.

[51] J. Li, G. Ma, M. Abdel-jawad, Y. Huang, Gas dispersion risk analysis of safety gap effect on the innovating FLNG vessel with a cylindrical platform, Journal of Loss Prevention in the Process Industries, 40 (2016) 304-316.

[52] J. Li, G. Ma, H. Hao, Y. Huang, Optimal blast wall layout design to mitigate gas dispersion and explosion on a cylindrical FLNG platform, Journal of Loss Prevention in the Process Industries, 49 (2017) 481-492.

[53] D.W. Johnson, J.B. Cornwell, Modeling the release, spreading, and burning of LNG, LPG, and gasoline on water, Journal of hazardous materials, 140 (2007) 535-540.

[54] R. Reid, Boiling of LNG on typical dike floor materials, Massachusetts Institute of Technology, LNG Research Centre, Cambridge, (1980).

[55] S. Saraf, G. Melhem, Modeling LNG pool spreading and vaporization, in: AIChE Spring Meeting, ioMosaic Corporation, Atlanta, GA, 2005.

[56] S. Brambilla, D. Manca, On pool spreading around tanks: Geometrical considerations, Journal of hazardous materials, 158 (2008) 88-99.

[57] D. Webber, S. Gant, M. Ivings, S. Jagger, LNG source term models for hazard analysis: A review of the state-of-the-art and an approach to model assessment, Prepared by Health \& Safety Laboratory for the Fire Protection Research Foundation, Final Report, (2010).

[58] B.R. Cormier, Computational fluid dynamics for LNG vapor dispersion modeling: a key parameters study, in, Texas A\&M University, 2008.

[59] K. Reddy, K. Yarrakula, Analysis of Accidents in Chemical Process Industries in the period 1998-2015, International Journal of ChemTech Research, 9 (2016) 177-191.

[60] F.I. Khan, S. Abbasi, Major accidents in process industries and an analysis of causes and consequences, Journal of Loss Prevention in the process Industries, 12 (1999) 361-378. 
[61] F.I. Khan, Use maximum-credible accident scenarios for realistic and reliable risk assessment, Chemical engineering progress, 97 (2001) 56-65.

[62] R. Pitblado, J. Baik, V. Raghunathan, LNG decision making approaches compared, Journal of hazardous materials, 130 (2006) 148-154.

[63] R. Pitblado, J. Baik, G. Hughes, C. Ferro, S. Shaw, Consequences of liquefied natural gas marine incidents, Process safety progress, 24 (2005) 108-114.

[64] B.K. Kim, Application of Computational Fluid Dynamics in the Forced Dispersion Modeling of LNG Vapor Clouds, in, Texas A\&M University, 2013.

[65] S.M. Tauseef, D. Rashtchian, S.A. Abbasi, CFD-based simulation of dense gas dispersion in presence of obstacles, Journal of Loss Prevention in the Process Industries, 24 (2011) 371376.

[66] T. Baalisampang, F. Khan, V. Garaniya, S. Chai, R. Abbasi, An Inherently Safer Layout Design for the Liquefaction Process of an FLNG Plant, International Journal of Maritime Engineering, 158, Part A2 (2016) 91-102.

[67] J.A. Klein, B.K. Vaughen, Process Safety: Key Concepts and Practical Approaches, CRC Press, 2017.

[68] J.L. Woodward, Estimating the flammable mass of a vapor cloud, John Wiley \& Sons, 2010.

[69] K. Kinsella, A rapid assessment methodology for the prediction of vapour cloud explosion overpressure, in: Proceedings of the International Conference and Exhibition on Safety, Health and Loss Prevention in the Oil, Chemical and Process Industries, Singapore, 1993, pp. 200211.

[70] R. Raman, P. Grillo, Minimizing uncertainty in vapour cloud explosion modelling, Process Safety and Environmental Protection, 83 (2005) 298-306.

[71] Q. Baker, M. Tang, E. Scheier, G. Silva, Vapor Cloud Explosion Analysis AIChE Loss Prevention Symposium, Atlanta, Georgia, USA, (1994).

[72] J.-E. Vinnem, Offshore Risk Assessment vol 2, Springer, 2014.

[73] GexCon AS, FLACS v10. 0 User's Manual, in, January, 2013.

[74] O.R. Hansen, M. Ichard, S.G. Davis, Validation of FLACS for vapor dispersion from LNG spills: model evaluation protocol, in: Proc. 2009 Mary Kay O'Connor Process Safety Symposium, 2010.

[75] A. Safitri, X. Gao, M.S. Mannan, Dispersion modeling approach for quantification of methane emission rates from natural gas fugitive leaks detected by infrared imaging technique, Journal of Loss Prevention in the Process Industries, 24 (2011) 138-145.

[76] C.D. Zinn, LNG codes and process safety, Process safety progress, 24 (2005) 158-167.

[77] T. Baalisampang, R. Abbassi, V. Garaniya, F. Khan, M. Dadashzadeh, Fire impact assessment in FLNG processing facilities using Computational Fluid Dynamics (CFD), Fire Safety Journal, 92 (2017) 42-52.

[78] J. Srebric, V. Vukovic, G. He, X. Yang, CFD boundary conditions for contaminant dispersion, heat transfer and airflow simulations around human occupants in indoor environments, Building and Environment, 43 (2008) 294-303.

[79] A. Luketa-Hanlin, R.P. Koopman, D.L. Ermak, On the application of computational fluid dynamics codes for liquefied natural gas dispersion, Journal of Hazardous Materials, 140 (2007) 504-517.

[80] D. Siuta, A.S. Markowski, M.S. Mannan, Uncertainty techniques in liquefied natural gas (LNG) dispersion calculations, Journal of Loss Prevention in the Process Industries, 26 (2013) 418-426.

[81] K.S. Rao, Uncertainty analysis in atmospheric dispersion modeling, Pure and applied geophysics, 162 (2005) 1893-1917. 
[82] A. Yegnan, D.G. Williamson, A.J. Graettinger, Uncertainty analysis in air dispersion modeling, Environmental Modelling \& Software, 17 (2002) 639-649.

[83] S. Lee, S. Seo, D. Chang, Fire risk comparison of fuel gas supply systems for LNG fuelled ships, Journal of Natural Gas Science and Engineering, 27 (2015) 1788-1795.

[84] J. Zhang, Designing a cost-effective and reliable pipeline leak-detection system, Pipes and Pipelines International, 42 (1997) 20-26.

[85] P.-S. Murvay, I. Silea, A survey on gas leak detection and localization techniques, Journal of Loss Prevention in the Process Industries, 25 (2012) 966-973.

[86] D. Napier, D. Roopchand, An approach to hazard analysis of LNG spills, Journal of occupational accidents, 7 (1986) 251-272.

[87] M.H. Hassim, M. Hurme, P.R. Amyotte, F.I. Khan, Fugitive emissions in chemical processes: The assessment and prevention based on inherent and add-on approaches, Journal of Loss Prevention in the Process Industries, 25 (2012) 820-829.

[88] T. Baalisampang, R. Abbassi, V. Garaniya, F. Khan, M. Dadashzadeh, Review and analysis of fire and explosion accidents in maritime transportation, Ocean Engineering, 158 (2018) 350-366.

[89] S. Lipton, J. Lynch, Handbook of health hazard control in the chemical process industry, Wiley-Interscience, 1994.

[90] R.L. Petersen, Effect of homogeneous and heterogeneous surface roughness on heavierthan-air gas dispersion, Journal of wind engineering and industrial aerodynamics, 36 (1990) 643-652. 


\section{Highlights}

1. Effect of equipment congestion level on dispersion characteristics of LNG is assessed

2. Retention time of LNG vapour increases with increase of congestion levels

3. Fugitive LNG spill and dispersion present fire and explosion hazard in a congested layout

4. The developed methodology may be adopted to improve detection of LNG releases in a congested processing facility 
Accidental release of Liquefied Natural Gas in a processing facility: effect of equipment congestion level on dispersion behaviour of the flammable vapour

Til Baalisampang ${ }^{\mathrm{a}}$, Rouzbeh Abbassi ${ }^{\mathrm{b}, *}$, Vikram Garaniya ${ }^{\mathrm{a}}$, Faisal Khan ${ }^{\mathrm{a}, \mathrm{c}}$, Mohammad Dadashzadeh $^{\mathrm{d}}$

a National Centre for Maritime Engineering and Hydrodynamics, Australian Maritime College, University of Tasmania, Launceston, Tasmania, Australia

${ }^{b}$ School of Engineering, Faculty of Science and Engineering, Macquarie University, Sydney, NSW, Australia

${ }^{c}$ Centre for Risk, Integrity and Safety Engineering, Faculty of Engineering \& Applied Science, Memorial University of Newfoundland, St. John's, NL, Canada

dHydrogen Safety Engineering and Research Centre (HySAFER), Ulster University, Newtownabbey, Northern Ireland, UK.

* Corresponding Author: rouzbeh.abbassi@mq.edu.au

\section{Abstract}

An accidental leakage of Liquefied Natural Gas (LNG) can occur during processes of production, storage and transportation. LNG has a complex dispersion characteristic after release into the atmosphere. This complex behaviour demands a detailed description of the scientific phenomena involved in the dispersion of the released LNG. Moreover, a fugitive LNG leakage may remain undetected in complex geometry usually in semi-confined or confined areas and is prone to fire and explosion events. To identify location of potential fire and/or explosion events, resulting from accidental leakage and dispersion of LNG, a dispersion modelling of leakage is essential. This study proposes a methodology comprising of release scenarios, credible leak size, simulation, comparison of congestion level and mass of flammable vapour for modelling the dispersion of a small leakage of LNG and its vapour in a typical layout using Computational Fluid Dynamics (CFD) approach. The methodology is applied to a case study considering a small leakage of LNG in three levels of equipment congestion. The potential fire and/or explosion hazard of small leaks is assessed considering both time dependent concentration analysis and area-based model. Mass of flammable vapour is estimated in each case and effect of equipment congestion on source terms and dispersion characteristics are analysed. The result demonstrates that the small leak of LNG can create hazardous scenarios for a fire and/or explosion event. It is also revealed that higher degree of equipment congestion increases the retention time of vapour and intensifies the formation of pockets of isolated vapour cloud. This study would help in designing appropriate leak and dispersion detection systems, effective monitoring procedures and risk assessment.

Keywords: Complex layout, LNG, fugitive leakage, dispersion modelling, CFD, FLACS 


\section{Introduction}

High demand for the consumption of natural gas, (LNG), means an outstanding increase in production, storage and transportation of natural gas in different forms (Baksh et al., 2017; Kumar et al., 2011). Hence, the potential hazards of LNG spills and the associated impacts on the exposed population and environment is of major concern (Foss et al., 2003). To assess potential risk of LNG spills and the consequences, it is vital to study LNG vapour dispersion behaviour. After the leakage, LNG hazards can be evaluated in three stages: source term (pool development and its evaporation); dispersion; and effects (due to fire thermal radiation and/or explosion overpressure) Lvings et al. (2007). To identify and assess the risks of LNG release, hazards of each phase need to be considered. Being 1.5 times heavier than air, after release into the atmosphere, the dispersion of LNG occurs in three phases: negative buoyancy dominated; stably stratified; and passive dispersion (Sun et al., 2013). The dispersion of LNG mainly depends on the evaporation rate of LNG pool and atmospheric effect. The LNG vapour initially released from spill is denser than the air and forms a vapour cloud around the release location close to the ground. The buoyancy is not dominant at this stage and the vapour disperses into the surrounds due to the wind. The atmospheric condition also matters at this phase by warming the vapour due to conduction when it is diluted in the surrounding environment (Woodward and Pitblado, 2010). This causes instantaneous vaporisation of LNG due to its cryogenic nature which leads to the formation of a flammable vapour cloud (Bui et al., 2015). Considering its complex dispersion behaviour, a detailed understanding of spilled LNG behaviour is required for the accurate prediction of potential consequences.

An accidental LNG release and its dispersion may cause severe consequences such as structural failure due to brittle fracture, asphyxiation, and fire and explosion. Dispersion of combustion products released after LNG vapour fire and explosion also presents a serious hazard to humans and the surrounding structures (Dadashzadeh et al., 2014). These events may lead to fatalities and financial losses. Past LNG accidents are reported in Woodward and Pitblado (2010). For example, fire and explosion occurred in a LNG facility in Skikda, Algeria on 19 January 2004 which resulted in 27 casualties, 56 injuries and $\$ 900$ million loss (Ouddai et al., 2012). Either LNG or refrigerant leakage from a defective pipe used to transport LNG and hydrocarbon products in liquid state was identified as a primary cause of the fire and explosion event (Ouddai et al., 2012). The release rate was about $10 \mathrm{~kg} / \mathrm{s}$ (Atkinson et al., 2017). More recently, on 3 March 2014, the Plymouth-Liquefied Natural Gas Peak Shaving Plant 
experienced a catastrophic failure which resulted in an explosion in a portion of the facility's LNG-1 purification and regeneration system (Rukke et al., 2016). The investigation report (Rukke et al., 2016) found that the primary cause of this accident was operator error which led to vessel and piping failure from detonation caused by internal auto-ignition due to a purge that failed to remove a gas air mixture from the system. The incident injured 5 employees and cost $\$ 45,749,300$. This shows that formation of a flammable vapour cloud after the release of LNG is a major issue. The wide flammability range of natural gas makes its dispersion behaviour a critical priority to be fully understood. If an ignition source is present and the vapour air mixture is in its flammable range, the vapour cloud will ignite and catastrophic consequences are likely (Alderman, 2005). The US Federal Regulation 49 CFR Part 193.2059 (US Goverment Publishing Office (GPO), 1980) and standard NFPA 59A (National Fire Protection Association (NFPA), 2006) require the use of validated consequence models to predict potential hazardous areas adjacent to LNG facilities in the event of an accidental LNG spill (Qi et al., 2010). For quantitative risk assessment of an accidental LNG spill, no enough data are available to calculate LNG leak frequency in LNG production and receiving facilities. To avoid this limitation, Kim et al. (2005) provided the top events of major LNG releases from membrane type LNG storage tanks and associated pipes considering release scenarios of overfilling, overpressurisation, under-pressurisation, failure of inlet lines and outlet lines and loss of mechanical integrity of the tank using Fault Tree analysis. Based on these failure mechanisms, total leak frequency was found to be $5.2 \times 10^{-5}$ per year. However, this may not be adequate for risk assessment and management of a large and complex facility with liquefaction and offloading processes.

Some large scale experiments and tests were carried out to gain an understanding of spill and dispersion characteristics of LNG such as the Burro series (Koopman et al., 1982), Coyote series (Goldwire et al., 1983), Falcon series (Brown et al., 1990), Maplin Sands tests (Colenbrander et al., 1984), Esso tests (Feldbauer et al., 1972), Shell jettison tests (Kneebone and Prew, 1974), Avocet (Koopman et al., 1979), and Brayton Fire Training Field (BFTF) (Cormier et al., 2009). Due to the difficulties, costs, and risks involved in conducting such experiments, computational modelling of LNG spill and dispersion is strongly favoured (Ikealumba and $\mathrm{Wu}, 2016$ ). To model LNG vapour dispersion, there are various approaches with different levels of complexity are available, i.e. simple empirical models, integral, shallow-layer models and fully three-dimensional CFD models (Baalisampang et al., 2017b). The use of CFD codes for LNG vapour cloud dispersion simulation is strongly recommended 
by the Sandia National Laboratories 2004 report (Hightower et al., 2004). CFD modelling allows for the representation of complex geometry and its effects on flow and dispersion (Cormier et al., 2009; Gavelli et al., 2008). According to Cormier et al. (2009) four publicly available CFD codes are widely used for LNG dispersion modelling namely FEM3 (Chan, 1992), Flame Acceleration Simulator (FLACS) (Dharmavaram et al., 2005), ANSYS Fluent (Gavelli et al., 2008) and ANSYS CFX (Qi et al., 2010; Sklavounos and Rigas, 2004). Moreover, Open Field Operation and Manipulation (OpenFoam) (Fiates et al., 2016) and Fire Dynamics Simulator (FDS) have also been used for LNG dispersion modelling (Melton and Cornwell, 2010).

Past LNG dispersion modellings were studied based on spill into impoundment (Gavelli et al., 2008; Havens and Spicer, 2005), over water (Brandeis and Ermak, 1983; Hightower et al., 2004; Hissong, 2007), trenches (Gavelli et al., 2010; Melton and Cornwell, 2010) and terrain (Chan and Ermak, 1984). These studies were performed incorporating large leaks of gas or LNG vapour. The large-scale field tests for LNG dispersion are summarised in Table 1.

\section{Table 1}

Large scale LNG dispersion tests

\begin{tabular}{|l|l|l|l|l|l|l|}
\hline Name & $\begin{array}{l}\text { Trial } \\
\text { number }\end{array}$ & $\begin{array}{l}\text { Atmospheric } \\
\text { condition based } \\
\text { on Pasquill } \\
\text { Stability Classes }\end{array}$ & $\begin{array}{l}\text { Wind } \\
\text { speed } \\
(\mathrm{m} / \mathrm{s})\end{array}$ & $\begin{array}{l}\text { Dispersion } \\
\text { over land } \\
\text { (L) or water } \\
\text { (W) }\end{array}$ & $\begin{array}{l}\text { Mass } \\
\text { flow rate } \\
(\mathrm{kg} / \mathrm{s})\end{array}$ & $\begin{array}{l}\text { Release } \\
\text { duration } \\
\text { (s) }\end{array}$ \\
\hline $\begin{array}{l}\text { Maplin Sands } \\
\text { 1980 (Hanna et } \\
\text { al., 1993) }\end{array}$ & 27 & C-D & 5.5 & W & 23.2 & 160 \\
\hline Burro Test & 35 & D & 8.6 & W & 21.5 & 95 \\
1980 & 3 & B & 9.8 & W & 27.1 & 135 \\
(Koopman et & 8 & E & 5.6 & L & 88 & 167 \\
al., 1982) & 9 & D & 8.8 & L & 99 & 174 \\
\hline $\begin{array}{l}\text { Coyote } \\
\text { 1981 }\end{array}$ & 3 & B-C & 5.8 & L & 117 & 107 \\
(Goldwire et & 6 & C-D & 6.8 & L & 136 & 79 \\
al., 1983) & D & 10.5 & L & 129 & 65 \\
\hline Falcon 1987 & 1 & G & 5.0 & L & 123 & 82 \\
(Brown et al., & 3 & D & 1.2 & L & 202 & 131 \\
1990) & 4 & D-E & 3.7 & L & 133 & 154 \\
\hline
\end{tabular}

The US Department of Energy Report 2012 (United States Department of Energy, 2012) considered $0.005 \mathrm{~m}^{2}$ ( $80 \mathrm{~mm}$ diameter) as a very small breach size in studying the impact of LNG spill. According to Fitzgerald (2016) the oil and gas industry has generally adopted the 2 inch $(50.8 \mathrm{~mm})$ maximum leak size for Facility Siting Studies (FSSs) and guidance relevant to 
leak size also tends to agree in either limiting leaks to a maximum diameter of 2 inches or uses a portion of the pipe cross-section as their assumed leak size. This has been considered as the accepted level of conservatism in most facilities. This shows that these leaks sizes, or smaller, are often not considered in risk analysis and their prevention or control strategies are not emphasised. However, typically smaller leaks $(10-25 \mathrm{~mm})$ are highly likely to occur in the LNG facility's lifetime (Woodward and Pitblado, 2010). A fugitive leakage often represents only a small source of leaks and seems to be inconsequential. However, if the leaked fuel is exposed to an ignition source within its flammable range, it will cause various transitional events in congested layout leading to catastrophic consequences. According to an Health and Safety Executive (HSE) report (HSE, 2017), more than 50\% of the total hydrocarbons (HCs) release incidents are minor ones (Table 2). On the other hand, an accumulation of several fugitive leakages from any source, or group of sources, creates a major release into the air which is equivalent to a large release. Given the high frequency of small leaks and the high potential to trigger major accidents, smaller leak and its dispersion may be too simplistic to ignore. Despite the high frequency of small leaks and potential for major accidents, dispersion of gas or LNG leaked from small leak sizes (smaller than or equal to 2-inch) has not been emphasised considering the effect of congestion levels on source terms and LNG vapour dispersion. According to Paris (2019) the strength of a gas explosion depends on various variables such as congestion, fuel types, flammable cloud size, shape and ignition location and strength. Equipment congestion plays a critical role in the gas dispersion and explosion (Li et al., 2014; Ma et al., 2014). Because equipment congestion changes Lower Flammability Limit (LFL) distance and concentration level (Cormier et al., 2009). According to the Yellow Book (Van Den Bosh and Weterings, 1997) the percentage of the vapour cloud varies, depending on different factors, including the type and amount of the material released, pressure at release, size of release opening, degree of confinement of the cloud, and wind, humidity and other environmental effects. The equipment congestion, obstacle and roughness of the surface affect source term parameters and dispersion behaviour. Cormier et al. (2009) claimed that wind velocity, obstacles, sensible heat flux, and the released mass affect LFL distance and vapour concentration level. Thus, this study considers the effects of equipment congestion on source terms, namely pool evaporation rate, pool area and evaporation rate per area for spreading pool on a steel plate. 
Table 2

HCs release incidents and percentage of minor release incidents on the UK Continental Shelf.

\begin{tabular}{|l|l|l|l|}
\hline Year & $\begin{array}{l}\text { Total HC } \\
\text { release } \\
\text { incidents }\end{array}$ & $\begin{array}{l}\text { Number of } \\
\text { minor } \\
\text { releases }\end{array}$ & $\begin{array}{l}\text { Percentage of } \\
\text { minor release } \\
\text { incidents (\%) }\end{array}$ \\
\hline 2007 & 185 & 110 & 59.46 \\
\hline 2008 & 147 & 93 & 63.27 \\
\hline 2009 & 179 & 95 & 53.07 \\
\hline 2010 & 186 & 109 & 58.60 \\
\hline 2011 & 142 & 82 & 57.75 \\
\hline 2012 & 105 & 58 & 55.24 \\
\hline 2013 & 118 & 70 & 59.32 \\
\hline 2014 & 94 & 47 & 50 \\
\hline 2015 & 93 & 50 & 53.76 \\
\hline 2016 & 104 & 55 & 52.88 \\
\hline
\end{tabular}

Modelling of gas dispersion in an offshore facility is generally difficult due to complex geometries and layouts. Contrary to conventional offshore facilities, a floating LNG (FLNG) processing facility is expected to have higher risks of vapour cloud dispersion, fire and explosion due to processing, storage and offloading of LNG and other flammable products in harsh environmental conditions (Baalisampang et al., 2018). It is stated by Cataylo and Tanigawa (2014) that leaks occur across LNG facilities. Li et al. (2016) investigated the effect of safety gap on dispersion of gas releases in FLNG platform and claimed that the safety gap reduces the gas cloud size between adjacent modules. But these studies (Li et al., 2016; Li et al., 2017) investigated the LNG dispersion phenomena considering large leak size which is a rare event. Small leaks occur frequently, which can be too simple to ignore in a complex layout due to resulting volume of LNG under ambient conditions and potential to cause serious events. Because of these, there is a need for modelling small leak and dispersion characteristics of LNG in FLNG processing facility for risk assessment and management. The current study aims at investigating small leak and dispersion behaviour of LNG in a typical FLNG processing facility by considering effect of equipment congestion. The result demonstrates that small leak of LNG can create hazardous scenarios for fire and explosion events and reveals that higher degree of equipment congestion increases the retention time of vapour and intensifies the formation of pockets of isolated vapour cloud. 


\section{Release and dispersion modelling}

Fig. 1 illustrates the developed procedure for the dispersion modelling of small LNG leak in a complex geometry. This consists of release scenario development, credibility estimation of release scenario, consideration of various degrees of congestion, CFD simulation and comparison of flammable vapour profile.

In step 1, possible release scenarios based on potential release cases of LNG are identified. This helps to select representative release scenarios which cause the release of hazardous material. Due to the large number of release scenarios, it is usual to consider only a few release cases to represent the entire range of scenarios. The release scenarios can be developed using analytical processes such as Hazard Identification (HAZID), and Hazard and Operability Study (HAZOP). The parameters related to release scenario have been considered in several studies (examples (Brambilla and Manca, 2008; Johnson and Cornwell, 2007; Reid, 1980; Saraf and Melhem, 2005; Webber et al., 2010)). Pool shape and spreading depend on surface types, pouring conditions, and obstacles (Brambilla and Manca, 2008). Once the LNG pool is formed, the rate at which vapour is produced is related mainly to the LNG spilled area and the rate of heat transfer to the liquid. The pool area is highly dependent on the local terrain over which the spill takes place (Brambilla and Manca, 2008). The presence of obstructions such as dyke or bund walls, the roughness of the ground can have a significant effect on pool area and shape (Brambilla and Manca, 2008; Webber et al., 2010). The vaporisation rate depends on the thermal conductivity of the ground, heat transferred from the air, and take-up rates by the air flow over the pool (Webber et al., 2010). As LNG vapour dispersion behaviour depends on source terms, all parameters associated with an LNG release scenario need to be carefully considered in the dispersion modelling (Webber et al., 2010). 


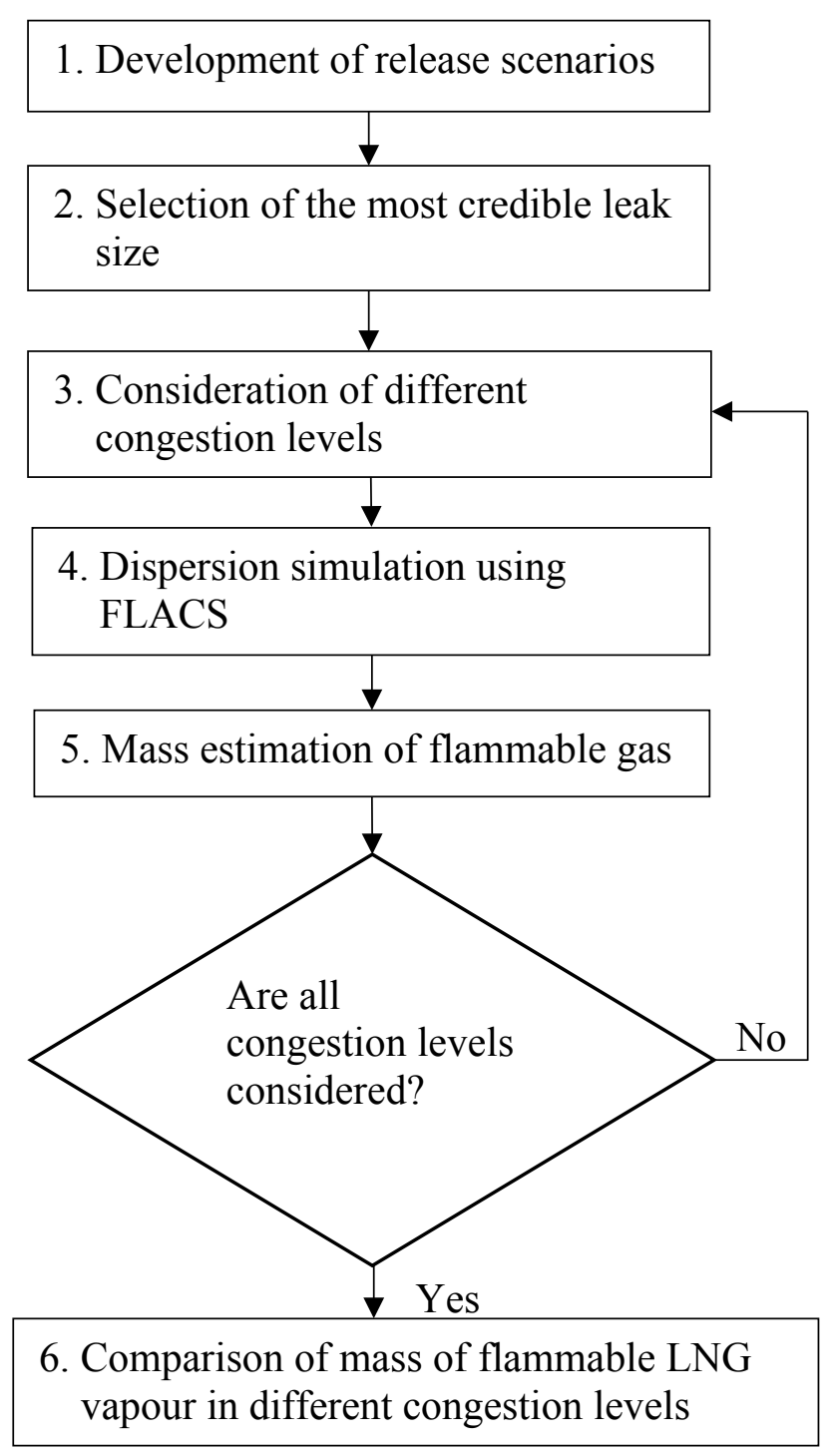

Fig. 1. Procedure for modelling LNG dispersion using CFD code

In step 2, probable LNG release scenarios are identified according to hazard identification and estimation. The past accident analyses (Khan, 2001; Khan and Abbasi, 1999; Reddy and Yarrakula, 2016) reveal that most of the catastrophic accidents occurred due to ignorance (the accident was unforeseen) and inadequate control arrangements. Thus, it is essential to adequately assess any potential threats/hazards in all areas of a facility foreseeing accident scenario to ensure effectiveness of control measures or emergency plans. The credibility of occurrence facilitates the identification of worse case scenarios and application of effective countermeasures. In a complex processing facility, there can be hundreds of potential release or leak scenarios, hence randomly selecting a few scenarios for modelling is neither appropriate nor reasonable. This makes the credibility estimation an efficient method 
to identify the most credible scenarios. A credible scenario is one with high probability of occurrence and high damage potential. The damage potential of each scenario is calculated based on hazard identification and assessment. For hazard identification and assessment during release of LNG, several approaches are used, i.e. worst case approaches, maximum credible event approaches and risk assessment approaches (Pitblado et al., 2006). Pitblado et al. (2005) have identified several maximum credible events including;

a. Maximum credible puncture hole $=0.25 \mathrm{~m}$,

b. Maximum credible hole from accidental operation events $=0.75 \mathrm{~m}$,

c. Maximum credible hole from terrorist events $=1.5 \mathrm{~m}\left(1.7 \mathrm{~m}^{2}\right)$,

d. Maximum credible operational spillage events $(10$ minutes $)=7,000 \mathrm{~m} 3 / \mathrm{hr}$, and

e. Maximum credible sabotage event $(60$ minutes $)=10,000 \mathrm{~m}^{3} / \mathrm{hr}$.

In step 3, various parameters that directly affect dispersion simulation are identified and defined. In semi-confined areas, gas dispersion depends on several factors such as wind speed and its direction, equipment congestion, mass flow rate and atmospheric conditions. In several literatures (Cormier et al., 2009; Kim, 2013; Tauseef et al., 2011), the impact of wind speed and its direction, mass flow rate and atmospheric conditions are commonly included. However, the impact of congestion level on dispersion of fugitive gases has not received much attention. Equipment arrangement or congestion is important in any processing facility that handles flammable or combustible materials. Tightly packed equipment increases equipment confinement and congestion and affects operations, maintenance, and emergency responses (Baalisampang et al., 2016). In such congested areas, an ignition source would be likely, as opposed to remote areas (Hightower et al., 2004). The consequences associated with the incidental loss of containment are expected to be less severe in less congested layouts than those with higher level of congestion. For instance, larger spaces between equipment reduce the fire impact on surroundings by decreasing exposure level and the thermal radiation intensity. For explosions, larger gaps between equipment reduce the congestion density which enhances the blast decay. These larger gaps decrease the magnitude of the blast waves and the potential effects on equipment, buildings and their occupants. In the case of toxic release, greater distances help reduce the impact on personnel by increasing diffusion and dilution of the toxic gas or vapour (Klein and Vaughen, 2017). Degree of equipment congestion is often defined based on Area Blockage Ratio (ABR) and Volume Blockage Ratio (VBR) (Woodward, 2010). $\mathrm{ABR}$ is defined as the area blocked by obstacles in relation to the total cross-sectional area, and the pitch, which is the distance between successive obstacles or obstacle rows. VBR is defined 
as the ratio of the volume occupied by congestion elements such as pipes, beams and plates to the volume of the portion of the plant under consideration. Kinsella (1993) defined congestion as the fractional area in the path of the flame front occupied by equipment, piping, fittings and other structures such as buildings and supporting columns. If congestion is more than the threshold of 30\%, it is considered 'high' for an offshore oil and gas facility (Raman and Grillo, 2005). Baker et al. (1994) have suggested the following definitions of degree of congestion:

- Low congestion: $\mathrm{ABR}<10 \%$, obstacles widely spaced, $<3$ layers of obstacles

- High congestion: ABR $>40 \%$, obstacles fairly closely spaced, $\geq 3$ layers of obstacles

- Medium congestion: Between low and high

In step 4, CFD simulation of the most credible leakage and dispersion scenario is performed considering plausible environmental conditions. The CFD model helps to determine the dispersion of the LNG vapour cloud in response to wind-vapour interaction, including heat transfer from the air and ground to the vapour cloud. This can inherently account for the effects of complex geometries, layouts and equipment, and also can assess the effect of vapour barriers on cloud dispersion (Gavelli et al., 2010). For CFD simulation in the current study, FLACS software is used. FLACS has been the leading tool for explosion consequence prediction in petrochemical installations for more than a decade and it is approved for LNG Vapour Dispersion Modelling under US Federal Regulations (49 CFR 193.2059) (Vinnem, 2014). Using a finite volume method, FLACS solves the conservations of mass, momentum, enthalpy, and mass fraction of species, closed by the ideal gas law represented by the general Equation 1 (GexCon AS, 2013).

$\frac{\partial}{\partial t}(\rho \emptyset)+\frac{\partial}{\partial x_{j}}\left(\rho u_{i} \emptyset\right)-\frac{\partial}{\partial x_{j}}\left(\rho \Gamma_{\varnothing} \frac{\partial}{\partial x_{j}}(\varnothing)\right)=S_{\varnothing}$

Where $t, \rho, u$ and $\varnothing$ represent time, density, velocity and general variable. FLACS has been extensively validated against different dispersion experiments including Coyote series $(3,5$ and 6), Burro tests (3, 7, 8 and 9), Falcon Tests (1, 3 and 4), Maplin Sand Test series (27 and 34) and Thorney Island Tests (45 and 47) (Hansen et al., 2009).

In step 5, flammable vapour footprint is estimated using a concentration range of 2.5$15 \%$. Estimation of flammable mass of dispersed vapour is needed to estimate fire and explosion hazards. In order to cause fire and or explosion, the concentration of LNG vapour should be within the flammability range (5 - 15\%) (Safitri et al., 2011). However, for computing safety distance, the U.S. Federal Government regulation 49-CFR-193 (Flammable vapour-gas dispersion protection) recommended using 50\% of LFL. This recommendation has 
been done to account for two potential effects during vapour dispersion (Zinn, 2005). Firstly, wind may break away pockets of flammable vapour from the continuous cloud and they may be carried beyond the continuous cloud. Secondly, there is the potential expansion of the area of combustion attributed to expanding gases and the high energy release overdriving the flammability limit. Thus, a conservative estimate of the downwind flammable distance is considered by assuming that the vapour pocket will dissipate when the cloud concentration is below half the LFL. Due to these assumptions the resulting cloud coverage length should be considered worst-case possibility (Zinn, 2005).

In the final step, flammable mass or volume of LNG vapour is estimated against different congestion levels and dispersion characteristics of fugitive LNG being assessed. Identification of a hazardous region in a facility would help to better understand the requirement of leak detection design and monitoring and control measures. It also would help to identify potentially safer areas during fugitive leaks at given atmospheric conditions.

\section{Application of the modelling procedure (A case study)}

The case study and analysis presented in this paper represents a generic solution method for simulation of vapour dispersion from an LNG spill in a facility with various degrees of equipment congestion. The proposed methodology is applied to a generic layout of a processing facility as shown in Fig. 2. The model is $160 \mathrm{~m}$ long, $60 \mathrm{~m}$ wide and $40 \mathrm{~m}$ high. Responses to leak, vaporisation and dispersion depend on several operating parameters. For illustration purposes, only a specific case was presented considering prevalent conditions.

\subsection{Development of release scenarios}

In an FLNG processing facility, LNG is present in liquefaction module, storage tanks, offloading system and their connecting pipes. As the main objective of this study is to assess the dispersion phenomenon of fugitive leakage of LNG, a typical small leakage under operational conditions is considered. In chemical processes, fugitive emissions result from equipment leaks, solvent transfers, filter changes, and spills (Keoleian et al., 1997). 


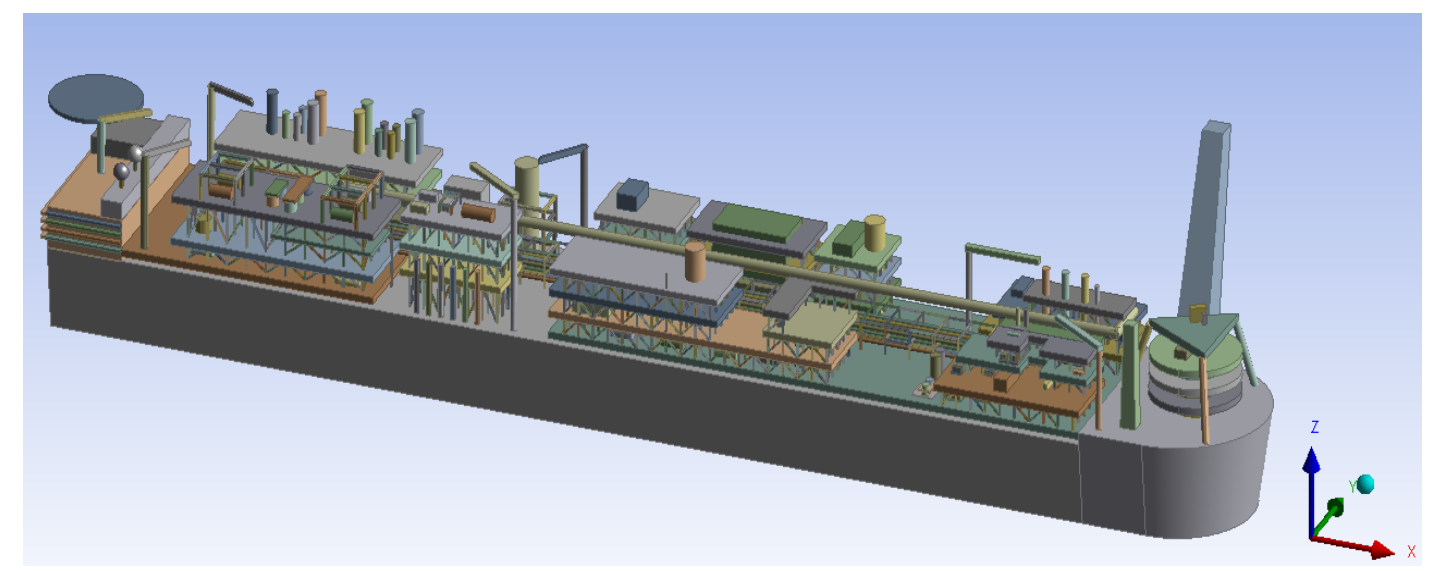

Fig. 2. A typical FLNG processing facility

For dispersion modelling, the most congested module is considered as shown in Fig. 3 with the dimensions of $60 \mathrm{~m} \times 45 \mathrm{~m} \times 5 \mathrm{~m}$. This layout is the lowest deck of a module which includes a greater amount of processing equipment than other modules. To assess impact of equipment congestion during LNG dispersion, three different layouts of equipment are considered as illustrated in Fig. 3. In this study, the equipment layout of the three congestions are derived considering a strategy to reduce vapour turbulence. LNG vapour dispersion depends on source terms (examples: leak rate, pool area and evaporation rate) (Webber et al., 2010). The detailed study of source terms is beyond the purpose of the study. However, in this study source terms are incorporated with a careful consideration of the recommendations given in FLACS user's manual (GexCon AS, 2013). 


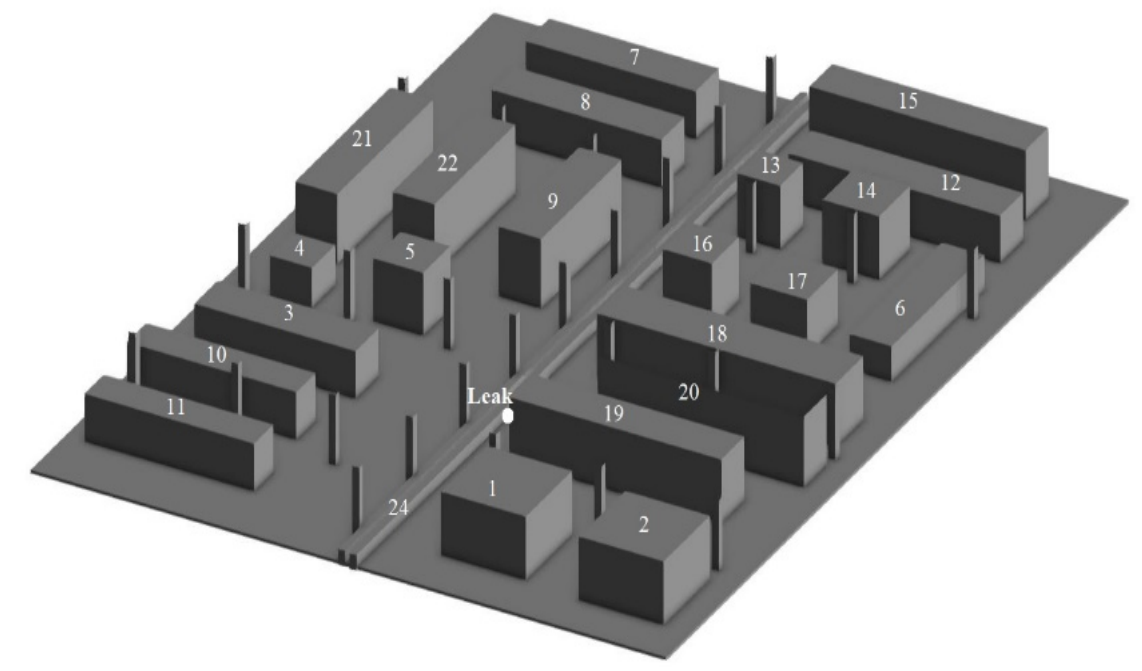

(a)

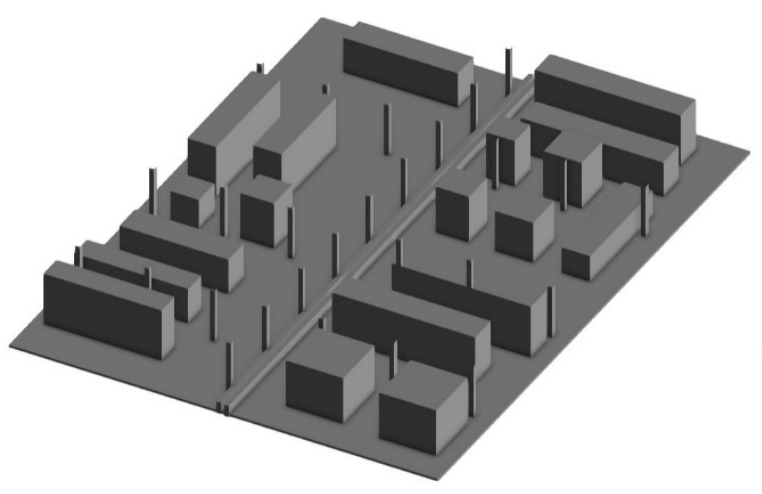

(b)

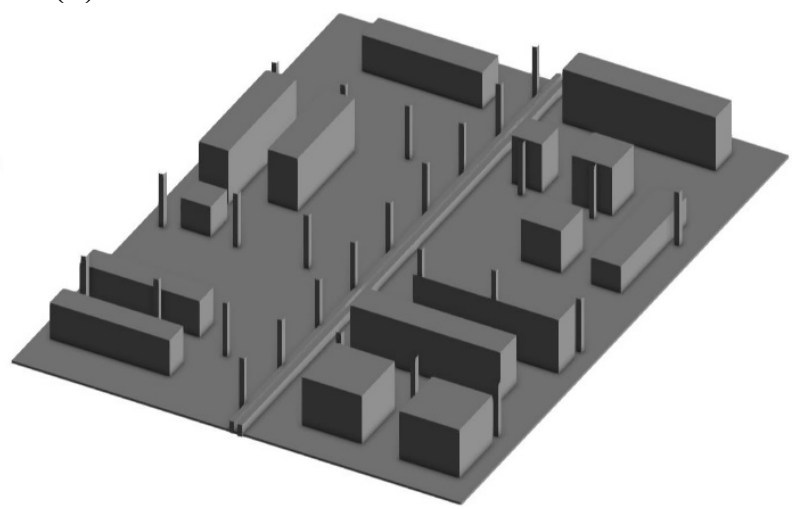

(c)

Fig. 3. Equipment layout in the three congestions based on VBR; (a) $22 \%$, (b) $18 \%$ and (c) $14 \%$.

\subsection{Selection of credible leak size}

In a complex processing facility, there can be several potential LNG release scenarios (Baalisampang et al., 2017a). Generally, in such large facilities, non-hazardous areas are ignored or not given due attention for risk assessment and mitigation because few or no accidents have been reported in such areas. In such situations, even a small leak may lead to a catastrophic accident. There is no universal consensus regarding the credible fugitive leak size. The maximum credible event (leak size/hole) proposed/identified by Pitblado et al. (2005) contradicts Woodward and Pitblado (2010) which stated that smaller leak size of 10-25 mm are highly likely to occur in an LNG plant lifetime. However, it has been found that 2 inch $(50.8 \mathrm{~mm})$ leak size is adopted as the maximum permissible leak in oil and gas industry in determining maximum credible events for Facility Siting Studies (Fitzgerald, 2016). This study 
aims to assess dispersion behaviour of LNG using permissible leak size to investigate potential hazards for fire and explosion. In this study, LNG leak from a puncture hole of $25 \mathrm{~mm}$ is considered as the maximum credible size which is $50 \%$ less than the maximum permissible leak. Additionally, after release, LNG shows different phenomena of vaporisation and dispersion than that of natural gas due to rapid phase change and volume. This signifies the need to study small leakage of LNG.

\subsection{Degree of congestion level}

Degree of equipment congestion is a pivotal part of safety management (Baalisampang et al., 2016). The volumetric congestions calculated in the three layouts are presented in Table 3. The first column shows the equipment number according to Fig. 3 (a). Equipment congestion along the flow front of the vapour is used to determine its effect on dispersion. Columns 2, 3 and 4 represent VBR in cases 1,2 and 3 respectively. To compare the potential impact of small emission of LNG in different levels of equipment congestion and confinement, three levels of equipment congestion are considered: $22 \%, 18 \%$ and $14 \%$. Dispersion characteristic of small leakage of LNG is assessed based on the mass or volume of combustible vapour in each layout.

\section{Table 3}

Calculation of equipment congestion in the three layouts.

\begin{tabular}{|c|c|c|c|}
\hline Equipment & Case $1\left(\mathrm{~m}^{3}\right)$ & Case $2\left(\mathrm{~m}^{3}\right)$ & Case 3 $\left(\mathrm{m}^{3}\right)$ \\
\hline 1 & 90 & 90 & 90 \\
\hline 2 & 90 & 90 & 90 \\
\hline 3 & 108 & 108 & - \\
\hline 4 & 21.20 & 21.20 & 21.20 \\
\hline 5 & 38.47 & 38.47 & - \\
\hline 6 & 108 & 108 & 108 \\
\hline 7 & 90 & 90 & 90 \\
\hline 8 & 90 & - & - \\
\hline 9 & 108 & - & - \\
\hline 10 & 108 & 108 & 108 \\
\hline 11 & 135 & 135 & 135 \\
\hline 12 & 135 & 135 & 28.26 \\
\hline 13 & 28.26 & 28.26 & 50.24 \\
\hline 14 & 50.24 & 50.24 & 126 \\
\hline 15 & 126 & 126 & - \\
\hline 16 & 28.26 & 28.26 & 43.96 \\
\hline 17 & 43.96 & 43.96 & 180 \\
\hline 18 & 240 & - & \\
\hline 19 & 180 & 180 & \\
\hline
\end{tabular}




\begin{tabular}{|c|c|c|c|}
\hline 20 & 192 & 192 & 192 \\
\hline 21 & 144 & 144 & 144 \\
\hline 22 & 144 & 144 & 144 \\
\hline 23 & 23.84 & 23.84 & 23.84 \\
\hline 24 & 30 & 30 & 30 \\
\hline Total volume & 2352.22 & 1914.22 & 1514.50 \\
\hline $\begin{array}{c}\text { Congestion levels } \\
\text { based on VBR }\end{array}$ & $22 \%$ & $18 \%$ & $14 \%$ \\
\hline
\end{tabular}

\subsection{Dispersion simulation using FLACS}

Dispersion of LNG vapour is greatly influenced by local atmospheric conditions, wind speed, atmospheric stability, and ground roughness. For an accurate dispersion simulation using CFD code, a precise representation of boundary conditions, initial conditions and atmospheric parameters are important. It is assumed that the gas cloud releases instantaneously and disperses under ambient atmospheric conditions considering the presence of the obstacles. Defining boundary conditions is a key player in an accurate CFD simulation (Srebric et al., 2008). According to Luketa-Hanlin et al. (2007), seven boundary conditions are required for an LNG simulation: inlet, outlet, top, two sides, bottom, and LNG pool. In all three layouts, the same boundary and initial conditions are used. The lower boundary in x-axis, the upper boundary in y-axis and upper boundary in z-axis are assigned as wind (inflow or parallel boundaries). The appropriate wind speed for flammable cloud dispersion is usually close to 2 to $4 \mathrm{~m} / \mathrm{s}$ (Woodward, 2010). Thus, wind speed is considered as $3 \mathrm{~m} / \mathrm{s}$ diagonally in the direction of $225^{\circ}$ to allow for maximum interaction of the dispersed gas with equipment. The reference height of the wind is considered as $2 \mathrm{~m}$. In these boundaries, relative turbulence intensity and turbulence length scale are assigned as 0.1 and $0.014 \mathrm{~m}$ respectively, based on recommendation given in FLACS user manual (GexCon AS, 2013). The remaining boundaries, except the bottom boundary, are considered as nozzle at the outflow). The outlet boundaries are kept sufficiently far from the potential natural gas cloud build up location to avoid their effects on dispersion phenomena. Initial conditions assigned for the simulation are provided in Table 4. To reduce uncertainty in this study, value of sensitive parameters such as wind speed, atmospheric stability and release rate have been chosen according to past studies (Cormier et al., 2009; Rao, 2005; Siuta et al., 2013; Yegnan et al., 2002). 


\section{Table 4}

Initial conditions used for the current study

\begin{tabular}{|l|l|}
\hline Parameters & Values \\
\hline Characteristic velocity & $3 \mathrm{~m} / \mathrm{s}$ \\
\hline Relative turbulence intensity & 0.1 \\
\hline Turbulence length scale & $0.014 \mathrm{~m}$ \\
\hline Temperature & $20^{\circ} \mathrm{C}$ \\
\hline Ambient pressure & $100 \mathrm{kPa}$ \\
\hline Ground roughness & $0.01 \mathrm{~m}$ \\
\hline Reference height & $2 \mathrm{~m}$ \\
\hline Pascal class & $\mathrm{F}$ \\
\hline
\end{tabular}

It is assumed that the LNG vapour consists of $92 \%$ methane, $7 \%$ ethane and $1 \%$ propane (GexCon AS, 2013). Release scenario depends on various parameters, i.e. leakage velocity, leaked size and type of surface. The leakage parameters are given in Table 5. It is assumed that a leak commences after $10 \mathrm{~s}$ so that the wind field can reach steady state before the occurrence of the leakage. A constant mass flow rate of $3 \mathrm{~kg} / \mathrm{s}$ is considered with an effective leak diameter of $0.025 \mathrm{~m}$ based on small leak characteristic (Lee et al., 2015; Woodward and Pitblado, 2010). In each simulation, the maximum simulation time is considered as $120 \mathrm{~s}$ and the leak stops at $80 \mathrm{~s}$. The release duration and the simulation time has been selected considering Emergency Shutdown (ESD) response time and response time of gas detectors. This duration is confirmed by offshore personnel. These values are also similar to those reported in the literature (Murvay and Silea, 2012; Zhang, 1997). According to Napier and Roopchand (1986), release duration from dock manifold area (nozzle/line discharge rate) failure is 1.5 minutes. Based on this, the release duration has been chosen. The focus of the case study was to primarily demonstrate the various steps of the release and dispersion modelling approach. However, this duration can be changed to any field scenario.

Table 5

Leak parameters

\begin{tabular}{|l|l|}
\hline Leak type & Jet \\
\hline Leak position & $(25.57,16,1)$ \\
\hline Leak direction & $-\mathrm{X}$ \\
\hline Start time & $0 \mathrm{~s}$ \\
\hline Duration & $80 \mathrm{~s}$ \\
\hline
\end{tabular}




\begin{tabular}{|c|l|}
\hline Outlet & \\
a. Area & $0.005 \mathrm{~m}^{2}$ \\
b. Mass flow rate & $3 \mathrm{~kg} / \mathrm{s}$ \\
c. Relative turbulence intensity & 0.02 (Low) \\
d. Turbulence length scale & $0.025 \mathrm{~m}$ \\
e. Temperature & $-162^{\circ} \mathrm{C}$ \\
f. Surface & Steel plate with thickness of $0.01905 \mathrm{~m}$ \\
\hline
\end{tabular}

The simulation volume is considered as $47 \mathrm{~m} \times 62 \mathrm{~m} \times 5 \mathrm{~m}$ with maximum grid size of $1 \mathrm{~m}$ in all directions. Around the leak location, the grid resolution is adjusted to $0.01 \mathrm{~m} \mathrm{in} \mathrm{x}, \mathrm{y}$ and $\mathrm{z}$ directions while at the locations far from this area, grids were stretched. The total number of control volumes during the dispersion simulation is 319,200 . Setting up the required parameters, the FLACS solver (dispersion and ventilation module) was used to run the simulation. To make the simulation results grid independent, sensitivity analysis was conducted by comparing gas concentrations at a monitoring point using the technique advised by GexCon AS (2013).

\subsection{Estimating mass of flammable LNG vapour}

The total mass of the released LNG is $240 \mathrm{~kg}$ which is the same in all simulations. However, this value does not represent the actual mass of flammable vapour as an entire mass of released LNG is not within the flammable range. All released mass of LNG does not remain in flammable concentration. The fraction of the released mass within the flammable range is estimated using a utility program of FLACS post processing result. The maximum vapours with $2.5-15 \%$ concentration obtained in the three simulations at $2.3 \mathrm{~m}$ above the ground are illustrated in Figs. 4-6. Under the given conditions, volume and mass of flammable vapour dispersed (available) in the three layouts are estimated using post processing results of simulation as shown in Table 6. The flammable mass is the mass of the fuel when the ratio ((fuel mass)/(fuel and air mass)) is within the flammable range (2.5-15\%). Thus, the flammable volume consists of the mixture of fuel and air. The likelihood of vapour ignition outside the given range at the given time is considered negligible.

Table 6

Mass and volume of flammable vapour in the three layouts

\begin{tabular}{|l|l|l|l|}
\hline Congestion levels & $\begin{array}{l}\text { Case 1 } \\
(22 \%)\end{array}$ & $\begin{array}{l}\text { Case 2 } \\
(18 \%)\end{array}$ & $\begin{array}{l}\text { Case 3 } \\
(14 \%)\end{array}$ \\
\hline Maximum flammable mass of vapour $(\mathrm{kg})$ & 9.53 & 3.52 & 2.05 \\
\hline Maximum flammable volume of vapour $\left(\mathrm{m}^{3}\right)$ & 218 & 84 & 45 \\
\hline
\end{tabular}




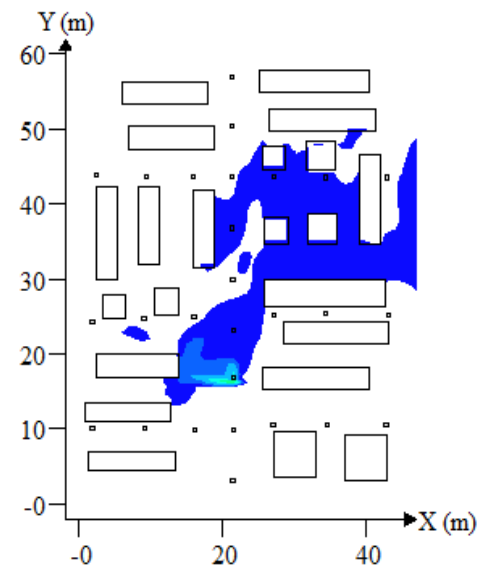

(a)

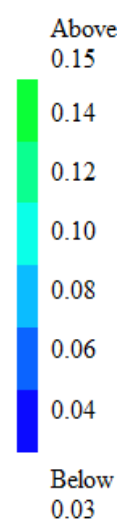

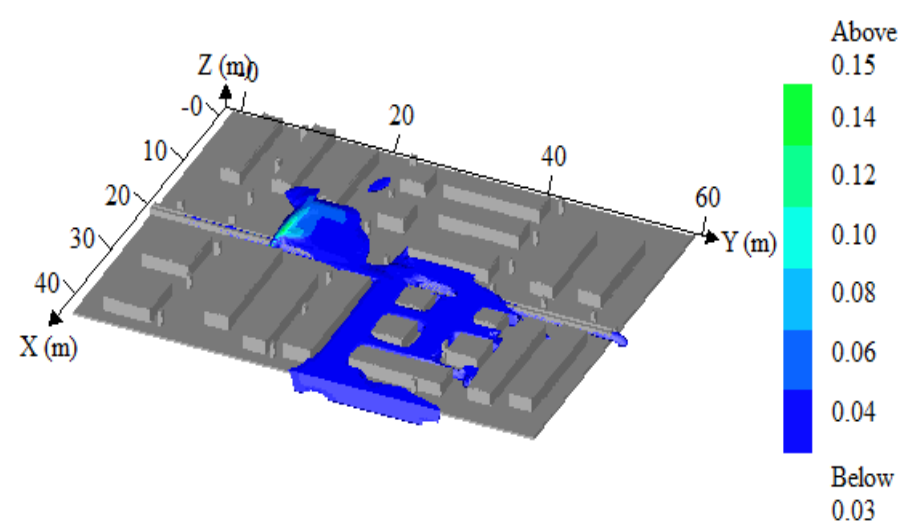

(b)

Fig. 4. Footprints of flammable vapour $\left(\mathrm{m}^{3} / \mathrm{m}^{3}\right)$ at $2.3 \mathrm{~m}$ above the ground in Case 1 (a) $2 \mathrm{D}$ and (b) 3D at $90 \mathrm{~s}$. The concentration range is selected to assess the presence of the flammable vapour in the layout.

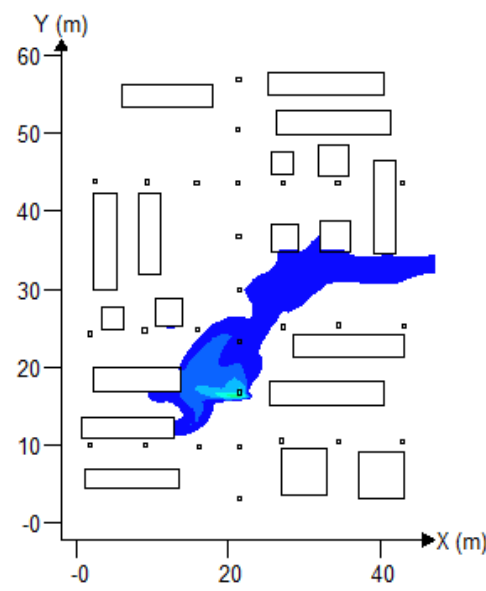

(b)

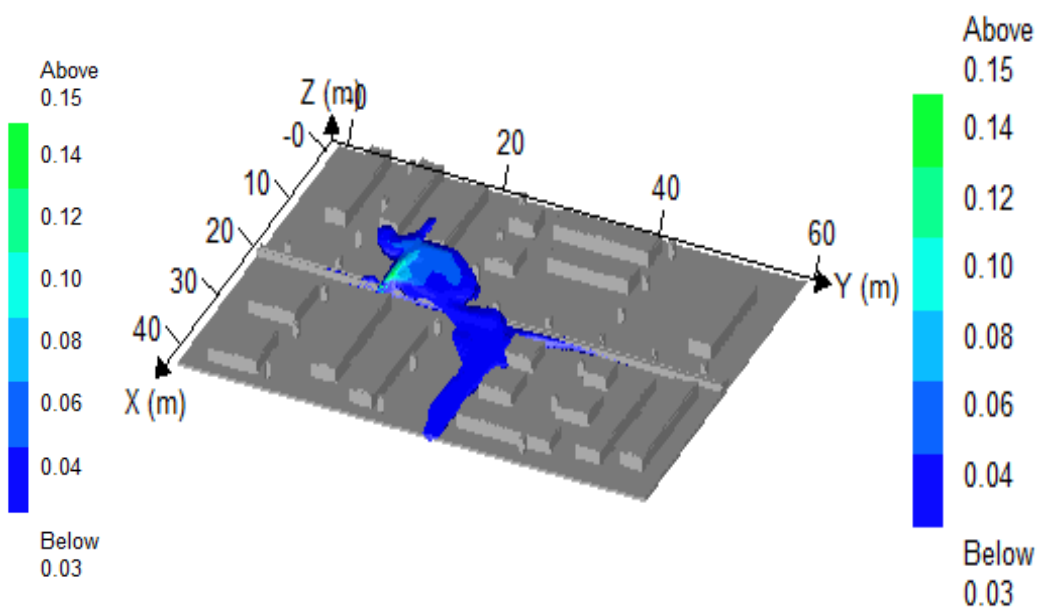

(b)

Fig. 5. Footprints of flammable vapour $\left(\mathrm{m}^{3} / \mathrm{m}^{3}\right)$ at $2.3 \mathrm{~m}$ above the ground in Case 2 (a) $2 \mathrm{D}$ and (b) 3D at $90 \mathrm{~s}$. The concentration range is selected to assess the presence of the flammable vapour in the layout. 


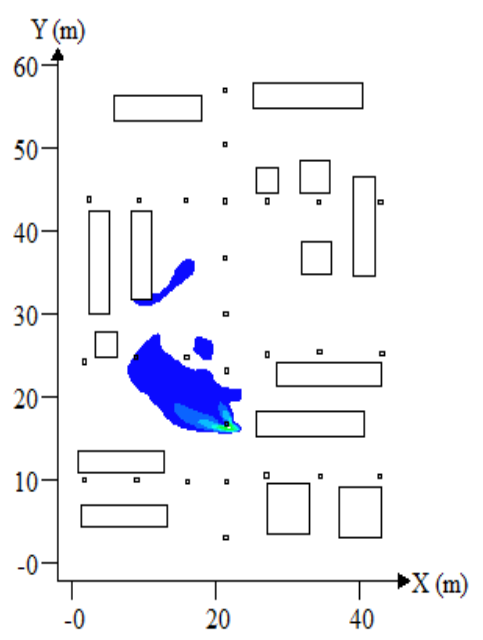

(a)

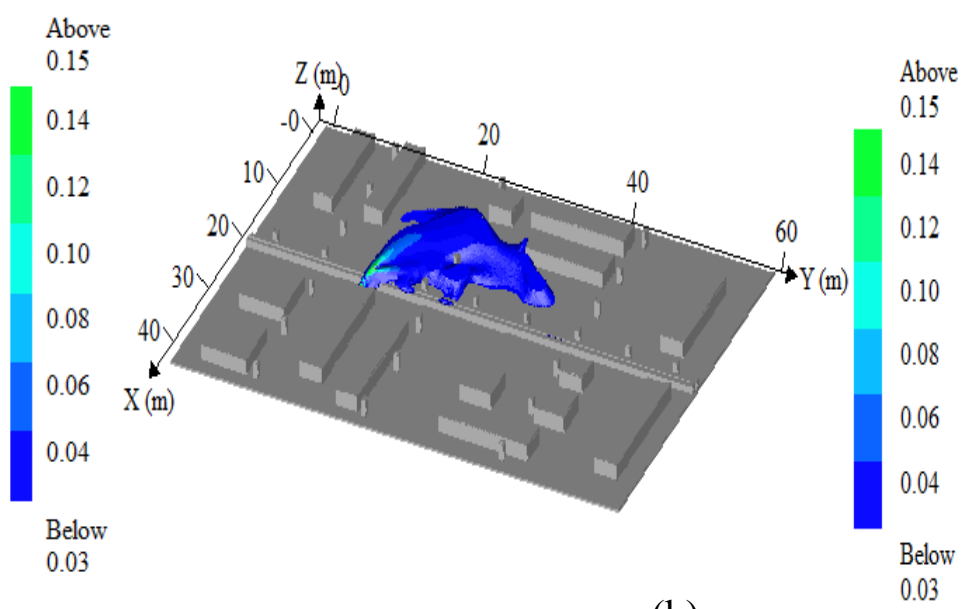

(b)

Fig. 6. Footprints of flammable vapour $\left(\mathrm{m}^{3} / \mathrm{m}^{3}\right)$ at $2.3 \mathrm{~m}$ above the ground in Case 3 (a) $2 \mathrm{D}$ and (b) $3 \mathrm{D}$ at $90 \mathrm{~s}$. The concentration range is selected to assess the presence of the flammable vapour in the layout.

\section{Results and discussion}

The most important parameter for dispersion is the footprint of flammable vapour in the air within the layout. To be ignited, the fuel vapour formed through the dispersion should be in the flammable range. The vapour mixture has an LFL of 0.05 and an Upper Flammability Limit (UFL) of 0.15 . Considering the safety margin, advised by the US Federal Regulation 49 CFR Part 193.2059 (US Goverment Publishing Office (GPO), 1980), the LFL is defined as 0.025. The effect of congestion level on the formation of flammable vapour was analysed by monitoring the dispersion characteristics. In each case, the areas outside the boundary of the vapour are non-hazardous at that time because in those areas LNG vapour is not in the flammable range. In this study, the potential fire and/or explosion hazard of small LNG leak is assessed considering both time dependent concentration analysis and area-based model which focused on the maximum damage area because a flammable cloud takes some time to develop before reaching its maximum value and the ignition can occur anytime and anywhere after the release. Hence, a given leak can lead to several explosion or fire scenarios depending on the cloud size at the time of the delayed ignition. Thus, this study considered interactions between congested regions and drifting clouds or gas cloud built-up from pool evaporation. A concentration plot at any given location as a function of time is helpful to determine the need of safety measures such as forced ventilation or vapour barrier and to analyse subsequent fire and/or explosion hazards. 


\subsection{Case 1}

The first level of congestion considered in the current study is $22 \%$. The LNG vapour tends to slump in the congested layout due to low air movement, after vaporisation of LNG as demonstrated in Fig. 7. The exact location of the leak is marked with red circle in Fig. 7 (ii), which is same in Figs. 8-9. The maximum flammable mass and volume are $9.53 \mathrm{~kg}$ and 218 $\mathrm{m}^{3}$, respectively at $40 \mathrm{~s}$. The presence of an obstacle in the centre of the flow path diverted the flow front and pockets of vapour accumulated around equipment. In addition to this, the presence of obstacles in the flow path diverted the flow and vapour was distributed in the spaces between obstacles. This allowed the vapour to remain in the layout for a longer time which increased the cloud size. The LNG vapour dispersed according to wind direction and entrained around obstacles leading to formation of pockets of vapour concentration in isolated locations. The leak stopped at $80 \mathrm{~s}$ and the hazardous vapour remained in the layout until $120 \mathrm{~s}$ as shown in Fig. 7. This increased the retention time and the likelihood of ignition of flammable hazard. This also points out how important it is to consider the appropriate flammable range in a safety design of such processing plants. One may only consider the regular value of $5 \%$ which shows a safer layout according to the dispersion results. However, in considering the LFL value recommended by the US Federal Regulation (US Goverment Publishing Office (GPO), 1980), it reveals that the layout is not safe after the release of LNG. If an ignition occurs within $110 \mathrm{~s}$, the vapour could be ignited with catastrophic consequences, i.e. flash fire in the case of immediate ignition or Vapour Cloud Explosion (VCE) in the case of delayed ignition. This implies that the $22 \%$ level of equipment congestion cannot be considered as a safe level. 


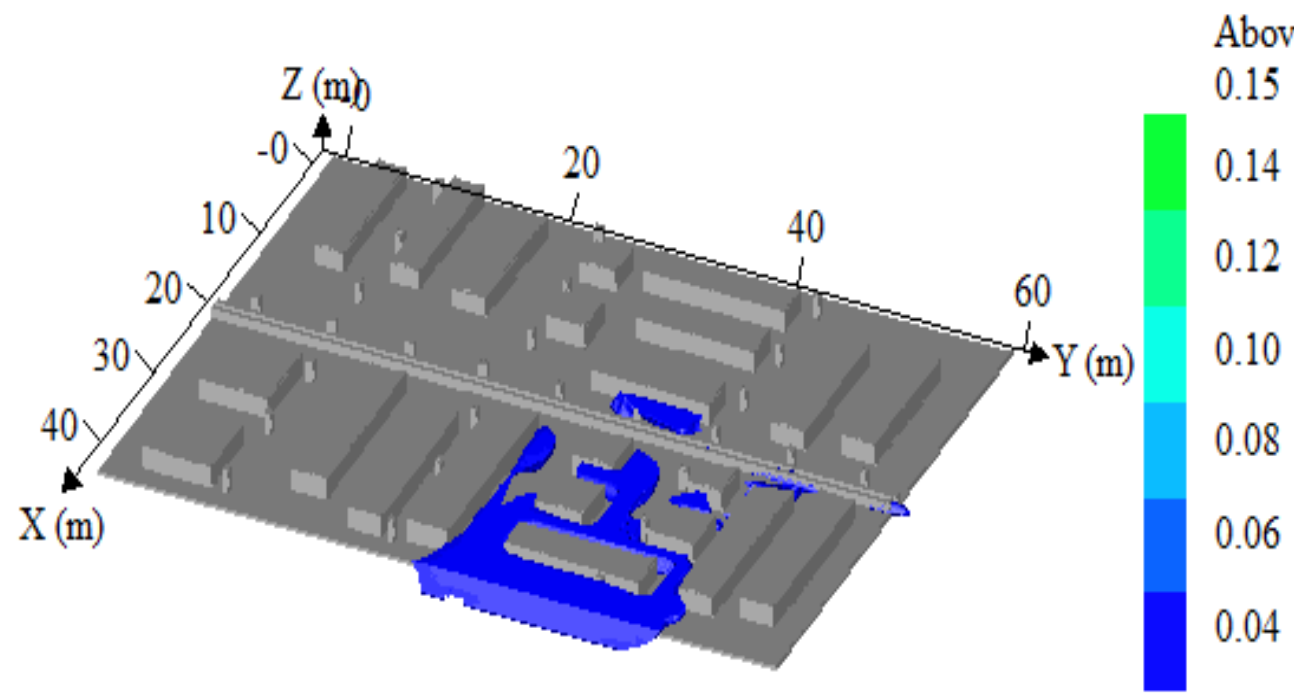

(i)

Below

0.03

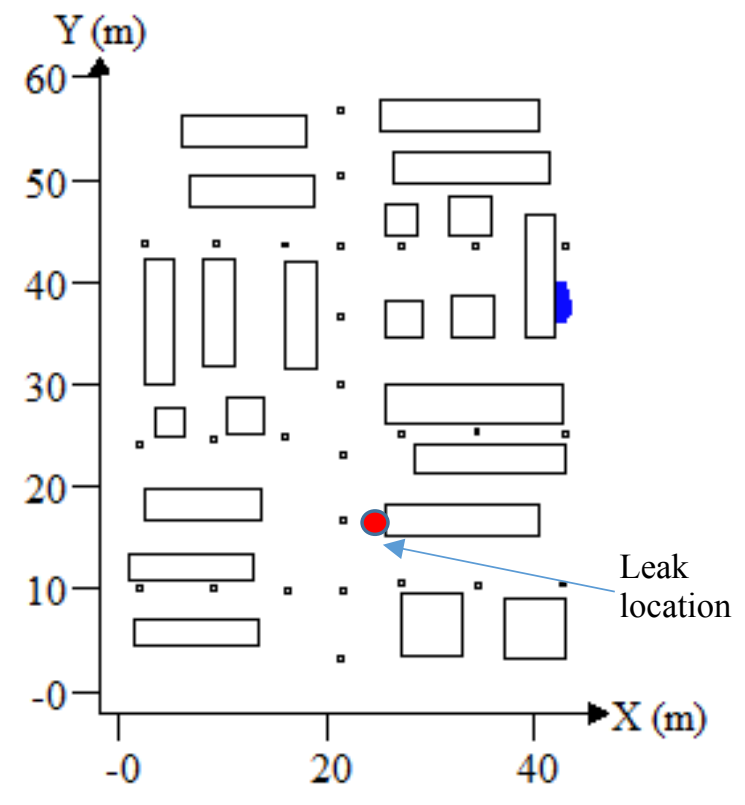

(ii)

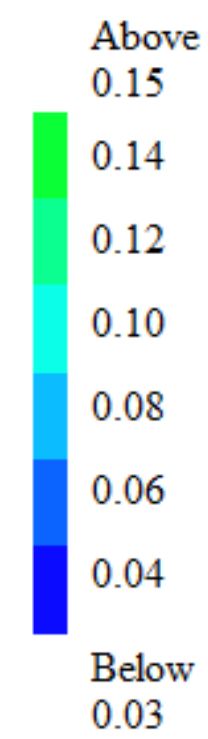

Fig. 7. Dispersion of LNG vapour in flammable volume concentration $\left(\mathrm{m}^{3} / \mathrm{m}^{3}\right)$ at $2.3 \mathrm{~m}$ above the ground in Case 1 at (i) $110 \mathrm{~s}$ and (ii) $120 \mathrm{~s}$. The concentration range is selected to assess the presence of the flammable vapour in the layout.

\subsection{Case 2}

In Case 2, the volumetric congestion is $18 \%$. The flow paths and vapour size at $100 \mathrm{~s}$ is shown in Fig. 8. The number of obstacles with larger influence in flow diversion in the middle of the flow was reduced. This reduced obstruction in the flow path of the cloud. As a result, the pockets of vapour were not formed, and the vapour path was simply diverted in two directions. The flammable vapour disappeared at $110 \mathrm{~s}$. Although the dispersion analysis shows 
an improvement in the safety level of the layout with $18 \%$ congestion, in this case the ignition of the vapour and flash fire is still a likely scenario.

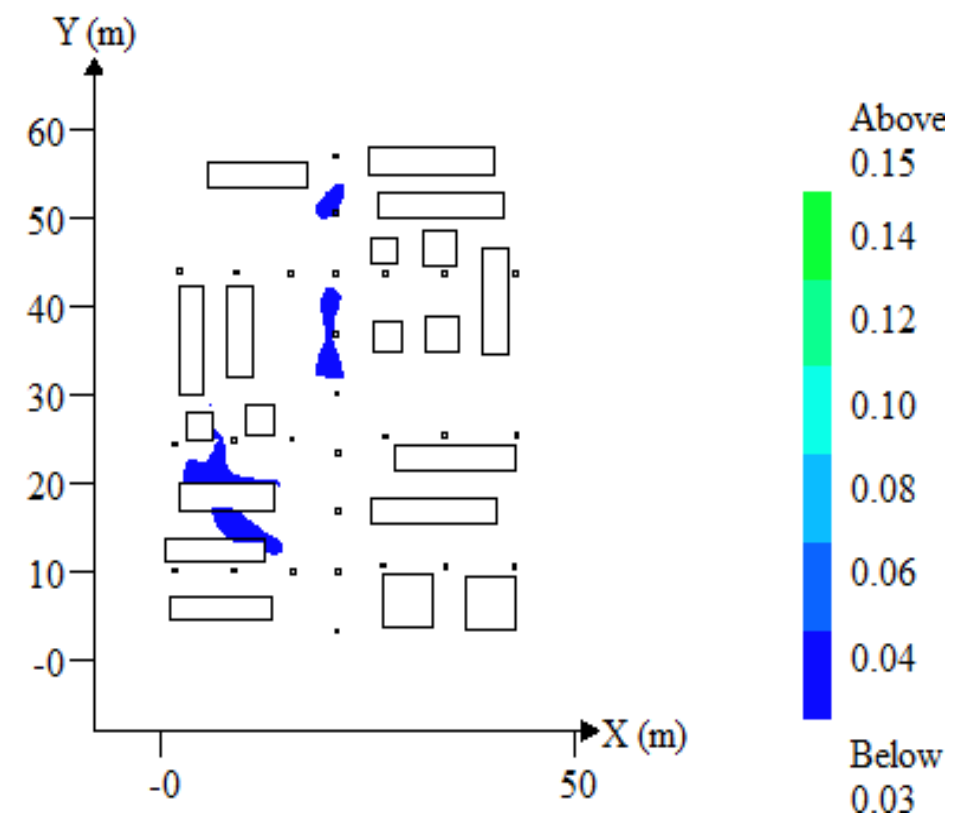

Fig. 8. Dispersion of LNG vapour in flammable volume concentration $\left(\mathrm{m}^{3} / \mathrm{m}^{3}\right)$ at $2.3 \mathrm{~m}$ above the ground in Case 2 at $100 \mathrm{~s}$. The concentration range is selected to assess the presence of the flammable vapour in the layout.

\subsection{Case 3}

In this layout, three more pieces of equipment were eliminated from the nearby flow front and $14 \%$ volumetric equipment congestion is obtained. The maximum vapour cloud footprint is observed at $78 \mathrm{~s}$. The absence of an obstacle immediate to the leakage area in the flow path resulted in undiverted flow of the vapour as demonstrated in Fig. 9. The decrease of congestion level facilitated the quick dispersion of vapour leading to the rapid dilution of flammable vapour with it disappearing at $100 \mathrm{~s}$. 

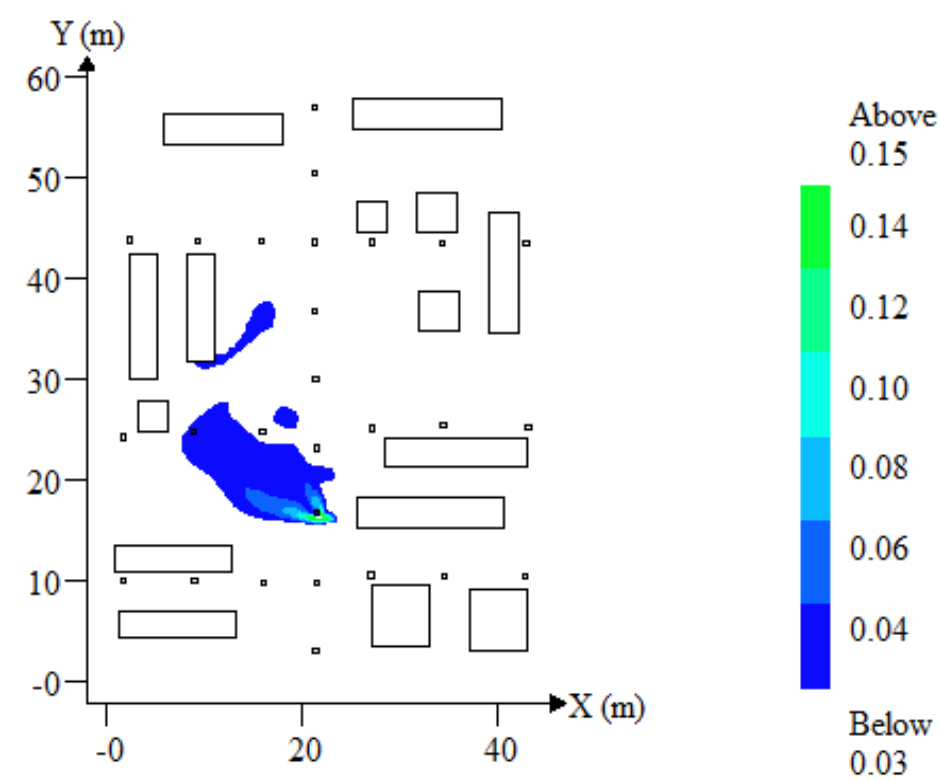

Fig. 9. Dispersion of LNG vapour in flammable volume concentration $\left(\mathrm{m}^{3} / \mathrm{m}^{3}\right)$ at $2.3 \mathrm{~m}$ above the ground in Case 3 at $90 \mathrm{~s}$. The concentration is selected to assess the presence of the flammable vapour in the layout.

The flammable mass of LNG vapour in three cases at different times is presented in Fig. 10. The flammable mass of LNG vapour is estimated using an inbuilt utility program of FLACS post processing result. The total mass of flammable material released as a function of time was calculated and determined the flammable mass in a vapor cloud by integrating across the concentration profiles between two concentration limits, the LFL and the UFL. It is found that under the same conditions, the dispersion characteristics influenced by obstacles have significant impact on the existence of flammable mass and volume in the given layout. There is no significant reduction in the mass and volume of flammable vapour after $10 \mathrm{~s}$ of the termination of the leak. In Case 1, flammable vapour remains in the layout until $40 \mathrm{~s}$ after the leak ceases and in Case 2, it remains $25 \mathrm{~s}$ after the termination of the leak. Similarly, in Case 3 , the flammable vapour disappeared after $18 \mathrm{~s}$ of the leak stopping. It is confirmed that the retention time of vapour drops with the decrease in congestion level and the formation of vapour pockets depends on obstacles in the flow path. The flammable concentration does not disappear promptly after stoppage of the leak; however, it gradually decreases within different time ranges which depend on the equipment congestion level. The isolated pockets of LNG vapour formation can remain undetected for certain time intervals. This suggests that in any typical congested or semi-confined areas, such accumulation may exist for a significant time even if the leak ceases. 


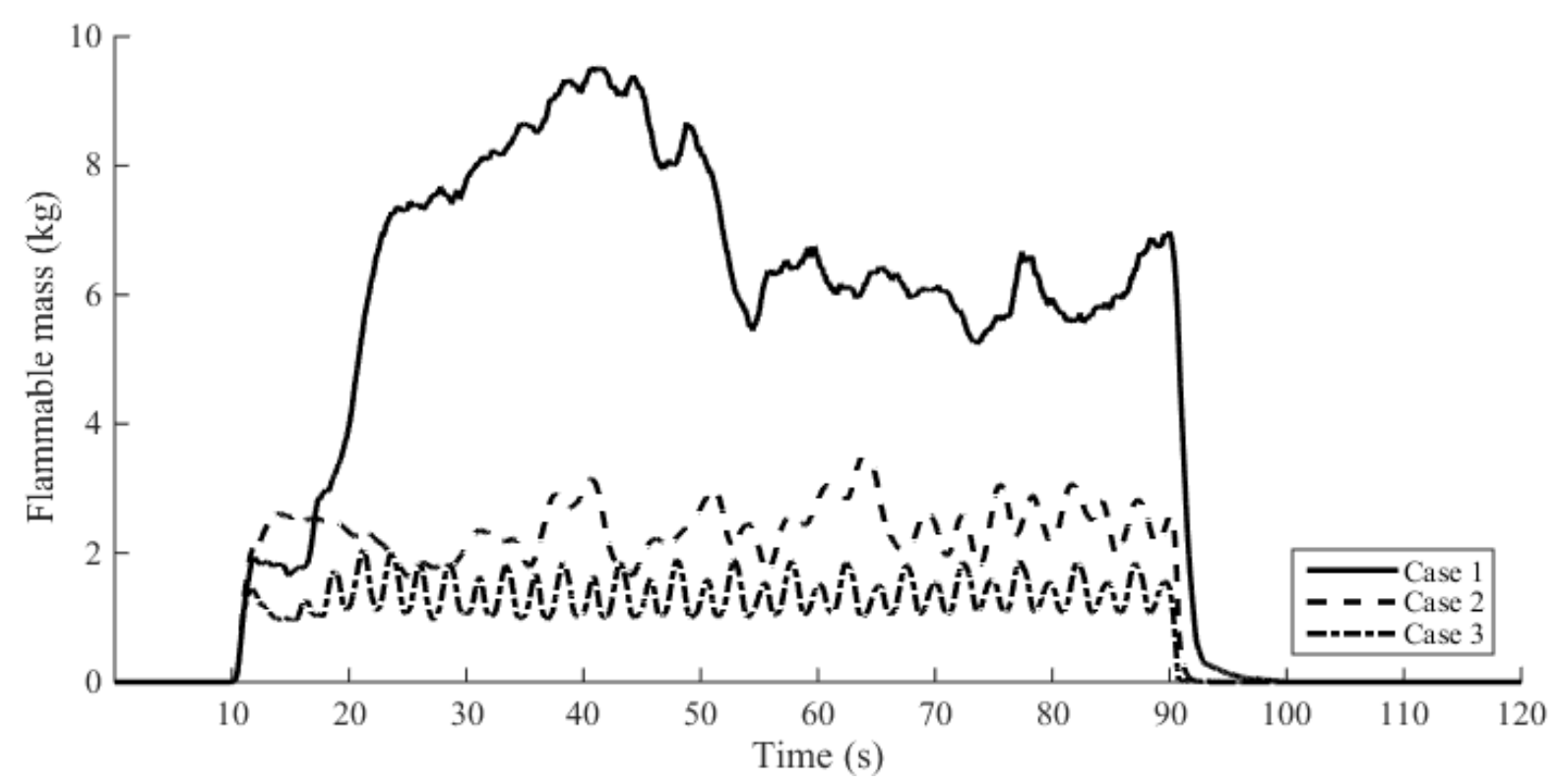

Fig. 10. The flammable mass of LNG vapour in three cases at different times.

Changing the congestion level, even by a small percentage and change of layout, can produce different vapour flow front and vapour cloud shape under the same environmental conditions. Furthermore, it is observed that mass and volume of flammable vapour in a layout depend on equipment congestion during the fugitive leakage of LNG. The presence of vapour at any instant of time decreases with reduction of congestion level as illustrated in Fig. 10. This is due to the combined effects of the increased effective contact area and heat transfer rate, and higher vapour dissipation rate than that of high congestion level (Webber et al., 2010). For illustration purposes, source terms such as a pool evaporation rate per area, pool area and pool mass for spreading pool on a steel plate are plotted and compared as given in Figs. 11-13. These illustrations show that equipment congestion can affect these parameters and subsequently the dispersion behaviour. However, under these considered scenarios, a clear correlation was not obtained due to the lack of uniform variations. As illustrated in Figs. 11-13, the time dependent plots in different congestion levels were not same under the same input parameters. Because of this, the effect of equipment congestion and layout on dispersion of LNG seems to be a key factor in assessing and modelling potential vapour dispersion hazards. This also signifies a need for vapour dispersion control strategies such as vapour barriers that can be employed to mitigate potential vapour dispersion hazards in the event of an LNG spill around the safety critical areas. 


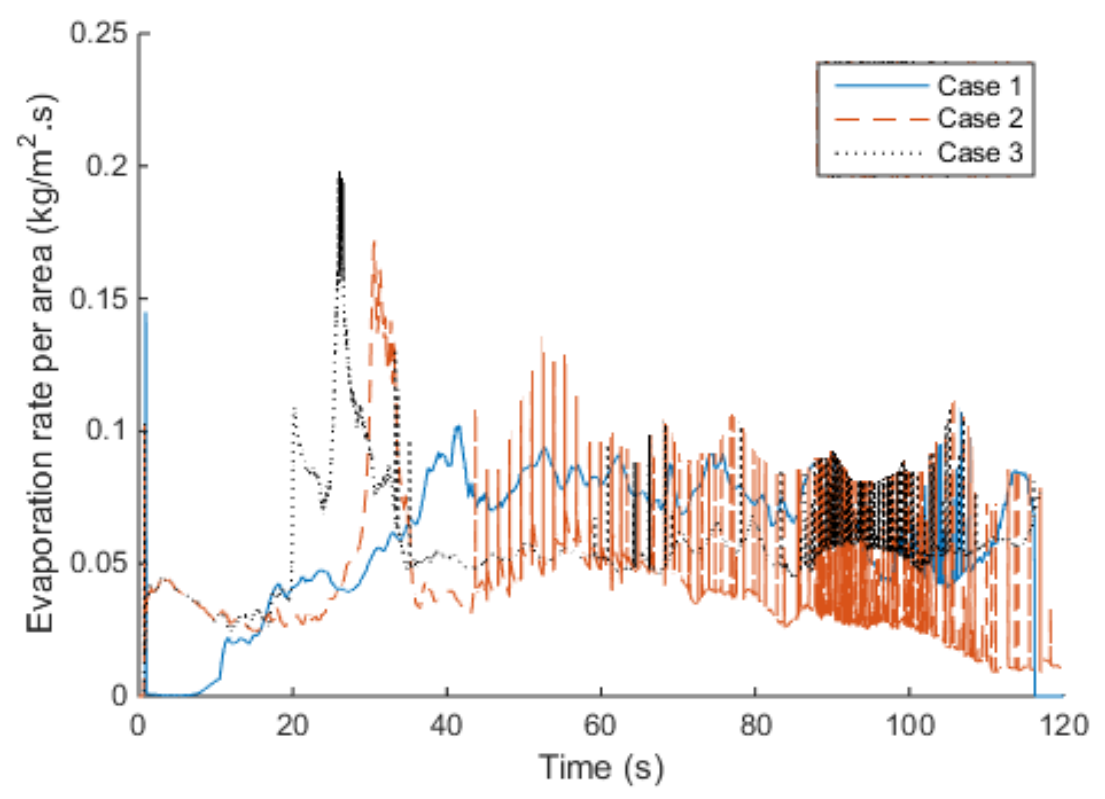

Fig. 11. A comparison of evaporation rate per area of the LNG pool in three cases.

Often fugitive gas dispersion is neglected assuming that a fugitive gas leak has no potential to cause major accidents and it is difficult to assess its direct impact (Hassim et al., 2012). It may have no impact, or its impact can be insignificant if the released gas does not ignite or ignites without propagating and transitioning to other events such as explosion event. However, there are many instances where fugitive leaks, dispersions and ignitions have caused catastrophic fire and explosion. It is agreed that heat radiation from the ignition of such a small quantity of gas may not cause direct asset damage, but, has the potential to trigger secondary or tertiary events thereby causing domino effects (chain of accidents) (Baalisampang et al., 2019). One example of small leak and major accident is the Skikda LNG accident which was initially caused by small leak which ignited and resulted in the first small explosion (Ouddai et al., 2012). This explosion breached the boiler and provided an ignition source to the external accumulation of combustible gas leading to the larger explosion. 


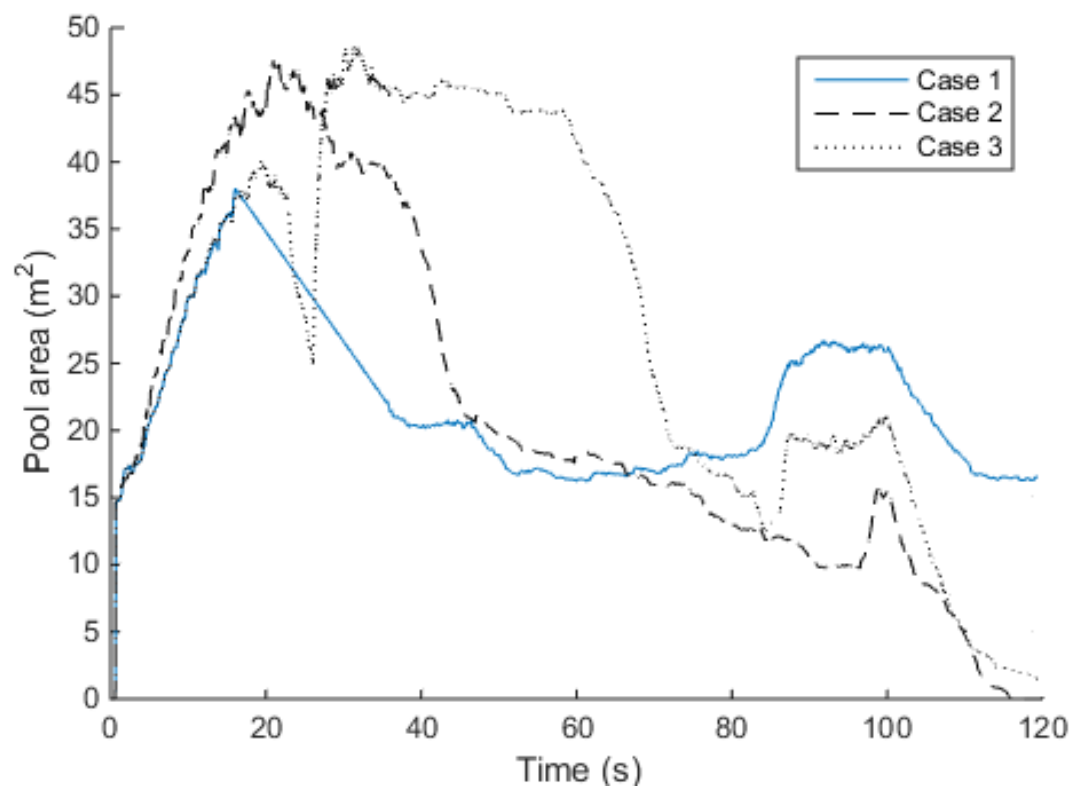

Fig. 12. A comparison of pool area in three cases.

Besides, fire and explosion hazard, LNG vapour has potential for asphyxiation hazard during an accidental release of LNG. Integration of an asphyxiation hazard analysis with dispersion modelling would help to identify potential impact to personnel in the facility. According to Lipton and Lynch (1994), workers frequently exposed to gases from fugitive emissions in processing plants. Even though, the quantity of fugitive emissions is very small, prolonged exposure may be threatening to health especially if carcinogens are involved. Consideration of fugitive emissions from an occupational health viewpoint is essential because each year more people die from work-related diseases than are killed in industrial accidents (Hassim et al., 2012). Therefore, it is important to reduce fugitive emissions as low as reasonably practicable to create a healthier, safer, more productive workplace as well as improving operating efficiency. 


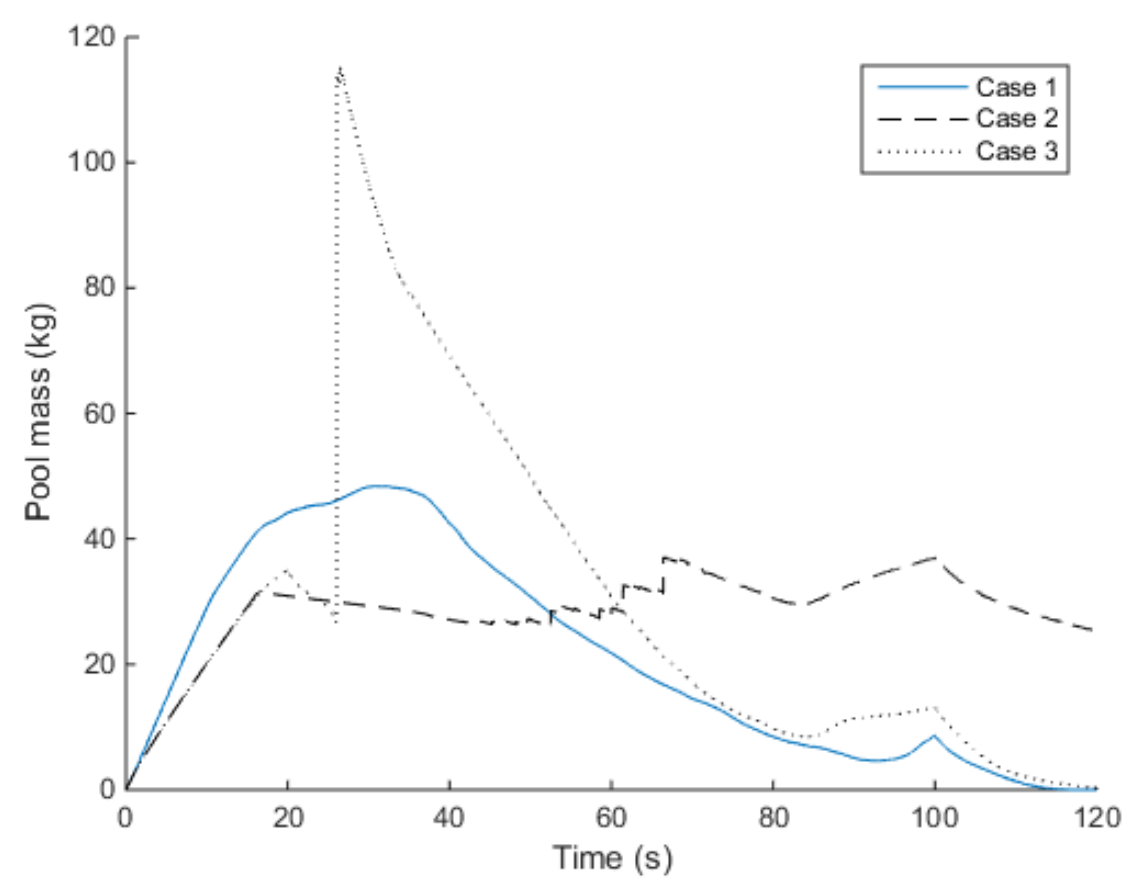

Fig. 13. A comparison of pool mass in three cases

For handling uncertainty of various parameters in dispersion modelling, different techniques are available such as Monte Carlo simulation and fuzzy sets theory. In the proposed methodology, uncertainties can be handled by using mean value of sensitive parameters obtained from past studies (Cormier et al., 2009; Rao, 2005; Siuta et al., 2013; Yegnan et al., 2002). Uncertainty analysis in dispersion of gas is well discussed in past studies (Rao, 2005; Siuta et al., 2013; Yegnan et al., 2002). For instance, Siuta et al. (2013) used fuzzy sets theory and Monte Carlo simulation for uncertainty analysis to model LNG source terms and dispersion models. To reduce uncertainty in dispersion modelling, value of sensitive parameters such as wind speed, atmospheric stability and release rate have been chosen according to these past studies. Moreover, a grid sensitivity analysis was performed using volumetric concentration to obtain grid independence solution. A comprehensive uncertainty analysis was beyond the scope of this study as the main purpose of the case study was to show the application of the proposed methodology. However, a detailed uncertainty analysis can be considered in future work.

\section{Conclusions}

In any congested and complex layout of processing facilities, a fugitive release of LNG would be a major safety concern. A methodology is proposed for modelling a small LNG leak and its dispersion. The methodology comprises of release scenarios, credible leak size, 
simulation, comparison of congestion level and mass of flammable vapour. The methodology is applied to a typical layout considering three levels of equipment congestion. The potential fire and/or explosion hazard of small LNG leak is assessed considering both time dependent concentration analysis and area-based model. The case study demonstrated that even after the termination of the leak, the LNG vapour continued to disperse, and the volumetric concentration was still within the flammable range. This led to accumulation of pockets of LNG vapours in the spaces between equipment. In the higher degree of congestion layout, higher amount of flammable mass and volume of LNG vapour was observed. The retention time of the flammable vapour in the higher congestion level layout was also more than that in the lower congestion level layout under the same operating conditions. Subsequently, this intensifies the formation of pockets of isolated vapour cloud. In a congested layout, the accumulation of flammable vapour of LNG would remain undetected and could pose fire and explosion hazards. It is therefore too conservative to neglect small leak scenario in a complex layout because of the effect of equipment congestion on source terms and dispersion behaviour. The case study results demonstrated that equipment congestion has effects on both source terms and dispersion of LNG vapour. This signifies a need for robust measures for detection and monitoring of such releases, including effective prevention and control measures such as ventilation, vapour barriers and emergency shutdown systems in a congested LNG processing facility. The study also confirmed that in considering $2.5 \%$ as lower flammability limit for assessment of hazard distance, as recommended by the US 49-CFR-193.2059 regulation, design safety could be improved. Furthermore, an asphyxiation hazard, likely to be posed by LNG vapour, would be an important aspect of LNG vapour dispersion modelling in future works.

\section{Acknowledgement}

The first author, Til Baalisampang would like to acknowledge the financial support received from the Australian Maritime College (AMC) of the University of Tasmania. The author thankfully acknowledges the technical support received from the Centre for Risk, Integrity and Safety Engineering (c-RISE), Faculty of Engineering \& Applied Science, Memorial University of Newfoundland, St. John's, NL, Canada. 


\section{References}

Alderman, J.A., 2005. Introduction to LNG safety. Process Saf. Prog. 24, 144-151.

Atkinson, G., Cowpe, E., Halliday, J., Painter, D., 2017. A review of very large vapour cloud explosions: Cloud formation and explosion severity. J. Loss Prev. Process. Ind. 48, 367375.

Baalisampang, T., Abbassi, R., Khan, F., 2018. Overview of Marine and Offshore Safety. Methods Chem. Process Saf. 2, 1-97.

Baalisampang, T., Khan, F., Garaniya, V., Chai, S., Abbasi, R., 2016. An Inherently Safer Layout Design for the Liquefaction Process of an FLNG Plant. Int. J. Marit. Eng. 158, Part A2, 91-102.

Baalisampang, T., Abbassi, R., Garaniya, V., Khan, F., Dadashzadeh, M., 2017a. Fire impact assessment in FLNG processing facilities using Computational Fluid Dynamics (CFD). Fire Saf. J. 92, 42-52.

Baalisampang, T., Abbassi, R., Garaniya, V., Khan, F., Dadashzadeh, M., 2017b. Modelling the impacts of fire in a typical FLNG processing facility. In International Conference on Safety and Fire Engineering-SAFE'17, Kochi, India.

Baalisampang, T., Abbassi, R., Garaniya, V., Khan, F., Dadashzadeh, M., 2019. Modelling an integrated impact of fire, explosion and combustion products during transitional events caused by an accidental release of LNG. Process Saf. Environ. Prot.

Baker, Q., Tang, M., Scheier, E., Silva, G., 1994. Vapor Cloud Explosion Analysis. In 28th Annual AIChE Loss Prevention Symposium, Atlanta, Georgia, USA.

Baksh, A.A., Abbassi, R., Garaniya, V., Khan, F. 2017. A network based approch to envisage potential accidents in offshore process facilities. Process Safety Progress, 36(2): 178-191.

Brambilla, S., Manca, D., 2008. On pool spreading around tanks: Geometrical considerations. J. Hazard. Mater. 158, 88-99.

Brandeis, J., Ermak, D.L., 1983. Numerical simulation of liquefied fuel spills: II. Instantaneous and continuous LNG spills on an unconfined water surface. Int. J. Numer. Meth. Fl. 3, 347361.

Brown, T., Cederwall, R., Chan, S., Ermak, D., Koopman, R., Lamson, K., McClure, J., Morris, L., 1990. Falcon series data report: 1987 LNG vapor barrier verification field trials. Lawrence Livermore National Lab., CA (USA).

Bui, A., Liu, T., Reed, M., Potorson, E., 2015. CFD Modeling of LNG Spreading and Atmospheric Dispersion. In 11th Global Congress on Process Safety, Austin.

Cataylo, A., Tanigawa, K., 2014. Floating LNG Challenges on Cryogenic Spill Control. In SPE International Conference on Health, Safety, and Environment, Society of Petroleum Engineers.

Chan, S.T., 1992. Heavy Gas Dispersion Incompressible Flow. Lawrence Livermore National Laboratory.

Chan, S.T., Ermak, D.L., 1984. Recent Results in Simulating LNG Vapor Dispersion over Variable Terrain. In G. Ooms, H. Tennekes (Eds.) Atmospheric Dispersion of Heavy Gases and Small Particles: Symposium, Delft, The Netherlands August 29 - September 2, 1983, Springer Berlin Heidelberg, Berlin, Heidelberg, pp. 105-114.

Colenbrander, G., Evans, A., Puttock, J., 1984. Spill Tests of LNG and Refrigerated Liquid Propane on the Sea, Maplin Sands, 1980: Dispersion Data Digest; Trial 27. Report TNER.84.028.

Cormier, B.R., Qi, R., Yun, G., Zhang, Y., Mannan, M.S., 2009. Application of computational fluid dynamics for LNG vapor dispersion modeling: a study of key parameters. J. Loss Prev. Process. Ind. 22, 332-352. 
Dadashzadeh, M., Khan, F., Abbassi, R., Hawboldt, K., 2014. Combustion products toxicity risk assessment in an offshore installation. Process Saf. Environ. Prot. 92, 616-624.

Dharmavaram, S., Hanna, S., Hansen, O., 2005. Consequence Analysis - Using a CFD model for industrial Sites. Process Saf. Prog. 24, 316-272.

Feldbauer, G., Heigl, J., McQueen, W., Whipp, R., May, W., 1972. Spills of LNG on watervaporization and downwind drift of combustible mixtures.

Fiates, J., Santos, R.R.C., Neto, F.F., Francesconi, A.Z., Simoes, V., Vianna, S.S.V., 2016. An alternative CFD tool for gas dispersion modelling of heavy gas. J. Loss Prev. Process. Ind. 44, 583-593.

Fitzgerald, G.A., 2016. Calculating facility siting study leak sizes-one size does not fit all. Process Saf. Prog. 35, 176-178.

Foss, M.M., Delano, F., Gulen, G., Makaryan, R., 2003. LNG safety and security. Center for Energy Economics (CEE).

Gavelli, F., Bullister, E., Kytomaa, H., 2008. Application of CFD (Fluent) to LNG spills into geometrically complex environments. J. Hazard. Mater. 159, 158-168.

Gavelli, F., Chernovsky, M.K., Bullister, E., Kytomaa, H.K., 2010. Modeling of LNG spills into trenches. J. Hazard. Mater. 180, 332-339.

GexCon AS, 2013. FLACS v10. 0 User's Manual. In GexCon AS.

Goldwire, H.C.J., Rodean, H.C., Cederwall, R.T., Kansa, E.J., Koopman, R.P., McClure, J.W., McRae, T.G., Morris, L.K., Kamppinen, L., Kiefer, R.D., 1983. Coyote series data report LLNL/NWC 1981 LNG spill tests dispersion, vapor burn, and rapid-phase-transition. Volume 1.[7 experiments with liquefied natural gas, 2 with liquid methane, and one with liquid nitrogen]. Lawrence Livermore National Lab., CA (USA).

Hanna, S., Strimaitis, D., Chang, J., 1993. Hazard Response Modeling Uncertainty (A Quantitative Method). Volume 2. Evaluation of Commonly Used Hazardous Gas Dispersion Models. Sigma Research Corp Westford MA.

Hansen, O.R., Ichard, M., Davis, S.G., 2009. Validation of FLACS for vapor dispersion from LNG spills: model evaluation protocol. In Twelfth Annual Symposium, Mary Kay O’Connor Process Safety Symposium, Texas A\&M University, College Station, Texas, pp. 712-743.

Hassim, M.H., Hurme, M., Amyotte, P.R., Khan, F.I., 2012. Fugitive emissions in chemical processes: The assessment and prevention based on inherent and add-on approaches. J. Loss Prev. Process. Ind. 25, 820-829.

Havens, J., Spicer, T., 2005. LNG vapor cloud exclusion zones for spills into impoundments. Process Saf. Prog. 24, 181-186.

Hightower, M., Gritzo, L., Luketa-Hanlin, A., Covan, J., Tieszen, S., Wellman, G., Irwin, M., Kaneshige, M., Melof, B., Morrow, C., 2004. Guidance on risk analysis and safety implications of a large liquefied natural gas (LNG) spill over water. DTIC Document.

Hissong, D.W., 2007. Keys to modeling LNG spills on water. J. Hazard. Mater. 140, 465-477.

HSE, 2017. Offshore Statistics and Regulatory Activity Report 2016. Health and Safety Executive.

Ikealumba, W.C., Wu, H., 2016. Modeling of Liquefied Natural Gas Release and Dispersion: Incorporating a Direct Computational Fluid Dynamics Simulation Method for LNG Spill and Pool Formation. Ind. Eng. Chem. Res. 55, 1778-1787.

Johnson, D.W., Cornwell, J.B., 2007. Modeling the release, spreading, and burning of LNG, LPG, and gasoline on water. J. Hazard. Mater. 140, 535-540.

Keoleian, G.A., Blackler, C.E., Denbow, R., Polk, R., 1997. Comparative assessment of wet and dry garment cleaning Part 1. Environmental and human health assessment. J. Clean. Prod. 5, 279-289. 
Khan, F.I., 2001. Use maximum-credible accident scenarios for realistic and reliable risk assessment. Chem. Eng. Prog. 97, 56-65.

Khan, F.I., Abbasi, S., 1999. Major accidents in process industries and an analysis of causes and consequences. J. Loss Prev. Process. Ind. 12, 361-378.

Kim, B.K., 2013. Application of Computational Fluid Dynamics in the Forced Dispersion Modeling of LNG Vapor Clouds. In Texas A\&M University.

Kim, H., Koh, J.-S., Kim, Y., Theofanous, T.G., 2005. Risk assessment of membrane type LNG storage tanks in Korea-based on fault tree analysis. Korean J. Chem. Eng. 22, 1-8.

Kinsella, K., 1993. A rapid assessment methodology for the prediction of vapour cloud explosion overpressure. In International Conference and Exhibition on Safety, Health and Loss Prevention in the Oil, Chemical and Process Industries, Butterworth-Heinemann, Singapore, pp. 200-211.

Klein, J.A., Vaughen, B.K., 2017. Process Safety: Key Concepts and Practical Approaches. CRC Press.

Kneebone, A., Prew, L., 1974. Shipboard jettison test of LNG onto the sea. In Proc. 4th Int. Conf. on LNG, International Conference on Liquefied Natural Gas, Algiers, Algeria, pp. 125.

Koopman, R., Bowman, B., Ermak, D.L., 1979. Data and calculations of dispersion on 5 m3 LNG spill tests. Lawrence Livermore Laboratory.

Koopman, R.P., Baker, J., Cederwall, R.T., Goldwire, H.C.J., Hogan, W.J., Kamppinen, L.M., Keifer, R.D., McClure, J.W., McRae, T.G., Morgan, D.L., 1982. Burro Series Data ReportLLNL/NWC 1980 LNG Spill Tests. UCID-19075.

Kumar, S., Kwon, H.-T., Choi, K.-H., Cho, J.H., Lim, W., Moon, I., 2011. Current status and future projections of LNG demand and supplies: A global prospective. Energy Pol. 39, 4097-4104.

Lee, S., Seo, S., Chang, D., 2015. Fire risk comparison of fuel gas supply systems for LNG fuelled ships. J. Nat. Gas Sci. Eng. 27, 1788-1795.

Li, J., Abdel-jawad, M., Ma, G., 2014. New correlation for vapor cloud explosion overpressure calculation at congested configurations. J. Loss Prev. Process. Ind. 31, 16-25.

Li, J., Ma, G., Abdel-jawad, M., Huang, Y., 2016. Gas dispersion risk analysis of safety gap effect on the innovating FLNG vessel with a cylindrical platform. J. Loss Prev. Process. Ind. 40, 304-316.

Li, J., Ma, G., Hao, H., Huang, Y., 2017. Optimal blast wall layout design to mitigate gas dispersion and explosion on a cylindrical FLNG platform. J. Loss Prev. Process. Ind. 49, 481-492.

Lipton, S., Lynch, J., 1994. Handbook of health hazard control in the chemical process industry. Wiley-Interscience.

Luketa-Hanlin, A., Koopman, R.P., Ermak, D.L., 2007. On the application of computational fluid dynamics codes for liquefied natural gas dispersion. J. Hazard. Mater. 140, 504-517.

Lvings, M., Jagger, S., Lee, C., 2007. Evaluating vapor dispersion models for safety analysis of LNG facilities research project. Health \& Safety Laboratory, Buxton, Derbyshire, UK.

Ma, G., Li, J., Abdel-jawad, M., 2014. Accuracy improvement in evaluation of gas explosion overpressures in congestions with safety gaps. J. Loss Prev. Process. Ind. 32, 358-366.

Melton, T.A., Cornwell, J.B., 2010. LNG trench dispersion modeling using computational fluid dynamics. J. Loss Prev. Process. Ind. 23, 762-767.

Murvay, P.-S., Silea, I., 2012. A survey on gas leak detection and localization techniques. J. Loss Prev. Process. Ind. 25, 966-973.

Napier, D., Roopchand, D., 1986. An approach to hazard analysis of LNG spills. J. Occup. Accid. 7, 251-272. 
National Fire Protection Association (NFPA), 2006. NFPA 13: Standard for the Installation of Sprinkler Systems (2002). National Fire Protection Association.

Ouddai, R., Chabane, H., Boughaba, A., Frah, M., 2012. The Skikda LNG accident: losses, lessons learned and safety climate assessment. Int. J. of Glob. Energy Issues 35, 518-533.

Paris, L., 2019. An engineer-based methodology to perform Explosion Risk Analyses. J. Loss Prev. Process. Ind. 57, 254-272.

Pitblado, R., Baik, J., Raghunathan, V., 2006. LNG decision making approaches compared. J. Hazard. Mater. 130, 148-154.

Pitblado, R., Baik, J., Hughes, G., Ferro, C., Shaw, S., 2005. Consequences of liquefied natural gas marine incidents. Process Saf. Prog. 24, 108-114.

Qi, R., Ng, D., Cormier, B.R., Mannan, M.S., 2010. Numerical simulations of LNG vapor dispersion in Brayton Fire Training Field tests with ANSYS CFX. J. Hazard. Mater. 183, 51-61.

Raman, R., Grillo, P., 2005. Minimizing uncertainty in vapour cloud explosion modelling. Process Saf. Environ. Prot. 83, 298-306.

Rao, K.S., 2005. Uncertainty analysis in atmospheric dispersion modeling. Pure and Appl. Geophys. 162, 1893-1917.

Reddy, K., Yarrakula, K., 2016. Analysis of Accidents in Chemical Process Industries in the period 1998-2015. Int. J. Chemtech. Res. 9, 177-191.

Reid, R., 1980. Boiling of LNG on typical dike floor materials. Massachusetts Institute of Tech,. LNG Research Centre, Cambridge.

Rukke, S., Katchmar, P., Hoidal, C., 2016. Failure Investigation Report - Liquefied Natural Gas (LNG) Peak Shaving Plant, Plymouth, Washington.

Safitri, A., Gao, X., Mannan, M.S., 2011. Dispersion modeling approach for quantification of methane emission rates from natural gas fugitive leaks detected by infrared imaging technique. J. Loss Prev. Process. Ind. 24, 138-145.

Saraf, S., Melhem, G., 2005. Modeling LNG pool spreading and vaporization. In AIChE Spring Meeting, ioMosaic Corporation, Atlanta, GA.

Siuta, D., Markowski, A.S., Mannan, M.S., 2013. Uncertainty techniques in liquefied natural gas (LNG) dispersion calculations. J. Loss Prev. Process. Ind. 26, 418-426.

Sklavounos, S., Rigas, F., 2004. Validation of turbulence models in heavy gas dispersion over obstacles. J. of Hazard Mater. 108, 9-20.

Srebric, J., Vukovic, V., He, G., Yang, X., 2008. CFD boundary conditions for contaminant dispersion, heat transfer and airflow simulations around human occupants in indoor environments. Build. Environ. 43, 294-303.

Sun, B., Utikar, R.P., Pareek, V.K., Guo, K., 2013. Computational fluid dynamics analysis of liquefied natural gas dispersion for risk assessment strategies. J. Loss Prev. Process. Ind. 26, 117-128.

Tauseef, S.M., Rashtchian, D., Abbasi, S.A., 2011. CFD-based simulation of dense gas dispersion in presence of obstacles. J. Loss Prev. Process. Ind. 24, 371-376.

United States Department of Energy, 2012. Liquefied Natural Gas Safety Research, Report to Congress May 2012. Washington, DC 20585.

US Goverment Publishing Office (GPO), 1980. Title 49 Code of Federal Regulations Part 193 (49-CFR-193), Liquefied natural gas facilities: Federal safety standards. U.S. Government Printing Office, Washington, DC.

Van Den Bosh, C., Weterings, R., 1997. Methods for the calculation of physical effects (Yellow Book). Committee for the Prevention of Disasters, Hague (NL).

Vinnem, J.-E., 2014. Offshore Risk Assessment Vol 2. Springer.

Webber, D., Gant, S., Ivings, M., Jagger, S., 2010. LNG source term models for hazard analysis: A review of the state-of-the-art and an approach to model assessment. 
Woodward, J.L., 2010. Estimating the flammable mass of a vapor cloud. John Wiley \& Sons. Woodward, J.L., Pitblado, R., 2010. LNG Risk Based Safety: modeling and consequence analysis. John Wiley \& Sons.

Yegnan, A., Williamson, D.G., Graettinger, A.J., 2002. Uncertainty analysis in air dispersion modeling. Environ. Modell. \& Soft. 17, 639-649.

Zhang, J., 1997. Designing a cost-effective and reliable pipeline leak-detection system. Pipes and Pipelines Int. 42, 20-26.

Zinn, C.D., 2005. LNG codes and process safety. Process Saf. Prog. 24, 158-167. 